Installation Technology Transfer Program

\title{
Developing Best Practices for Capturing As-Built Building Information Models (BIM) for Existing Facilities
}

Eddy Rojas, Carrie Dossick, and John Schaufelberger

August 2010

Prepared under Contract W9132T-08-2-0020

for the Installation Technology Transfer Program (ITTP)

under the supervision of

Beth A. Brucker, Project Manager (CEERD-CF-N)

Construction Engineering Research Laboratory

U.S. Army Engineer Research and Development Center

2902 Newmark Drive

Champaign, IL 61822 



\section{Developing Best Practices for Capturing As-Built Building Information Models (BIM) for Existing Facilities}

Eddy Rojas, Carrie Dossick, and John Schaufelberger

University of Washington

Department of Construction Management

Seattle, WA 98195

Final report

Approved for public release; distribution is unlimited.

\footnotetext{
Prepared for U.S. Army Corps of Engineers

Washington, DC 20314-1000

Under Contract W9132T-08-2-0020

Monitored by Construction Engineering Research Laboratory

U.S. Army Engineer Research and Development Center 2902 Newmark Drive, Champaign, IL 61822
} 


\begin{abstract}
The operation and maintenance of U.S. Army real property could greatly benefit from the availability of advanced forms of digital asbuilt facility data, such as those used in Building Information Modeling (BIM) systems. The Army Corps of Engineers requires the use of BIM on all new construction projects associated with the Army Standardization program. This study extends an earlier analysis performed by the University of Washington for the U.S. Army Engineer Research and Development Center under the Installation Technology Transfer Program, documented in ERDC/ CERL CR-10-1. The objective was to determine the most efficient method for capturing essential as-built information about U.S. Army facilities for application in a BIM-driven support tool for operation and maintenance decision making. The study also evaluated the potential applicability of readily available tools such as the Construction Operations Building information exchange (COBie) data format, Google SketchUp, Google Earth, three-dimensional Portable Document Format (3D PDF), and BIM integration technologies, with a focus on task-centered interface and workflows. The findings constitute a summary of best practices for meeting the research objective and facilitating implementation by Army Departments of Public Works.
\end{abstract}

DISCLAIMER: The contents of this report are not to be used for advertising, publication, or promotional purposes. Citation of trade names does not constitute an official endorsement or approval of the use of such commercial products. All product names and trademarks cited are the property of their respective owners. The findings of this report are not to be construed as an official Department of the Army position unless so designated by other authorized documents. 


\section{Preface}

This study was conducted for the U.S. Army Assistant Chief of Staff for Installation Management (ACSIM) under Installation Technology Transfer Program (ITTP) contract W9132T-08-2-0020. The ITTP Project Manager was Kelly M. Dilks, CEERD-CF-M.

The work was performed under the supervision of the Engineering Processes Branch (CF-N) of the Facilities Division (CF), U.S. Army Engineer Research and Development Center - Construction Engineering Research Laboratory (ERDC-CERL). The project manager and technical reviewer was Beth A. Brucker, Research Architect, CEERD-CF-N. At the time of publication, Donald K. Hicks was Chief, CEERD-CF-N; L. Michael Golish was Chief, CEERD-CF; and Martin J . Savoie was the Technical Director for Installations. The Deputy Director of ERDC-CERL was Dr. Kirankumar Topudurti and the Director was Dr. Ilker Adiguzel.

COL Gary E. J ohnston was the Commander and Executive Director of ERDC, and Dr. J effery P. Holland was the Director. 


\section{Unit Conversion Factors}

\begin{tabular}{|c|c|c|}
\hline Multiply & By & To Obtain \\
\hline British thermal units (International Table) & $1,055.056$ & joules \\
\hline cubic feet & 0.02831685 & cubic meters \\
\hline cubic inches & $1.6387064 \mathrm{E}-05$ & cubic meters \\
\hline cubic yards & 0.7645549 & cubic meters \\
\hline degrees (angle) & 0.01745329 & radians \\
\hline degrees Fahrenheit & $(\mathrm{F}-32) / 1.8$ & degrees Celsius \\
\hline feet & 0.3048 & meters \\
\hline gallons (U.S. liquid) & $3.785412 \mathrm{E}-03$ & cubic meters \\
\hline horsepower (550 foot-pounds force per second) & 745.6999 & watts \\
\hline inches & 0.0254 & meters \\
\hline miles (U.S. statute) & $1,609.347$ & meters \\
\hline miles per hour & 0.44704 & meters per second \\
\hline mils & 0.0254 & millimeters \\
\hline pounds (mass) & 0.45359237 & kilograms \\
\hline square feet & 0.09290304 & square meters \\
\hline square inches & $6.4516 \mathrm{E}-04$ & square meters \\
\hline square miles & $2.589998 E+06$ & square meters \\
\hline square yards & 0.8361274 & square meters \\
\hline tons ( 2,000 pounds, mass) & 907.1847 & kilograms \\
\hline yards & 0.9144 & meters \\
\hline
\end{tabular}




\title{
DEVELOPING BEST PRACTICES FOR CAPTURING AS-BUILT BUILDING INFORMATION MODELS (BIM) FOR EXISTING FACILITIES
}

\author{
2009 Broad Agency Announcement \\ U.S. Army Engineer Research and Development Center (ERDC) \\ CERL-15 Research Area
}

Research Team:

Faculty

Dr. Eddy Rojas, Professor

Dr. Carrie Dossick, Assistant Professor

Dr. John Schaufelberger, Professor

Graduate Research Asst.

JJ Powell

BIM Development

Matt Quijano

Software Development

James Lee

Field Research Assistants

Jill Browning

Ana Levan

Danielle Pierce

Jimmy Soong

Tyler Sprague

Chi Leung Tsui

Fort Lewis DPW

Teresa Hansen

Scott Smith

Jeff Whitehead

Facility Point of Contact

LT Ryan Butler, Commander 3-17FA, 5/2 ID 


\section{Executive Summary \\ Developing Best Practices for Capturing As-Built Building Information Models (BIM) for Existing Facilities}

\section{Basic Technology}

An FY08 project titled "Evaluating Alternative Methodologies for Capturing AsBuilt Building Information Models (BIM) for Existing Facilities" focused on finding the most efficient (cost and time) method for capturing existing facility as-built information for Army installations. The results of the FY08 study suggested that tablet computers with customized software for COBIE data capture offered the best option for collecting as-built information. This FY09 study addresses a follow-up question: given the knowledge about the most effective method for capturing BIM data for existing facilities, how can the process be optimized for actual field use so that the DPW can incorporate these procedures into its daily operations and maintenance as well as real property asset management activities? Therefore, the FY09 study focuses on the development of an implementation plan or best practices (practical guidelines) to effectively transfer the FY08 project-generated knowledge into day-to-day DPW field operations. Furthermore, technologies such as SketchUp, Google Earth, and Adobe Forms and 3D PDF are offering new opportunities as navigational interfaces through which building data can seamlessly flow from global to spatial to building data and equipment levels.

An active PDF template was developed and placed on rugged Motion F5 Tablet personal computers. This method for surveying COBIE data captures the history of items of most interest to the surveyors and places these items on pull-down menus to allow for efficient input of repeating data. The principal investigator and four research assistants used the tablet PCs to survey a Company Operations Facility (Building \#11751) on Fort Lewis, carefully noting the time, cost, and physical and mental effort to conduct the survey. Both a spatial (mechanical room, offices, corridors, storage areas, restrooms) and a systems (interior lighting, MEP systems, fire and smoke detection, doors and windows) approach to surveying the data were conducted. The PDF survey form data was then transferred to the COBIE format by a software application. The COBIE data was then uploaded into a low fidelity 3D BIM. Based on an analysis of their findings the researchers developed an optimized process presented as a best practice for this project.

\section{Benefits}

The move by the Corps of Engineers in mandating the use of BIM in the MILCON process is the first step towards getting computable as-built engineering data into the hands of the installation's DPW. However, this only addresses new facilities, which represent a very small portion of facility information needs at the installation level. The real benefits of obtaining and maintaining computable life-cycle facility data will not materialize until a significant portion of the new and existing facilities managed by DPW are integrated into a coherent digital system. Documents are no longer the primary, core representation of a facility. Instead, a database, at any moment, is a shared resource for 
the installation to conduct reliable, collaborative decisions on as-maintained facility data. Documents become special-purpose work products generated from the database (i.e. equipment replacement parts diagrams). This study demonstrates that the capturing of COBIE data for existing facilities and its integration with BIM models is not only feasible, but also affordable. The major challenges of implementing such an initiative Army-wide are addressed in this study by developing best practices for the entire process, including its institutionalization within DPWs.

Costs

The results of this study demonstrate that the cost of capturing COBIE data for a building of 25,000 SF and integrating it into a model of sufficient fidelity to perform operations and maintenance tasks at the installation is estimated at approximately $\$ 1,500$, when the process is institutionalized. This cost includes the labor necessary to develop the BIM model, customize PDF floor plans for the facility, perform the field survey, convert the data into COBIE format, and merge the COBIE data with a low to mid-level fidelity BIM model. For the purpose of this study, a low-fidelity BIM refers to a mass model where spaces are represented by rectangular masses with different colors and spaces are identified by room numbers. A mid-fidelity BIM includes doors and window locations as well as walls, but does not include MEP. The amortized cost of survey software and hardware is also included in this estimate. This number assumes that surveys are performed by DPW personnel. The labor cost of $\$ 50 / \mathrm{hr}$ was chosen for DPW staff at an average GS 9 level. If these activities are to be performed by a contractor, an additional mark-up would probably be required. However, the cost of further development of the prototype PDF template developed for this study and the long-term maintenance of the application is not included. Additional expenditures may also be required if CAD files for the building to be surveyed do not exist. These costs will vary from facility to facility depending on the circumstances and the level of detail required. The following table shows the main line items and the assumptions used when estimating costs. Using these numbers, a typical 25,000 SF facility would cost $\$ 1455$ to survey, or $\$ 5.82$ per 100 SF.

\begin{tabular}{|c|c|c|c|c|c|c|}
\hline \multirow{7}{*}{ Fixed Costs } & Type & Description & Assumptions & Cost/HR & \multicolumn{2}{|c|}{ Cost/100SF } \\
\hline & \multicolumn{3}{|l|}{ Software and Equipment Costs } & \multirow[b]{2}{*}{$\$ 3.33$} & \multirow[b]{2}{*}{ S } & \multirow[b]{2}{*}{0.17} \\
\hline & COBIE Survey Equipment & $\begin{array}{l}\text { Motion F5 Tablet PC and } \\
\text { Accessories }\end{array}$ & $\$ 5,000 /$ unit, 3-year replacement cycle, $500 \mathrm{hrs} /$ year & & & \\
\hline & MS Office 2007 & $\begin{array}{l}\text { Platform for operating COBIE } \\
\text { spreadsheet output }\end{array}$ & Enterprise license available & & S & - \\
\hline & Adobe Acrobat 9 Pro & $\begin{array}{l}\text { Pro version used to build PDF } \\
\text { Survey Application }\end{array}$ & Enterprise license available & & S & - \\
\hline & Adobe CS4 & Image editing & Enterprise license available & & S & - \\
\hline & Autodesk Revit Architecture & BIM development software & Enterprise license available & & S & - \\
\hline \multirow[t]{4}{*}{$\begin{array}{l}\text { Operational } \\
\text { Costs }\end{array}$} & \multicolumn{3}{|c|}{ Project-based Costs of Conducting and Supporting COBIE Facility Surveys } & & & \\
\hline & Surveyors & DPW Personnel & 13 hours to complete Battalion HQ facility & 50.00 & $S$ & 2.60 \\
\hline & BIM Development Labor & Recurring Activities per facility & 6 hours & 50.00 & $S$ & 1.20 \\
\hline & PDF Survey Form Specification & $\begin{array}{l}\text { Detailed COBIE Survey } \\
\text { Information per Project/Facility }\end{array}$ & 6 hours & 50.00 & $S$ & 1.20 \\
\hline \multirow[t]{2}{*}{$\begin{array}{l}\text { Logistics } \\
\text { Costs }\end{array}$} & \multicolumn{3}{|c|}{ Mobilization, Access, and Communication During Actual Survey Work } & & & \\
\hline & Survey Logistics & Access and Communication & $25 \%$ of survey task time (time spent collecting data) & 50.00 & s & 0.65 \\
\hline \multicolumn{5}{|c|}{ TOTAL COST PER 100 SF: } & $S$ & 5.82 \\
\hline
\end{tabular}


In order to ensure a successful Army-wide implementation, the prototype PDF survey application developed for this study will require an update to the recently released COBIE 2 standard with support for subsequent COBIE releases, software maintenance, and installation support. It is estimated that this effort would require an initial, one-time investment of $\$ 50,000$, plus upgrade and support expenditures of $\$ 25,000$ annually. It was determined during the study that one day of hands-on training was sufficient for mastering the PDF application. The study assumed for long-term Army-wide success and cost savings that enterprise license agreements (ELA) would be available for Microsoft, Adobe, and Autodesk products. Based on past Corps experience, an installation may have 1-2 copies of a BIM application (Revit), 1 copy of a model integrator/viewer (Navisworks) and 1-2 copies of specialty applications (AutoCAD, AutoCAD Map, etc.). Off-site training costs conservatively run $\$ 1200$ for each user. The approximate yearly costs for software and training are $\$ 12 \mathrm{k}$ to $\$ 20 \mathrm{k}$. With an Enterprise License Agreement from the vendor, where the installation uses license pools, the costs are easily reduced by 50-60 percent.

\section{Recommendation}

As with any emerging technology, there is a question about when adoption of BIM across the ACSIM/IMCOM enterprise makes the most economic sense. When is the right time to make initial planning and pilot investments? Getting installations prepared for BIM will require a varied set of tools and skills. Although BIM stems from traditional processes, it represents a new business process for facility acquisition, delivery, and sustainment. BIM technology, content, standards, manpower, education and training are all key components when considering BIM. The IMCOM Center for Future Installation Strategy, working with the Engineer Research and Development Center's (ERDC) Center for the Advancement of Sustainability Innovation (CASI), is developing an IMCOM Futures BIM Report to address ACSIM/IMCOM implementation of BIM technologies.

This project focused on capturing BIM content in the COBIE data framework. At the onset of this project, it was thought that GFEBS would be further along and would be the initial system that could accept COBIE data. Since GFEBS hasn't been fully deployed, it is recommended that the Army invest in the mapping of required BIM data content to Army business SRM areas/systems such as GFEBS, SMS (Builder), ISR, Army Mapper, HQIS applications, among others. These cross-over technologies are emerging at different timelines, with some ready to link with BIM today and others still in development. The linkages enabled by BIM will become an important part of the decision rationale for planning and programming the IT investments necessary to evaluate and implement BIM capabilities for the Army.

According to the recently published 2009 SmartMarket report on BIM by McGraw Hill Construction, $70 \%$ of owners surveyed report a positive ROI from BIM in better communication, lower project cost and overall better construction project outcomes. These owners stated that visualization of architectural design, improved understanding 
of design intent, cost savings due to clash detection ability, rework avoidance, fewer RFIs, fewer change orders, better-designed and better-performing buildings are the main reasons of the positive ROI to date. Owner's, however, did rank insufficient BIMcompatible content available for their SRM type needs as a major challenge to adoption for downstream stakeholders.

It is our recommendation that the Army should be proactive and invest in initial pilots of this technology at selected DPWs. These pilots will ensure Army requirements are captured in the BIM content during the SRM life-cycle. This would require the development of a professional COBIE data capture application based on the PDF format to run on tablet computers. During these pilots, it is recommended that one system be targeted for automated delivery of BIM content (i.e. map ISR or SMS-Builder data structures to BIM content). This will demonstrate the beneficial link between the BIM and one of the Army's standard systems.

Partial Vendor List

Vendor

Motion F5 Tablet PC

Adobe Systems

Autodesk Revit

Autodesk Navisworks
Website

www.motioncomputing.com/products/tablet_pc_f5.asp

www.adobe.com/products/acrobatproextended/

www.autodesk.com/revit

www.autodesk.com/navisworks

References

- The recommendations presented in this study are based on the results of the FY08 and FY09 projects performed by CERL and the University of Washington with support from the Fort Lewis DPW.

- FY08: Evaluating Alternative Methodologies for Capturing As-Built Building Information Models (BIM) for Existing Facilities

- FY09 Developing Best Practices for Capturing As-Built Building Information Models (BIM) for Existing Facilities

- COBIE Spreadsheet Step-by-Step Guide and other COBIE related references can be found on the Whole Building Design Guide: http://www.wbdg.org/tools/cobiex.php.

- 2008 SmartMarket Report "Building Information Modeling (BIM), McGraw-Hill, http://construction.ecnext.com/mcgraw hill/includes/BIM2008.pdf 


\section{Table of Contents}

Executive Summary ii

Chapter 1: Introduction 1

Chapter 2: Best Practices for Capturing COBIE Data in the Field 3

Chapter 3: Rationale for Best Practices 15

Chapter 4: Time and Cost Estimates 28

Chapter 5: Recommendations for Institutionalization Within DPW 33

Chapter 6: Technology Issues $\quad 39$

Chapter 7: Conclusions and Future Work 44

Appendix 1: Experimental Design $\quad 45$

Appendix 2: Adobe Survey Application Screenshots 50

Appendix 3: Survey Completion Rates and Collected Data 57

Appendix 4: Cost Estimate Calculations 61

Appendix 5: Fieldwork Photographs $\quad 64$

Appendix 6: Timed Tests, Assessing Efficiency and Familiarity 67

$\begin{array}{ll}\text { Appendix 7: Surveyor Feedback } & 70\end{array}$

Appendix 8: Autodesk Revit to Google Earth (Low-Fidelity BIM) 75 


\section{Chapter 1: Introduction}

The objective of this study was to determine the most efficient method for capturing existing facility as-built information for Army installations. In addition, the team evaluated the potential of using SketchUp, Google Earth, and 3D PDF technologies. The objective was to develop best practices for collecting inventory data and integrating this information with digital as-built models of facilities. This FY09 study explores tools and methodologies recommended in the FY08 study, with a focus on task-centered interface and workflows.

This document reports the team's findings following an in-depth exploration into the potential of COBIE data collection and BIM integration technologies and practices. It is both a report of best practices and a field guide for those implementing this survey process. The following chapters describe:

- Best practices for conducting COBIE facility surveys

- Rationale for best practices recommendations

- Guidelines for estimating time and cost

- Recommendations for institutionalization of this process within DPW

- Exploration of technologies related to BIM and COBIE integration

Additional information, including assessments, survey completion rates and data, and software instructions are contained in the Appendices.

The team undertook two main study activities: (1) collecting non-spatial component data and (2) exploring methods of integrating that data with the spatial data developed in as-built Building Information Models of the facility studied. COBIE data collection methodologies and interface were developed and tested during four weeks of fieldwork at Fort Lewis, WA. At the same time, the research team created a series of as-built digital models for the facility to merge with the COBIE data at three different levels of detail. BIM geometry was developed in a "Low-, Medium-, and High-Fidelity" format, although only the "Low-" and "Medium-" levels proved feasible for integration. Following the two primary work activities, the team developed and documented a number of methods for integration of spatial and non-spatial COBIE data. The results of the study and recommendations for Best Practices (BP) are presented in this report.

Chapter 2 describes the specific steps and standards for collecting COBIE data in existing facilities. This chapter may be excerpted as a guide for developing and conducting COBIE inventories of component data on Army installations. In addition, this chapter also contains specific steps for the development and integration of facility spatial data. The Best Practices Guide includes the following basic topics:

1. BIM Development

2. Survey Application Development: Template

3. COBIE Data Converter

4. Tablet PC Setup

5. Facilities-Specific Information

6. Schedule Fieldwork 
7. Beginning Fieldwork

8. Ongoing Facilities Survey

9. Data Conversion and Formatting 10. Options for Data Storage and Access

Detailed observations and rationale for the research team's best practices recommendations can be found in Chapter 3 . This chapter describes the efforts, lessons learned, and insights behind each specific best practices recommendation.

Chapter 4 is intended to serve as a guide for project managers, clients, and other team members who are responsible for estimating time and costs related to completing as-built COBIE surveys and BIM integration for existing facilities. Using the methodologies developed in this study and the best practices outlined in Chapter 2, survey teams can develop an accurate scope, schedule, and budget for COBIE data collection projects. Some assumptions are made regarding team composition, amortization rates, logistics and planning time, and hourly pay rates. Refer to Appendices 3 and 4 for details regarding these assumptions.

The research team also proposes methods of integrating the best practices and technologies into DPW. These recommendations are presented in Chapter 5 . The principles and steps presented may vary from installation to installation, but are intended to be a starting point for USACE and DPWs to consider the process of adopting and establishing COBIE Existing Facilities Surveys within their structures. In general, topics covered include team development, scope planning, goals definition, and technology integration strategies.

Chapter 6 describes the specific steps and standard practices for developing the BIM model(s) containing the spatial data to be associated with the non-spatial COBIE survey data. The research team explored a variety of software platforms and methods for aggregating and associating data both internally and externally, relative to the BIM model. This chapter describes the team's work in the areas of technology outlined in the research proposal. Details and instructions specific to the team's recommended methods of BIM development and data integration are contained within Chapter 2 and Appendix 6. 


\title{
Chapter 2: Best Practices for Capturing COBIE Data in the Field
}

\author{
BIM Development
}

1.1. Obtain relevant documents: Coordinate with Survey Project Manager, DPW POCs and GIS/IT department to obtain relevant 2D drawings and specifications for the facility (facilities) being modeled.

\subsection{Verification of $2 \mathrm{D}$ drawings}

1.2.1. Facility/Site visit to be conducted in coordination with DPW POCs, Survey Project Manager, and Facility POC. Should be combined with as-built verification for survey development.

\subsection{Low-Fidelity BIM}

1.3.1. Scope: primarily a "massing" model, only relevant spaces are included.

1.3.2. Detail: Spaces are the lowest level of detail.

1.3.3. Spaces contain hyperlinks to local folders or secure web-server locations.

\subsection{Medium-Fidelity BIM}

1.4.1. Scope: similar to Low-Fidelity BIM, extents depend on project scope.

1.4.2. Spaces contain objects as components placeholders.

1.4.3. Hyperlinks to local folders or secure web-server locations are located in any of the following:

1.4.3.1. Room-mounted data plate

1.4.3.2. On individual objects

1.5. Revit to Navisworks

1.5.1. Obtain as-built drawings.

1.5.2. Use as-built drawings to model masses of each room or space in Revit.

1.5.3. Export Revit file to Navisworks.

1.5.4. Within Navisworks link non-spatial data collected from field survey to respective mass.

1.5.5. Export from Navisworks to Google Earth.

\subsection{Revit to COBIE}

1.6.1. Obtain as-built drawings.

1.6.2. Use as-built drawings to model specified level of detail.

1.6.3. Export Revit model using Autodesk COBIE Data Aggregator plug-in. 


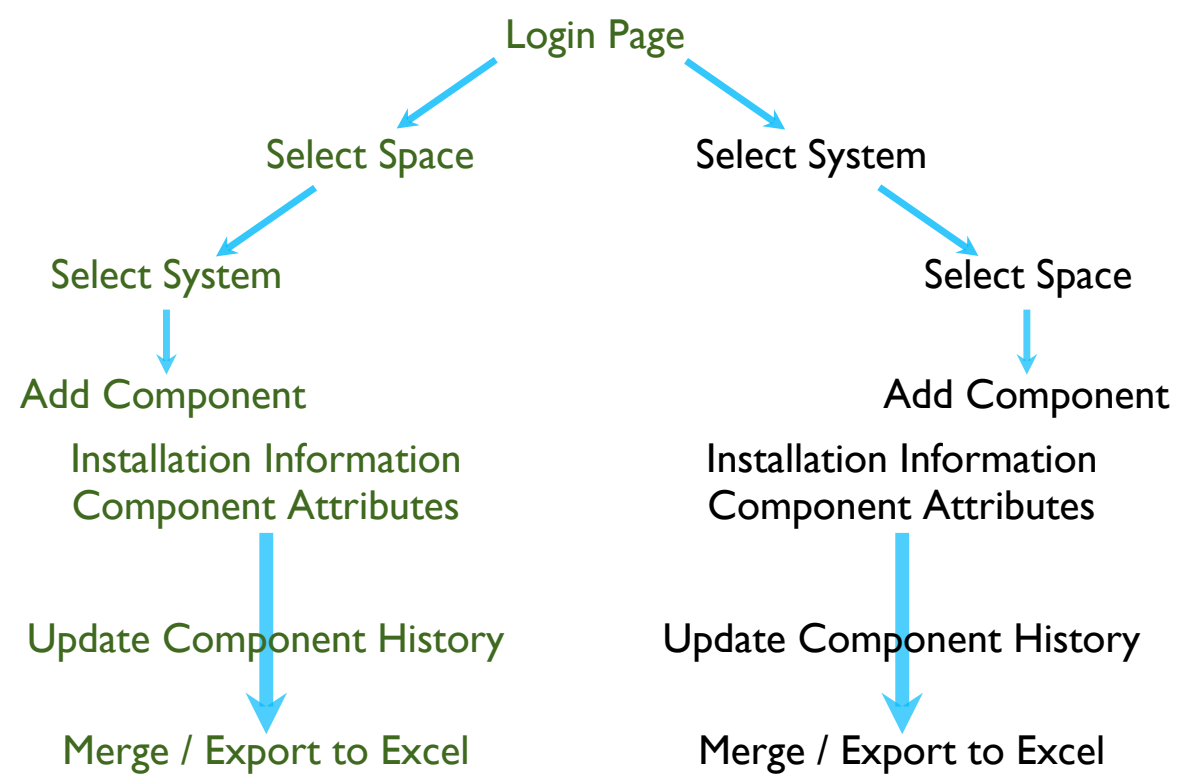

Figure 1: Application Data Hierarchy.

\section{Survey Application Development: Template}

The Survey Application Template should provide for the two basic methods of targeting data in the field shown in Figure 1 and should be effective/adaptable enough to complete tasks efficiently within either data pathway.

Space-by-space Method: All relevant data is captured within each respective space in the facilities being surveyed. Expect surveyors to alternate between system functions and/or component types frequently.

System-by-system Method: A systems-focused approach wherein surveyors gather all relevant data pertaining to a particular system or group of systems, building-wide. Typically done for MEP-focused surveys.

The Application Template can be designed as a series of separate PDF template pages with hidden/visible fields containing relevant COBIE data/categories, and can be controlled using simple Java scripting within Adobe Acrobat.

1.0.2.1. JavaScript configuration files must be appropriately installed in the correct program support folder: for Windows XP systems, copy the "config.js" file to the following folder (also noted in the program "readme" file):

\section{C:/documentsandsettings/<USERNAME>/appdata/roaming/adobe/Acrobat/9.0/javascript}

Design interface to maximize Tablet PC screen size when running application in "full-screen" mode. Buildable screen area is 10.4" (diagonal dimension) or 1024 x 768 pixels, approximately 9" (vertical dimension) by 6" (horizontal dimension). 
Use the following sources to build attribute fields:

Specifiers Properties Information Exchange (SPIE), Component nameplate data, OmniClass Reference Lists, DPW items of interest and previous DPW facility surveys.

\section{COBIE System Functions}

Using sources from BP 2.3.1, drop-down menus or search fields may be used to allow users to specify the facility systems being surveyed. If system functions are not pre-selected or limited (and therefore, vast), provide a combination drop-down/search field so that surveyors may limit source lists from within the application.

Components: Two "page templates" govern the organization of component data:

Standard Component Lists provide a systems-limited list of all standard components included within the Facility Survey. This should be the default component list, and surveyors should arrive at this page before choosing either "Component History" or "Non-Standard" components.

Component History Lists

1.4.1.1. This function searches the saved "Component History Text File" in order to present the user with previously surveyed component data. The resulting list should be limited by selected system, and should be available/accessed from the Standard Component List Component List.

Component Data Page: Attributes for each component are collected, entered, and saved as separate text files.

1.4.2.1. A field for "Product Type" (COBIE Tab 06-Register) should be included to facilitate the association of component data to space and system in the data conversion process.

1.4.2.2. Installation Data Fields: Primarily free-text fields to record Manufacturer, Serial and Model Number, Quantity (see 2.5.3.3).

1.4.2.3. Multiple Installations: See BP 2.8 .3 and 9.2. Provide a mechanism to allow users to quickly indicate the number of installations of components that contain the same attribute/installation data (i.e., lighting fixtures, doors, heat registers).

1.4.2.4. Attribute Fields: Derived from the sources listed in 2.3.1, the attributes for any given component are pulled from the master data file by the JavaScript command. Additional fields can be "hidden" if they are not required, based on the number of attributes.

1.4.2.5. Image Loading: see BPs 2.8.5 and 3.2.1.

1.4.2.6. Save Function: As each component is saved, a separate file with a unique name based on the data hierarchy (e.g., 11751.1.106.Door.Data) that indicates the facility, floor, room, and component type. 
1.4.2.7. Modifications: Using the Component History Function on the page prior to the Component Page, the user can select, update, and save new or different information for a given component. This update must overwrite the individual data file upon selecting "Save", but should not overwrite the Component History File. Overwriting the Component History File is a function of collecting new components. In the case of a modification, components already exist in the history file, and should remain. Overwriting may cause the application to improperly read/search the component history, and may therefore nullify the essential efficiency function.

1.4.2.8. Component History Function Integration: Component data derived from previously surveyed items may be used to pre-populate data fields within the Component Data Page. Executing the Save Function should prompt the system to overwrite the Component History Text File to include the new component data.

Add Non-BP Components: Provide users a method to include components that do not match the standard set provided in either Component List. This may be accommodated via an "Add New Component Type" button on each of the Component List pages. The user should be required to specify COBIE Product Type and Register data that differs from the standard component sets.

Attributes and Installation Information

For the purposes of this survey process, Installation items are treated are treated as attributes. Both attributes and installation should be located in a level position relative to the hierarchy of information described in Figure 1.

Interactive floor plans should be created using clean, easy-to-read plan images. This allows the user to intuitively select the space being surveyed.

Floor plan images may be edited in either $2 D$ CAD or image editing software (such as Adobe Photoshop CS4) to remove extraneous annotations.

Save each individual floor plan as a PDF file, and open in Adobe Acrobat 9 Professional.

Select: Tools $>$ Forms $>$ Show Forms Toolbar

Use the Button tool to create transparent rectangular buttons for each space in the floor plan.

Button properties may be set to execute a JavaScript or file-action to open the next page in the survey.

Integrating Efficiency Functions and Additional Tools

Button navigation 
1.7.0.1. Buttons used for submitting/retrieving data and navigating survey pages should be logically organized in a way that is easily assimilated by the users. It should be relatively easy to locate primary save and navigation functions, and the interface should be presented in a consistent manner throughout all pages.

1.7.0.2. Embedded "Esc" button: Each page should feature an "escape" feature that enables the user to exit full screen mode from within the survey pages. For placement, consider this a "primary navigation function", refer to item 2.7.1.

1.7.0.3. "Back button": Each page should feature an easy-to-find button that returns the user to the previous page in the application hierarchy.

Component history function: This function allows the user to populate a new component entry with inherited attributes from a previously surveyed component within the same system.

1.7.1.1. Using a text file that is overwritten at the time of each component save, this function "searches" the Component History Text File to locate and sample the requested component attributes to be used in the survey of a new component.

1.7.1.2. The "Load Component History" function operates via a similar, but separate, template page than the standard component list page.

Button or drop-down for multiple installations. See BP 9.2.

"Remove component" function: Consider providing a way for users to remove components at will from within the survey application. Users should be able to select or browse components within the Component History list, and should be allowed to remove selected components. Provide a reminder/prompt to double check that the user intends to delete the component.

Image capture may be incorporated into the PDF Survey Form fields within the component data page. Providing this functionality allows surveyors to quickly identify components loaded from the history file. The Motion F5 Tablet PC has an optional camera that can interface with the survey form, in order to upload thumbnail images.

Bar Code Scanning: Serial numbers and other bar-coded data can be captured using the Motion F5's built-in scanner, by simply placing the cursor in the appropriate field and starting the scanner function. No additional coding is necessary to integrate this functionality.

Link to Reference Materials Folder:

1.7.6.1. At a minimum, provide a link to external folder that contains Reference Material, such as help guides, floor plans, and schedule information.

1.7.6.2. Ideally, Reference Material should be converted to PDF and augmented with Button-style navigation tools that allow the user to open documents directly within the application.

1.7.6.3. Additional information, see BP 3.3. 


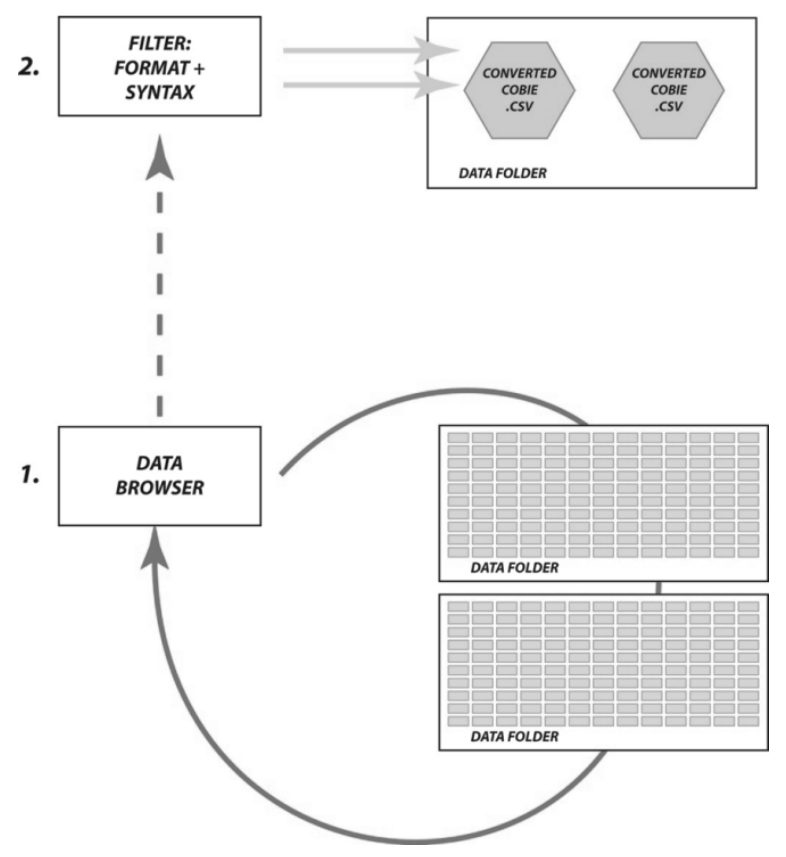

Figure 2: Conceptual Schematic of the Java script COBIE Data Converter. The Data Browser locates the archive folder containing individual component data files. The "Filter" correctly formats the data provided by the Browser, converts it to a comma-separated-value file, and saves the new file in a destination folder specified by the user.

1. COBIE DATA Convertor: The COBIE Data Converter is a separate Java scripted application that locates, filters, and formats the facility survey data, and outputs the information in "comma separated value" format, compatible with COBIE worksheet dated 1/16/08. The ".csv" file can be imported into spreadsheet software like MS Excel, or "cut and pasted" into a COBIE spreadsheet.

1.1. The Data Converter should be created in parallel with the PDF Survey Application. When developing a professional application to implement COBIE Existing Facility Surveys, factor in time and resources to develop this converter.

1.2. Data formatting aggregator function should be based on the latest version of the COBIE tab format. Export to .csv or tab-delimited formats are most readily compatible.

1.3. Multiple component installations: the COBIE Data Converter should be scripted to create "N" number of data entries in the .csv output file, based on the quantity specified in the "quantity drop-down menu" on the component page (PDF Survey Application). The converter reads the quantity, makes the appropriate number of "copies", and renames each with a numbered suffix, counting up from 1. 


\subsection{Install the COBIE Data Converter on the Tablet PC.}

1.4.1. When installing the Data Converter on the Tablet PC, it is important to preserve the file structure of the program file. The Converter needs to be able to locate the "SRC" files (Space, Register, Component), and the Java script explicitly identifies the folders in relation to the parent folder.

1.4.2. Set up the file structure for managing and transferring the survey data files on the Tablet PCs. This file structure should be used in the facility "home" or archive files on the DPW server or office storage location. The file structure should facilitate converting and archiving survey data by providing folder locations for each part of the conversion process.

1.4.2.1. "Source data" folder: contains the individual saved survey files. (.data or .txt format). Typically this will be the "compdata" folder located within the PDF Survey Application Program file.

1.4.2.2. "Processed data" folder: this folder is empty prior to conversion. This is the destination folder to be selected when running the Data Converter. The Converter will save the "comma separated value" files to this folder.

1.4.2.3. Original data files: Provide a location to archive the original survey files.

1. Tablet PC setup

1.1. All Tablet PCs should be running:

1.1.1. Adobe Acrobat 9 Pro (extended version is only recommended if the survey scope includes Adobe 3D PDF capabilities).

1.1.2. Current Survey Application Version (.pdf).

1.1.3. Place JavaScript Configuration File in correct Adobe JavaScript folder, see BP 2.1.3.

1.1.4. Current Converter Version (.jar).

1.1.5. Windows Journal (.jnt).

1.1.6. Optional Software Items:

1.1.6.1. Autodesk DWF Viewer (free).

1.1.6.2. Screen-capture Utility (Screenhunter, or similar).

1.2. Optional equipment to consider:

1.2.1. Motion F5 Camera for component image capture. Images may be uploaded to data files or field notes.

1.2.2. Barcode Scanner, for Serial and Model number capture.

1.2.3. Additional Stylus Pens.

1.3. Reference material for surveyors, to be placed in the survey folder, or in another local folder, with an alias on the desktop for quick access. Links to 
either the reference folder or to specific guides may be added to the PDF survey form pages.

1.3.1. Best Practices Field Guide

1.3.2. Survey Form instructions/help guide

1.3.3. Tablet PC User Guide

1.3.4. Relevant drawings

1.3.5. Relevant facility specifications, equipment notes

1.3.6. Project, facility schedule

1.3.7. Point-of-Contact information.

1. Survey Application: Facilities-Specific Information

1.1. Obtain relevant 2D drawings and specifications: see BP 1.1 and Figure 3 . The Survey Project Manager coordinates the acquisition of relevant 2D CAD or PDF drawings to complete necessary BIM tasks and PDF form customization.

1.2. Verify as-built conditions: The Survey PM conducts a pre-survey verification of as-built conditions, including an assessment of the facility's accessibility requirements. Provide relevant observations for both BIM and PDF form development.

1.3. Create "clean" floor plan set: see section 2.6.1.

1.4. Create interactive floor plan in Adobe Acrobat, see section 2.6.2-2.6.5.

1.5. Loading basic COBIE information: using relevant, non-spatial COBIE tab and column data including:

1.5.1. Tab 01-Contact: Include all individuals contributing data to the survey project.

1.5.2. Tab 02-Facility: List all facilities included in the scope of the survey project.

1.5.3. Tab 03-Floor: List all floors included in the survey project.

1.5.4. Tab 04-Space: Identify all spaces being included in each facility survey. It is not necessary to subdivide subspaces within numbered rooms (i.e., 106 versus 106A, 106B, 106C). However, if this is desired due to significant differences in subspace function, then be sure to coordinate with the BIM developer and ensure that space definitions remain consistent throughout the survey project.

1.5.5. Tab 05-System: List all systems included in each facility. This list may be based on the IFC definitions, the Omniclass Reference lists, or DPW systems.

1.5.6. Tab 06-Register: Data derived from this worksheet becomes the "link" between individual components, their respective space locations, and 
system functions within the facility being surveyed. Essentially the Register Tab contains a list of component or product types, but it is through the register that specific component installation data will link to both space and system. This link completes the "unique identity" for each component within the facility.

\subsubsection{Tabs 07-Component, 08-Attribute,14-Installation}

1.5.7.1. The final page in the application sequence combines information from Tab 07, 08 and 14. Attributes may be limited by the needs of DPW, and the scope of the survey project. Installation data is standard - typically any and all information that is available should be collected.

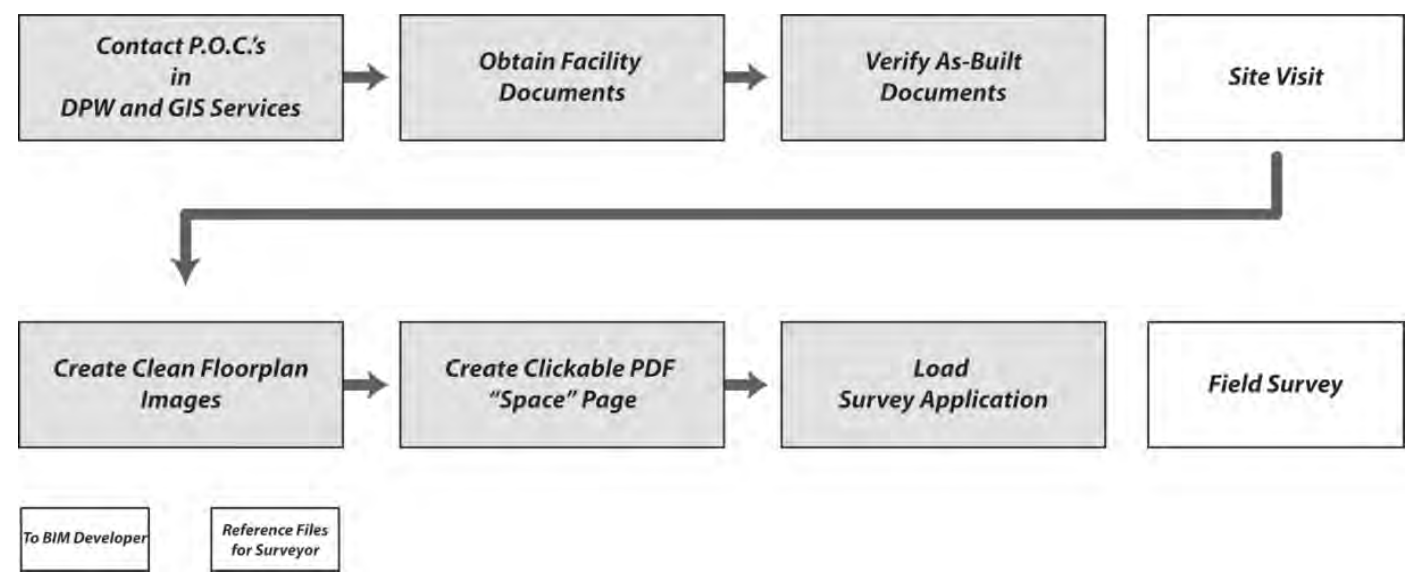

Figure 3: Pre-Fieldwork activities.

1. Schedule the Fieldwork

1.1. Considerations for planning around facility/base activities:

1.1.1. During winter months, many facilities are either unoccupied or are preparing for deployment activities. Base-wide events are at a much lower level than in summer. For most COBIE survey activities, October through April is better for conducting facility surveys.

1.2. Facility Points-of-Contact

1.2.1. Develop and maintain contact with facility POCs, schedule survey as early on as possible. This may be the first activity performed in a survey project (see Figure 3).

1.2.2. Maintain communications with POCs, keep them informed of changes/additions to schedule.

1.3. Develop preliminary schedule of facilities to be surveyed, using known/updated task completion rates. 
1.3.1. See Appendix 3 for a table of these rates, listed in square feet per minute.

1.3.2. Plan for approximately $25 \%$ additional time for logistics, access.

2. Beginning Fieldwork

2.1. Contact should be made with the Facility POC, and/or Commanding Officer, prior to conducting survey activities.

2.1.1. Provide a schedule of activities, spaces requiring access, and plans for an escort, if necessary.

3. Ongoing Facilities Survey

3.1. Formulate a plan and a route for each day's task. If the task involves limited access or secured spaces (i.e., SIPR-Net Room or Secure Storage Vaults), plan an additional $15 \%$ logistical time per secure space.

3.2. Develop a rapport with facilities staff. Inform both Facility POC, the Commanding Officer, and Staff Duty of the day's intended tasks, and doublecheck access requirements if necessary.

3.3. Following each task, update field notes and back-up data files as necessary.

3.4. Data Organization: See sections 9.1, 9.5 and 10.2.

3.5. Convert and Archive Data upon Survey Completion (per facility): See sections 9.1, 9.5 and 10.2.

4. Data Conversion and Formatting

4.1. Data should be compiled, converted, and archived following closeout of each facility survey. This phase should be done before data is moved from the Tablet PC to ensure minimal data loss.

4.1.1. Open the COBIE Data Converter (.jar application) on Tablet PC.

4.1.2. Follow the instructions on-screen to correctly locate the "Space", "Contact", and "Register" templates, as well as the source and destination folders for the survey data. See Appendix 2 for instructions and screenshots.

4.2. Save the new COBIE .csv files in a folder for back up and transfer. 
4.3. Archive raw survey data files, according to the file structure established in section 10.2 .

1. Options for Data Storage and Access

1.1. Archiving Facility Survey Data: Develop a filing structure so that archived facility files raw, converted, and merged can be easily located. This file structure should be used in both the office-based survey computers and the Tablet PCs. Each Facility file should include the following:

1.1.1. Raw data files

1.1.2. COBIE .csv (converter output)

1.1.3. Merged Facility COBIE Spreadsheet, complete

1.1.3.1. Merged Survey + BIM COBIE Data

1.1.3.2. Individual Files

1.1.4. As-Built Documents

1.1.4.1. 2D drawings and specs

1.1.4.2. BIM geometry

1.1.5. Copy of Integrated BIM File (Office-based computers)

1.2. Integrated Data Formats: Figure 4 refers to two methods of integration that are feasible and currently recommended. Depending on the needs of the client and the scope of the survey project, the team may seek to produce one or both of these: a "merged COBIE spreadsheet" containing spatial and non-spatial data, or a Low-Fidelity BIM containing hyperlinks that access COBIE facility data.

1.2.1. Merged COBIE (BIM Data + Survey Data): Both Revit and the COBIE Survey are capable of producing data organized within a COBIE formatted spreadsheet.

1.2.1.1. Export Revit Model data using the Revit-COBIE Schedule Template.

1.2.1.2. Open exported COBIE data in Excel, and fill in appropriate information within Tabs 01-06.

1.2.1.3. Convert facility survey data to .csv format using the COBIE Data Converter.

1.2.1.4. Open the facility COBIE Spreadsheet.

1.2.1.5. Copy/Paste converted facility data into the appropriate COBIE Tabs.

1.2.1.6. Examine IDpicks and other linkages for errors.

1.2.2. Google Earth Low-Fidelity with Hyperlinks

1.2.2.1. Export Revit model to Navisworks

1.2.2.2. Open exported Navisworks file, associate hyperlinks and GPS coordinates.

1.2.2.3. Export Navisworks model to Google Earth .kmz format. 


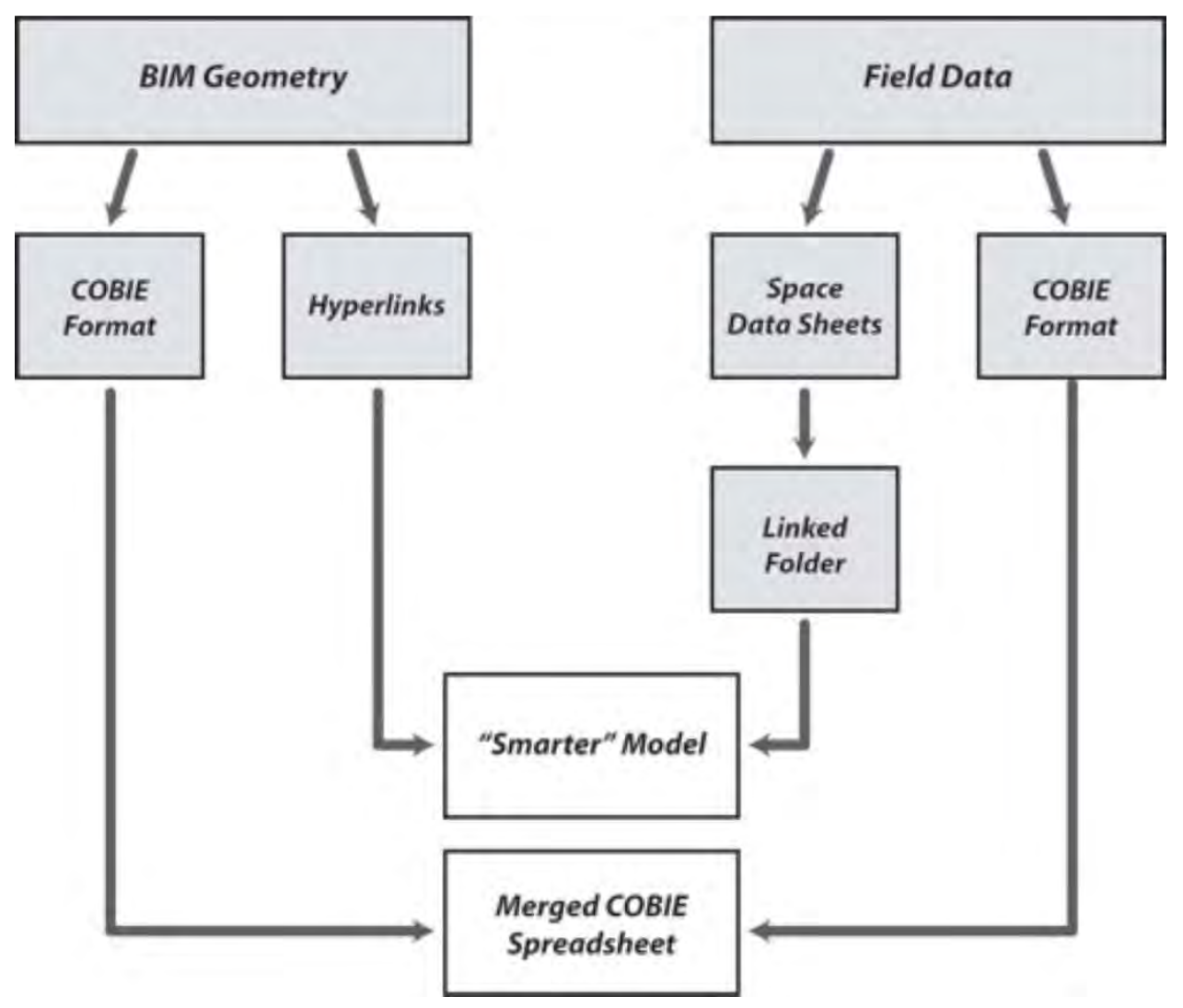

Figure 4: Two primary methods for integrating spatial and non-spatial COBIE data. 


\section{Chapter 3: Rationale for Best Practices}

This chapter describes in detail the research team's observations and rationale for Best Practices recommendations described in Chapter 2.

\section{BIM Development}

1.1.2D drawings may be imported into Revit to use as "underlays" when building the BIM geometry. At a minimum, paper copies may be referred to, but digital versions are ideal. Specifications and schedules for mechanical and other systems help the BIM developer to correctly identify and locate componentry within the facility spaces.

1.2. BIM geometry must be built using the most current information about the facility. The BIM developer needs to coordinate on-site verification of as-built conditions with the team.

1.3. The "Low-Fidelity" BIM model is intended to be a quick, easily accessible and transmittable vehicle for COBIE data. This model can easily be loaded onto a server location and/or placed within Google Earth or other GIS database on a secure server. Primarily a massing-model, the Low-Fidelity BIM is relatively quick to build and integrate with COBIE survey data. During the research phase, it was found that this level of detail was easily integrated using hyperlinks to browser-supported data sheets for each space within the facility.

1.4. The "Medium-Fidelity" BIM contains more detail and component data within the geometry itself. While it does not contain assemblies or material properties, the Medium Fidelity BIM may contain representative objects within spaces that serve as placeholders or links for specific components. The Medium-Fidelity BIM is more compatible with the "Merged COBIE" form of data integration at this point. Hyperlinked spaces are easily cluttered at this level of detail. It may be possible in the near future to work within a SketchUp or Adobe platform to develop linkable products.

\subsection{Revit to Navisworks}

1.5.1. As-built drawings were obtained through DPW GIS/IT services. POC Scott Smith located and provided 2D CAD and PDF drawings for developing the BIM and the PDF Survey Application. Scott, an employee of the private firm Qinetiq, contracted to provide IT services, works within the GIS services department for DPW.

1.5.2. $2 \mathrm{D}$ floor plans and other reference material were delivered to the BIM developer for use as "underlays" within Revit.

1.5.3. - 1.5.5 For placing hyperlinks and uploading the Low-Fidelity BIM to Google Earth, Autodesk Navisworks was used as a "middle-platform". Navisworks allowed the BIM developer to reliable place hyperlinked 
markers within rooms, create "clickable" layers that could be activated/deactivated, and complete the Google Earth upload process.

\subsection{Revit to COBIE}

1.6.1. See Rationale for BPs 1.3, 1.4, and 1.5.1-1.5.2.

1.6.2. The BIM Developer contacted several individuals within Software Development Companies, non-profit groups, and private consulting firms (i.e., AEC3) who are currently working on integration solutions for a variety of platforms.

1.6.3. Autodesk has been working to develop both COBIE-formatted schedule templates and an aggregator that has the capability to process exported attribute data into a COBIE formatted spreadsheet.

\section{Survey Application Development}

2.1. The research team developed a hierarchy for organizing and navigating the survey process and data along two methods of gathering data. This hierarchy is presented via an interface that is intended to be as intuitive as possible, and allows the user to collect component data "Space-by-Space" or "System-bySystem". While it is clear from the results of the field study that the latter takes considerably longer to complete the facility inventory, the process revealed a higher square-foot-per-minute average rate in many task areas than was observed in the "space-by-space" method. In some cases, DPW may opt to develop survey projects that single out specific systems or groups of systems for which to gather data. Appendix 3 contains tables that show completion rates for each survey team during the field trials, in SF per Minute, as well as the total times (Minutes) to complete each task group. The field study was conducted at Building 11751, Company Operations Facility for 3-17 Field Artillery Battalion, 5/2 Stryker Brigade Combat Team. The symmetrical nature of the plan allowed the field teams to gather complete data for one entire half of the facility (south half of floor one, south half of floor two), from which we extrapolated completion rates for the entire facility (see Appendix 1 for more on the experimental design).

2.1.1. Space-by-space Method: developed as the most intuitive approach to gathering data. This process focuses on gathering complete data for each space in the facility.

2.1.2. System-by-system Method: allows DPW to tightly focus their efforts on a few key systems. 
2.1.3. Several iterations of the PDF Survey Application were developed. An early version of the application involved a parallel launch of a java-based engine that controlled the operation and navigation of the PDF interface. The engine worked as a background application, retrieving, sending, and formatting COBIE data to and from the master and destination files. Several problems including processing speed and Adobe Acrobat's security protocols led to the abandonment of this type of program. Working within Adobe's Java scripting tools, the programmer developed a Java script to configure and control the navigation of a series of PDF templates for each step in the survey process. Each page contains data fields that are populated with COBIE data and categories based on user selections. The PDF template sequence "collects" the data selections and, upon saving the program, this information is saved as a separate file. The result is a relatively lightweight application that creates inherently backed-up data files. The Tablet PC must be running Windows XP currently Vista is not supported.

2.1.3.1. Java script configuration installation: see BP 2.1.3. Adobe's security protocols designate select "trusted" folders for Java scripts and other configurations and customizations. The application will not function unless this file is correctly installed.

2.2. The Motion F5 screen is $10.4 "$, measured diagonally, which translates to roughly 9" x 6" orthogonal dimensions. Initially, the PDF Survey Application was designed to be operated in full screen mode, using the F5's "floating" input panel that appears when a cursor is placed in any text field. However, Adobe's security features appear to block this functionality in both full-screen mode and standard view. The application was modified to allow the user to utilize the "docked" input panel while running in full screen mode.

2.3. Attribute fields were built using a combination of Omniclass Reference lists, DPW derived attributes, and required COBIE installation column data. Attributes were limited in scope to include only visually accessible items and to facilitate complete data sets within the experiment time frame, but also to give a representative sampling of the breadth of collectable component data.

2.4. COBIE System Functions: systems surveyed were derived from the Omniclass system functions, List 23.

2.4.1. If system functions are not pre-selected or limited (and therefore, vast), provide a combination drop-down/search field so that surveyors may limit source lists from within the application.

\subsection{Component List pages (see Appendix 2, Figures 18 and19)}

2.5.1. In an effort to reduce user error, a standard set of components was provided, pre-loaded in the master data file, for each system surveyed. The Standard Component List Page displays these lists by system function selected. 
2.5.2. A major priority for the research team was to provide a way for users to populate new component data entries with inherited attributes from previously loaded components, without having to manually enter the data. The Component History List displays these items, based on the system function selected, and populates the new component attribute fields. The user is required to change unique data such as component name, number of installations, and serial number.

2.5.2.1. See rationale for BP 2.9.2 for further descriptions of the Component History Function.

2.5.3. Attributes for each component are collected, entered, and saved as separate text files.

2.5.3.1. COBIE Spreadsheet Tab 06-Register eventually serves as a primary link to correctly associate components and attributes to spaces and systems within the facility. In the final product, the "Product Type" column is a way to add another identifier to the unique "DNA" of each component. Within the PDF Survey Application, "Product Type" is included.

2.5.3.2. Primarily free-text fields to record Manufacturer, Serial and Model Number, Quantity (see 2.5.3.3).

2.5.3.3. See BP 2.8.3 and 9.2. Provide a mechanism to allow users to quickly indicate the number of installations of components that contain the same attribute/installation data (i.e., lighting fixtures, doors, heat registers).

2.5.3.4. Derived from the sources listed in 2.3.1, the attributes for any given component are pulled from the master data file by the JavaScript command. Additional fields can be "hidden" if they are not required, based on the number of attributes.

2.5.3.5. See BPs 2.8.5 and 3.2.1.

2.5.3.6. As each component is saved, a separate file with a unique name based on the data hierarchy (e.g., 11751.1.106.Door.Data) that indicates the facility, floor, room, and component type.

2.5.3.7. Using the Component History Function on the page prior to the Component Page, the user can select, update, and save new or different information for a given component. This update must overwrite the individual data file upon selecting "Save", but should not overwrite the Component History File. Overwriting the Component History File is a function of collecting new components. In the case of a modification, components already exist in the history file and should remain. Overwriting may cause the application to improperly read/search the component history, and may therefore nullify the essential efficiency function.

2.5.3.8. Component data derived from previously surveyed items may be used to pre-populate data fields within the Component Data Page. Executing the Save Function should prompt the system to overwrite the Component History Text File to include the new component data. 
2.5.4. Provide users a method to include components that do not match the standard set provided in either Component List. This may be accommodated via an "Add New Component Type" button on each of the Component List pages. The user should be required to specify COBIE Product Type and Register data that differs from the standard component sets.

2.5.5. As part of the attempt to reduce bias and increase efficient, intuitive data collection throughout the application interface, all component traits were equally weighted and located within the component page.

2.6. Interactive floor plans are a key part of the intuitive space selection. Users are able to keep track of their progress and location in the facility as a regular part of collecting data.

2.6.1. - 2.8.5 Editing floor plan PDF files may be done in Adobe CS4 or Autodesk AutoCAD prior to export as a PDF.

2.7. Efficiency improvements and improved user familiarity was studied using two separate timed tests during the field study period. A description of these assessments and the results is located in Appendix 6. Completion rates for all weeks, including total components/attributes gathered are included in Appendix 3. On average, teams collected approximately 360 components, and 1500 attributes (including installation data) for the areas surveyed during the field study (half of each floor within Building 11751).

\subsubsection{Button navigation}

2.7.1.1. Buttons used for submitting/retrieving data and navigating survey pages are logical way-finding devices and are familiar to most users. From Surveyor Post-surveys: "[the application interface was] generally straightforward, a few opportunities to refine, such as order of the buttons [sic]." (AJL, Week2)

2.7.1.2. Several surveyors and testers found that they needed to hard-restart when they were unable to "escape" from the full screen mode, due to difficulties with the docked virtual keypad.

2.7.1.3. From surveyor post-survey comments: "I am impressed with the speed of inventorying[sic] many similar spaces, however, the software could be improved a bit by adding a "back" button . . . from the attribute page" (DLP, Week 1)

2.7.2. Component history function: This function allows the user to populate a new component entry with inherited attributes from a previously surveyed component within the same system.

2.7.2.1. Using a text file that is overwritten at the time of each component save, this function "searches" the Component History Text File to locate and sample the requested component attributes to be used in the survey of a new component.

2.7.2.2. The "Load Component History" function operates via a similar, but separate, template page than the standard component list page. 
2.7.3. Button or drop-down for multiple installations. See BP 9.2.

2.7.4. Several FRA staff commented that at various points within the application interface, it would be useful to be able to remove previously entered components. This function was not provided in the field-tested version but could easily be accommodated in a manner similar to the inclusion of a Component History Function. From surveyor post-survey comments: "Need to be able to delete component or have a summary of catalogued components to review saved work" (TS, Week 4). A glitch in the component history script caused the application to "miss" certain components within the history file, after duplicates were manually removed (due to a recognition of an error). We found that this might have been avoided if the application included a menu-based data removal function. This caused a delay of approximately 30 minutes during the fourth week, and required the use of an alternate Table PC while the initial machine was repaired.

2.7.5. Surveyors developed a number of methods and mnemonic devices to record and recall component types and iterations using the Component History Function. Several mentioned identifying the correct component from the history list was difficult. Adding thumbnail images to the history or Component Page would facilitate quick identification of components.

2.7.6. Four of the FRA surveyors utilized the Motion F5 built-in barcode scanner with great efficiency. This tool aided the capture and input of serial numbers and model numbers, particularly for difficult-to-reach components (i.e., heat detectors).

2.7.7. FRAs preferred to refer to reference material located on the Tablet PC than to carry binder-based reference material provided by the GRA. Embedded links within the application to the reference folder on the Tablet PC would eliminate the need to exit full-screen mode or to navigate outside the application.

\section{COBIE DATA Convertor:}

3.1. During the study, the Java script COBIE Data Converter was developed following the deployment of the PDF Survey Application. This was mainly due to the continued search for viable integration options. The converter's main purpose is to filter and format the component data files created during the facility survey. Ideally, both java-developed applications would be created at the same time or in close sequence, and the optimal scenario would be one in which data conversion could be linked or launched within the PDF Survey Application. Due to Adobe Acrobat's security features, it was not possible to launch another application from within Acrobat itself, and adding the conversion scripting to the back-end of the application appeared to be significantly complicated. The goal was to create a streamlined survey application and intuitive interface. At the time, it appeared that additional data conversion might have unnecessarily slowed or complicated the surveyors' progress. It now seems to be a valid avenue to explore, as integration between the converter 
and the survey application could be a significant accuracy improvement and efficiency measure.

3.2. The research team reverse-engineered the data conversion based on the COBIE spreadsheet tab format and the intended outcome of the data conversion. They sought to utilize the facility's space number (SpaceID) and the Register information (SystemID, Product Type) to properly link component data to the spaces and systems within the Building 11751. The Tab 06Register serves as the link between system and component, while the component tab directly refers to Tab04-Space.

3.2.1. The converter's output is in ".csv" (Comma-Separated Value) format, which is easily imported into the COBIE Spreadsheet form within MS Excel. Once the team had defined the integration goals for the data, the JavaScript creation was relatively quick. Conversion of the data takes only a few minutes, with most of the time spent on verifying the archived folder structures for locating, converting, and storing the data.

3.3. The JAR COBIE Data Converter reads the quantity field within the Component Installation data and creates a set of copies based on the number entered. These copies are given an ordered name based on the primary component surveyed, and are placed within the COBIE Spreadsheet with appropriate linkages to the Register and Space. It may be beneficial to modify this aspect of data conversion and include it in the initial data save process within the PDF Survey Application. This seems to be an appropriate place to begin integrating the two scripted applications. In either case, the iterations are treated in the same manner, but by integrating the conversion/copy function into the survey application, there is less chance to duplicate work or create additional errors.

3.4. Installing the Converter on the Tablet PC or any other equipment is relatively simple. The application and configuration files are self-contained within a file structure that needs to remain intact. The Tablet PC should be running the latest version of Java, available for free from Sun Microsystems. In order to convert the files, it must be easy for the user to locate both the "filter" files and the data to be converted. This is why it is necessary to establish a standard file structure for collecting, storing, archiving, and transferring data (see BP 10.2).

3.4.1. The Converter needs to be able to locate the "SRC" files (Space, Register, Component), and the Java script explicitly identifies the folders in relation to the parent folder. The "SRC" files are the "filters" that explicitly define the format for data conversion, based on the corresponding COBIE tabs, "04-Space, 06-Register, 07-Component".

3.4.2. Four iterations of the JAR Data Converter were attempted; the team discovered that during installation, the original JAR file structure was altered, causing the application to incorrectly "point" or search within the wrong file folders. The computing systems developer created a file structure that could be simply copied directly to the Tablet PC's "Desktop", "Program Files", or "My Documents" file, without having to place or install individual configuration files. The application is then able 
to be launched and run within seconds of installation and is totally selfcontained.

3.4.2.1. The team found that a simple, universal folder system enabled efficient, uncluttered file transfers, and facilitated communication during data exchange and troubleshooting. This concept could be applied to the indefinite storage and maintenance of the facility data and could be easily modified and assimilated for use within each military installation.

\section{Tablet PC setup}

\subsection{Required software:}

4.1.1. Adobe Acrobat 9 Pro: The team found that at this point, opportunities for integration using Adobe Acrobat's 3D functions are still quite undeveloped. Until there are better importing/exporting capabilities within Revit (and other BIM software), Adobe's impressive 3D capabilities are not easily put to use for the purpose of viewing component attributes via imported BIM geometry. Therefore, the team was able to reduce the functionality needed to create application interfaces and support the PDF Survey Application; all that is required to run the application is Adobe Acrobat 9 (free), while Acrobat 9 Professional is required.

4.1.2. Current Survey Application Version (see Rationale for BP 2).

4.1.3. Current Converter Version (.jar) and the latest version of Java, available from Sun Microsystems (see Rationale for BP 3).

4.1.4. Windows Journal (.jnt): This application comes standard with Windows $\mathrm{XP}$, and provides a quick way for users to record notes, observations, and reminders.

4.1.5. Optional Software Items: these are other items that the team found helpful. Autodesk DWF Viewer is a free application that allows users to view, scale, measure and comment on .dwg CAD drawings.

4.1.5.1. Screen-capture Utility (Screenhunter, or similar): During the field trials, for training as well as documentation purposes, "Screenhunter" was used to capture screenshots and record video of the interface in action. This was helpful for communicating techniques to new users and aided communication with the software developer, regarding bugs, glitches, and workarounds.

\subsection{Optional equipment to consider:}

4.2.1. Motion F5 Camera for component image capture: It quickly became apparent that the intuitive, task/visual based interface needed some additional functionality to help surveyors rapidly identify components within the Component History List. Although not included in this version of the PDF Survey Application, image uploading would greatly increase the accuracy and efficiency of several processes within the survey tasks. 
4.2.2. Barcode Scanner, for Serial and Model number capture: During some tasks, such as Interior Lighting and Fire/Smoke Protection, surveyors had a difficult time physically reaching many types of components. In several cases, surveyors in different weeks developed a method of using the Motion F5's built-in barcode scanner to capture serial and product numbers for items like Heat Detectors, Light Fixtures, and Alarms. The users simply placed a cursor in the appropriate field, started the scanner, and swept the code. The corresponding number then appeared in the field.

4.2.3. Additional Stylus Pens: The research team ordered additional stylus pens and tips, which became useful when a surveyor misplaced an nontethered stylus during the 4th week.

4.3. Reference Material for surveyors: During the study, each team was provided additional reference material relative to the different components of their work. The teams were given: instructional guides for the PDF Survey Application, Motion F5 Tablet PC Guide, 2D drawings for the building, weekly and daily schedules, and POC/study contact information. The material was provided in two forms: 1) Digitally, in a folder accessible from the desktop; 2) Paper-based, in a binder which they were given at the beginning of the week. Invariably, surveyors chose to leave the binders with the gear storage bins. Many preferred the lightweight feeling of relying solely on the Tablet PC and the resources installed on it.

5. Survey Application: Facilities-Specific Information

5.1. See Rationale for BP 2. In addition to using the as-built CAD drawings, it will be important to consider including specifications for specific systems as a prerequisite for developing and customizing the PDF Survey Application and developing the project schedule. Our teams relied solely on training, on-site documentation, and the application to guide their data acquisition. Realistically, the DPW team should use all available documentation to inform their inventory.

\subsection{See Rationale for BP 2.6.1.}

5.3. Create interactive floor plan in Adobe Acrobat, see Rationale for BP 2.6.2-2.6.5.

5.4. - 5.4.7. Loading basic COBIE information: Using relevant, non-spatial COBIE tab and column data as well as attributes derived from DPW survey processes and interests, the project manager takes on the responsibility to customize the PDF Survey application for the facilities and tasks included in the survey project. It is expected that to do so, part of the professional development of the PDF Survey Application must include developing a method or interface for entering and modifying data fields, pick lists, and collection parameters. The research team used master data files - simple text files that provided the raw lists through which the java script directed Adobe Acrobat to search. It is 
assumed that the interface would likely be more secure and would incorporate drop-down menus, text fields, and programmable button selection.

6. Schedule the Fieldwork: This part of the survey process proved to be one of the most critical aspects of our work. Although access and logistics is a significant issue that any survey team will face, the research team's status as an external group became a greater time factor than might typically be the case. During the pre-field phase of the study, the GRA and the team maintained contact with DPW, and collaborated with POCs to schedule the field trials and arrange access. However, during the first week of the fieldwork it became clear that the occupants of the facility being used in the study were in the process of deploying.

\subsection{Considerations for planning around facility/base activities:}

6.1.1. The GRA was fortunate to have a conversation with John Perez, Facilities Operations Specialist with the Fort Lewis Business Operations and Integration Division. Mr. Perez and his staff are responsible for conducting inspections to evaluate maintenance, "non-fair wear and tear" and sanitation within DPW-maintained buildings on the Fort Lewis installation. Anytime a building occupant plans to move out of an assigned space, Mr. Perez and his team conduct an inspection of the physical condition of the room and/or building. Because of the yearly schedule for deployments and troop movements on/off base, Mr. Perez's team finds that the vast majority of inspections occur during the summer months, while relatively few are scheduled from October-April. His observation regarding base-wide activity levels has implications for the kind of surveys we are targeting as a part of this study. During the fieldwork period, the team had significant scheduling difficulties early on due to conflicts with the building occupants' orders for deployment. Our presence also made it more difficult for the building occupants to do their work, while the deployment activities made it nearly impossible to access many of the facility spaces. In addition, Fort Lewis like many other installations, holds ROTC programs throughout the summer, thereby increasing the on/off base activity levels. Simply put, many installations are very busy during summer months. Given this, and considering Mr. Perez' observations regarding inspections, it is reasonable to conclude that mid-fall, winter months, and early spring are the best times of the year to conduct COBIE facility surveys with relatively little interference or complications due to base-wide events and activities. Mr. Perez also noted that briefings and logistical planning for facility inspections begins 4-6 months prior to the scheduled fieldwork.

6.2. Facility Points-of-Contact: The Facility POC for Building 11751, Rear Detachment Commander LT Ryan Butler, was instrumental in facilitating survey activities and troubleshooting access issues, including the conflict with the battalion deployment. The schedule conflict posed a serious challenge both to the completion of that week's tasks, not to mention to the relationships built to 
support the survey activities. The facility occupants' deployment activities were initially scheduled for the week prior to the start of fieldwork. However, external issues and circumstances caused the battalion's deployment process to move at a much slower pace. The repercussions of this meant that the COBIE Facility Survey fieldwork had to be postponed until the following week. This event highlighted the importance of communication with building occupants, rapport building, and scheduling around facility/installation events.

6.3. The goal was to make time and cost estimation a simple process. The team's productivity analysis developed a set of average rates to be used in the calculation of facility survey time.

6.3.1. See Appendix 3 for a table of these rates, listed in square feet per minute.

6.3.2. Allowing for $25 \%$ additional time related to logistics: See "Chapter 5: Recommendations for Institutionalization within DPW."

\section{Beginning Fieldwork}

\subsection{Contacting Facility POC, and/or Commanding Officer}

7.1.1. The Company Operations Facility used in this study is primarily an administrative building. However, the facility is also designed to provide unit storage and secure storage for arms and secure spaces for the battalion command. It has been previously noted that the Facility POC played a crucial role in facilitating access, assisting in troubleshooting, and developing a weekly and daily routine during the field trials. LT Butler serves as the Rear Detachment Commander for the 3-17 FA Battalion that occupies Building 11751, and as such, he is the only personnel entrusted with pass-codes and access to every space within the facility. It would have been impossible to complete survey tasks within many of the spaces without coordinating our efforts with LT Butler's schedule on a daily basis. It is important to reiterate that access and logistics would be different for a DPW-based Project Team, however, such a team would still find it necessary to coordinate with the Facility POC for many, if not all, of the survey tasks and spaces.

\section{Ongoing Facilities Survey}

8.1. See Rationale for BP 7.1.1. Secure spaces are an increased access issue, and pose a logistical challenge to contracted or internally staffed project teams.

8.2. Develop a rapport with facilities staff. Much of what has been stated regarding Facility POCs can be reiterated for other building occupants. For instance, the assigned POC may not be available at all times or all days. The CO may assign another staff person to act as an alternate or interim POC or may assign staff duty to act as escort in certain facility areas. 
8.3. Field notes and data back up are important tools for promoting and maintaining continuity and communication during the survey project.

8.4. Data Organization: See Rationale for BP 9.1, 9.5 and 10.2.

8.5. Convert and Archive Data upon Survey Completion (per facility): See Rationale for BP 9.1 and 10.2. The research team found that data management proved most effective and error-free when data handling was kept to a minimum.

9. Data Conversion and Formatting

9.1. See Rationale for BP 8.5, 10.1. In order to streamline the data management but also provide standard structures for communicating and transferring data, the team recommends archiving and converting data on the Tablet PC before it is moved. This will become an important step, particularly for survey projects that involve many facilities or several surveyors. Once the data is ready to transfer back to the BIM Developer or Project Manager, it should already be archived and converted, thus enabling a "one-folder" transfer.

\subsection{See above.}

9.3. See Rationale for BP 10.1.

\section{Options for Data Storage and Access}

10.1. One of the challenges faced by the research team and the field trials team was to collect, organize, convert, and transfer hundreds of individual data files for each facility survey team (4 in all, although two teams consisted of two persons, which required the GRA and data management team to coordinate and process data from six total computers). Beyond the initial file-save function within the PDF Survey Application, data organization was handled after survey completion, during post-processing. This manual organization could present a logistical and clerical problem for the project team. It is recommended that each team implement standards regarding file structure, naming, and transfer protocols.

10.2. For an in-depth exploration and background on the technologies explored in this study, see Chapter 6 . Depending on the needs of the client and the scope of the survey project, the team may seek to produce one or both of these: a "merged COBIE spreadsheet" containing spatial and non-spatial data, or a Low-Fidelity BIM containing hyperlinks that access COBIE facility data.

10.2.1.1. - 10.2.1.5. The research team discovered that a feasible workflow involved the creation of the BIM slightly ahead of other tasks involving COBIE spreadsheets, data conversion or otherwise. The 
BIM geometry proved to be relatively simple to create and typically required between 3-4 hours to develop. Other tasks within the BIM software included developing and populating the COBIE template for Revit (within the scheduling functionality), and exporting the BIM geometry as COBIE data to place within a COBIE spreadsheet. By working "forward" in this manner, the Project Manager is given a COBIE spreadsheet that has already been "started" and already contains the basic BIM COBIE data, such as areas, floor-floor heights, etc. The PM can then avoid duplicating any work, or managing multiple COBIE spreadsheets.

10.2.1.2. The PM should have access to a COBIE checker, either stored locally or on a secure network, where the team can examine the document for errors and reference problems.

10.2.2. Google Earth Low-Fidelity with Hyperlinks

10.2.2.1. Export Revit model to Navisworks

10.2.2.2. Open exported Navisworks file, associate hyperlinks and GPS coordinates.

10.2.2.3. Export Navisworks model to Google Earth .kmz format 


\section{Chapter 4: Time and Cost Estimates}

For those planning survey projects, estimating the time and cost to complete survey tasks for each facility is crucial. Central to this task are the completion rates for various survey tasks within installation facilities, based on the average square feet per minute that a surveyor can complete. The estimator needs to consider the time it takes to complete each task, the logistical time to support and access each task, and the labor-hours that correspond to completion of the facility survey. This chapter serves as a guide for project managers, clients, and other team members who are responsible for estimating time and cost to conduct COBIE surveys of existing facilities.

Using the completion rates found in Table 1 below, you will be asked to estimate the total completion time for each facility within the survey project scope. To do this, you must first determine the approximate areas for each of the space types listed. Using the space types, rather than a simple average, will more produce more accurate estimate results. It is important to represent the space type areas as accurately as possible in order to develop a strong estimate for time and cost. For example, mechanical and bathroom spaces are more labor intensive during data collection, due to the types of components and the critical maintenance data needed, as compared with office or storage spaces. However, at this time not all possible space type rates have been documented, therefore if a facility contains a space type that is not listed, use the same rate as "Mechanical Room," or 12 SF per minute.

Table 1: Refer to the following completion rates to estimate facility survey times and labor costs, based on hourly wage rates. Columns 1-6 refer to rates for different space types. Note that Col.1 and 2 include adjacent corridor spaces. For a survey that focuses exclusively on an MEPsystems inventory, refer to column 6.

\begin{tabular}{|l|c|c|c|c|c|c|}
\hline & 1 & 2 & 3 & 4 & 5 \\
\hline & $\begin{array}{l}\text { Corridor w/ } \\
\text { Office }\end{array}$ & $\begin{array}{l}\text { Corridor w/ } \\
\text { Bathroom }\end{array}$ & Storage & $\begin{array}{l}\text { Mechanical } \\
\text { Room }\end{array}$ & $\begin{array}{l}\text { Admin. } \\
\text { Multifunctio }\end{array}$ \\
\hline $\begin{array}{l}\text { SF / MIN } \\
\text { (average) }\end{array}$ & 25 & 14 & 140 & 12 & 59 & 45 \\
\hline
\end{tabular}

To estimate time and cost, begin here:

1. Using the target facility's space type areas (SF) and the survey rates (SF/Min) in Table 1, calculate the total time required to complete each task in Table 2.

2. Convert the total time for all tasks into labor-hours. Enter this number into Table 3, as "Survey Task Labor Hours".

3. To complete Table 3 and obtain a basic facility survey cost:

- Multiply the total survey task time by .25 to find the time required for logistics and access, enter this number in the row "Survey Logistics", under column "Hours of Use". 
- Enter the total number of "Hours of Use" for Hardware and software. This is equal to the Survey Task Labor, plus survey logistics. (Assume $\$ 5000$ for all survey hardware and software, amortized over 3 years, and 500 hours of use per year. $\$ 3.33$ per hour of use, multiplied by the total survey task time plus survey logistics)

- Add BIM Development labor-hours (requires approximately 6 hours to carry out BIM geometry and integration tasks).

Table 2: Survey Rates by Task Type.

\begin{tabular}{|c|c|c|c|c|c|c|}
\hline & $\begin{array}{l}\text { Corridor w/ } \\
\text { Office }\end{array}$ & $\begin{array}{l}\text { Corridor w/ } \\
\text { Bathroom }\end{array}$ & Storage & $\begin{array}{l}\text { Mechanical } \\
\text { Room }\end{array}$ & $\begin{array}{l}\text { Admin. } \\
\text { Multifunction }\end{array}$ & $\begin{array}{l}\text { MEP System } \\
\text { (sys by sys) }\end{array}$ \\
\hline $\begin{array}{l}\mathrm{SF} / \mathrm{MIN} \\
\text { (average) }\end{array}$ & 20 & 10 & 106 & 11 & 43 & 45 \\
\hline multiplied by & $x$ & $x$ & $x$ & $x$ & $x$ & $x$ \\
\hline \multicolumn{7}{|c|}{$\begin{array}{l}\text { Target Facility } \\
\text { Square-footages }\end{array}$} \\
\hline \multirow{2}{*}{$\begin{array}{l}\text { Total time per } \\
\text { task }\end{array}$} & & & & & & : \\
\hline & Total Minutes & \multicolumn{4}{|c|}{ Total Labor-Hours = } & \\
\hline
\end{tabular}

- Add PDF Survey Form Specification labor-hours. Approximately 6 hours. Baseline labor includes all pre-field activities associated with obtaining and verifying facility as-builts, specifying/customizing the PDF Survey Application, and basic Tablet PC setup/configuration.

- Multiply all "Use-Hours" by the hourly rate for surveyors. For the purposes of the examples provided below, we assume $\$ 50$ per hour.

- Add all subtotals for fixed, operational, and logistics costs to find total facility cost.

\section{Examples of Estimating Time and Cost to Complete Facility Surveys}

Below are two examples of how to calculate time and cost required to complete a facility survey, based on the Best Practices and estimating guidelines presented in this report. The first set of tables represents time and cost estimations for the Building 11751, a Company Operations Facility in the North Fort Area. This is the facility used to conduct field trials of the survey and BIM development process recommended by the research team during July 2009. The total completion time for a single-person team using a Space-by-Space workflow was 13 hours. Two-person teams were able to complete data collection in approximately 10 hours. The second set of tables represents a hypothetical example, based on a facility included in FY08 study. Area calculations 
for spaces that did not fall under space type categories with available square-foot-perminute data were estimated using the highest cost data available.

Table 3: Calculate Costs per Facility.

\begin{tabular}{|c|c|c|c|c|c|c|}
\hline Description of Cost & Assumption & Cost / HR & & $\begin{array}{l}\text { Hours of } \\
\text { Use }\end{array}$ & & Subtotal \\
\hline \multicolumn{7}{|l|}{ Fixed Costs* } \\
\hline $\begin{array}{l}\text { Survey hardware and } \\
\text { software }\end{array}$ & $\$ 5000 /$ unit & $\$ 3.33$ & $x$ & & $=$ & \\
\hline \multicolumn{7}{|l|}{ Operational Costs* } \\
\hline BIM Geometry & baseline $=6$ hours & $\$ 50.00$ & $x$ & & $=$ & \\
\hline PDF Specification & baseline $=6$ hours & $\$ 50.00$ & $x$ & & $=$ & \\
\hline Survey Task Labor & $\begin{array}{l}\text { labor-hours to complete survey } \\
\text { tasks see Table } 2\end{array}$ & $\$ 50.00$ & $x$ & & $=$ & \\
\hline Survey Logistics & $25 \%$ of survey task time & $\$ 50.00$ & $x$ & & $=$ & \\
\hline \multicolumn{6}{|c|}{ Total Cost to Survey Facility } & \\
\hline
\end{tabular}

Table 4: Example 1 - Calculating Completion Rates for Building 11751

\begin{tabular}{|l|c|c|c|c|c|}
\hline & Corridor w/ & Corridor w/ & Storage & Mechanical & Admin. \\
\hline SF / MIN & 20 & 10 & 106 & 11 & 43 \\
\hline & $X$ & $X$ & $X$ & $X$ & $\times$ \\
\hline Target Facility & 3286 & 1843 & 17433 & 987 & 597 \\
\hline $\begin{array}{l}\text { Total time per } \\
\text { task }\end{array}$ & 164 & 184 & 164 & 90 & 14 \\
\cline { 2 - 7 }
\end{tabular}


Tables 5: Example 1 - Calculating Costs for Building 11751.

\begin{tabular}{|l|l|l|l|l|}
\hline Description of Cost & Assumption & Cost / HR & Hours of Use & Subtotal \\
\hline Fixed Costs* & & & \\
\hline $\begin{array}{l}\text { Survey hardware and } \\
\text { software }\end{array}$ & $\$ 8000 /$ unit & $\$ 5.33$ & 12.5 & $\$ 66.67$ \\
\hline Operational Costs* & & & \\
\hline BIM Geometry & baseline $=6$ hours & $\$ 50.00$ & 6.0 & $\$ 120.00$ \\
\hline PDF Specification & baseline $=6$ hours & $\$ 50.00$ & 6.0 & $\$ 120.00$ \\
\hline Survey Task Labor & $\begin{array}{l}\text { labor-hours to complete } \\
\text { survey tasks see Table 2 }\end{array}$ & $\$ 50.00$ & 10 & $\$ 500.00$ \\
\hline Survey Logistics & 25\% of survey task time & $\$ 50.00$ & 2.5 & $\$ 125.00$ \\
\hline \multicolumn{2}{|c|}{ Total Cost to Survey Facility } & & $\$ 931.67$ \\
\hline
\end{tabular}

Tables 6: Example 2 - Calculating Costs per Facility, (Based on a 20,300 SF building, calculated by space type, system-only calculations excluded).

\begin{tabular}{|l|c|c|c|c|c|c|}
\hline & $\begin{array}{l}\text { Corridor w/ } \\
\text { Office }\end{array}$ & $\begin{array}{l}\text { Corridor w/ } \\
\text { Bathroom }\end{array}$ & Storage & $\begin{array}{l}\text { Mechanical } \\
\text { Room }\end{array}$ & $\begin{array}{l}\text { Admin. } \\
\text { Multifunction }\end{array}$ & $\begin{array}{l}\text { Other Space } \\
\text { Types }\end{array}$ \\
\hline $\begin{array}{l}\text { SF / MIN } \\
\text { (average) }\end{array}$ & 20 & 10 & 106 & 11 & 43 & 10 \\
\hline & $\mathrm{X}$ & $\mathrm{X}$ & $\mathrm{X}$ & $\mathrm{X}$ & $\mathrm{X}$ & $\mathrm{X}$ \\
\hline $\begin{array}{l}\text { Target Facility } \\
\text { Square- } \\
\text { footages }\end{array}$ & 4150 & 2400 & 5800 & 1200 & 2450 & 4300 \\
\hline $\begin{array}{l}\text { Total time per } \\
\text { task }\end{array}$ & 208 & 240 & 55 & 109 & 57 & 430 \\
\cline { 2 - 7 } & & 1098 & & & 18.3 & \\
\hline
\end{tabular}


Tables 7: Example 2 - Calculating Costs for the Above Facility.

\begin{tabular}{|c|c|c|c|c|}
\hline Description of Cost & Assumption & Cost / HR & Hours of Use & Subtotal \\
\hline \multicolumn{5}{|l|}{ Fixed Costs* } \\
\hline $\begin{array}{l}\text { Survey hardware and } \\
\text { software }\end{array}$ & $\$ 5000 /$ unit & $\$ 5.33$ & 22.9 & $\$ 122$ \\
\hline \multicolumn{5}{|l|}{ Operational Costs* } \\
\hline BIM Geometry & baseline $=6$ hours & $\$ 50.00$ & 6.0 & $\$ 120.00$ \\
\hline PDF Specification & baseline $=6$ hours & $\$ 50.00$ & 6.0 & $\$ 120.00$ \\
\hline Survey Task Labor & $\begin{array}{l}\text { labor-hours to complete } \\
\text { survev tasks see Table } 2\end{array}$ & $\$ 50.00$ & 18.3 & $\$ 915$ \\
\hline Survey Logistics & $25 \%$ of survey task time & $\$ 50.00$ & 4.6 & $\$ 228.75$ \\
\hline \multicolumn{4}{|c|}{ Total Cost to Survey Facility } & $\$ 1,505.75$ \\
\hline
\end{tabular}




\section{Chapter 5: Recommendations for Institutionalization Within DPW}

Developing COBIE Surveys within any military installation's DPW will require significant planning, support, and allocation of staff to build a project team and carry out the Best Practices established in Chapter 2. The specifics of building the project team will somewhat depend on the manner in which COBIE surveys are contracted and will vary base to base. Team composition depends on the scope of the survey work and the requirements for application development. The project team may be developed around distinct roles for each major task area, or duties might be shared among a smaller number of team members. For the purposes of the Best Practices recommendations and this discussion of institutionalization, the project team is assumed to be staffed in-house. Other configurations may involve the contracting of services for some or all roles in the project team.

\section{Building the Project Team}

The project team consists of the following roles: survey staff, BIM geometry modeler, and the project manager. These roles may be individually assigned, or may be combined into "hybrid positions", depending on personnel resources at a given installation.

Survey staff members are those who conduct COBIE Existing Facilities Surveys and are "in-the-field" for the duration of the survey project. One surveyor per building can survey an average of 45 SF per minute, and unless surveys are time-critical it is recommended that the project team assign only one person to survey one facility. The total number of surveyors may depend on the project scope and schedule. For instance, if the survey project consists of 30 facilities and must be completed within 15 weeks, the project team might want to consider deploying 2-3 surveyors to conduct parallel facility surveys. Refer to Chapter 4 and Appendix 4 for additional guidance regarding estimating man-hours and cost.

The BIM geometry modeler is responsible for assessing and creating BIM geometry for each facility in the survey project. This person manages the development and conversion of all COBIE spatial data in the survey project. This role will require BIM training in the platform used by USACE and DPW. This role may be augmented to include data management, following data transfer from survey staff to the project team.

Assign one person on the team to keep track of all tasks, phases, and documentation related to the survey and BIM development. The project manager is responsible for coordinating the survey, verifying as-built conditions, and conducting/managing survey tasks. Depending on the configuration of the project team, this role may be expanded to include roles and responsibilities within other task areas. The project manager is also responsible for specifying and customizing the PDF Survey Application for the survey project, or for coordinating such activities.

Implementation of the building surveys requires the support and cooperation of DPW staff as well as leadership within the facilities being examined. Depending on how the process is staffed and instituted within the DPW, there may be a variety of access and security issues related to conducting the surveys. Points-of-Contact (POC) are 
critical partners that support the survey project. POCs provide critical assistance in areas of scheduling, logistics, and resources.

Depending on whether the survey project is staffed in-house or by contract, a hierarchy of support will need to be developed through cooperation with DPW services. In both cases, the project team will likely need support related to access, scheduling, equipment, and facility drawings and specifications.

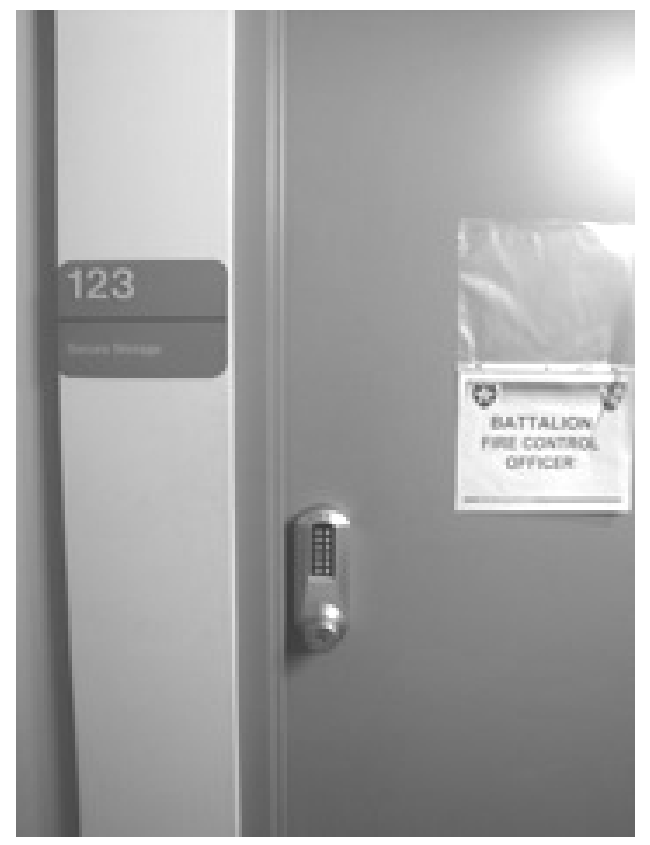

Figure 5: Cipher-locks restrict access to most non-public spaces within newer facilities, including offices, storage areas, secure storage vaults, and SIPR Net rooms. Typically, only the commanding officer of the battalion will have the pass-code for all locked spaces, therefore close contact with the $\mathrm{CO}$ in charge of facilities to be surveyed is crucial to reducing logistics time.

The Facility POC is crucial to the completion of facility survey tasks. This person coordinates with the project manager to provide scheduling support, facilitate access within the facility, and to resolve conflicts. Typically, the Facility POC role is filled by the Commanding Officer in charge of a given facility. The Facility POC may assign a staff person to assist in escorting surveyors or preparing spaces for access. It is extremely important to establish POCs early on in the planning process. Often, POCs will have knowledge of events such as brigade deployments, facilities occupancy, changes in the use of space, and seasonal or installation-wide activities that can have a major impact on the efficient execution of the facilities survey.

It is assumed that the PDF Survey Application will be professionally developed outside of the regular survey project structure. See Appendix 4 for assumptions and information about development of the application. This person will likely play an important support role for project teams. Team members responsible for customizing the PDF Survey Application might contact the application support person for assistance, troubleshooting, or additional guidance/training.

\section{Establish the Project Scope and Schedule}

This pre-planning phase requires input from a number of stakeholders, including those in DPW, leadership within the facilities being surveyed, and the contracted project team. An early assessment of the scope of survey work to be done will help to establish 
the kinds of technical and logistical planning required. DPW and the Survey Contractor should clearly identify the following:

- Survey focus: systems or complete data sets for space types?

- Number and type of facilities to be surveyed.

- Components to be surveyed, including the range of attributes required.

- Determine the priorities for staffing and contracting

The number and type of facilities to be surveyed is a function of the needs defined by DPW, the budget available for conducting survey projects, and the range of sizes and types of facilities to be surveyed. DPW may choose to prioritize facilities, and develop survey project phases based on operations needs, available documentation, and budget. Regardless, it will likely be important to group-develop survey projects that have some coherence based on facility type, size and occupancy.

Identifying the primary spaces within each facility provides a basis for estimating completion times and cost (see Chapter 4). This information provides the project scope that will provide a basis for making decisions regarding what types of systems, spaces, and components to include in the surveys. Determining the system functions intended for study helps define the component sets that will be included in the survey and the PDF Survey Application data. This, in turn, allows the project team to develop the range of component attributes required, based on the standard components to be surveyed within each system.

Staffing priorities are likely to be a reflection of scope and budget. If cost is the determining factor, one surveyor per building will likely be sufficient. If completion within a short amount of time is a priority, then consider that two surveyors per building can complete survey tasks in 3/4 the time (at twice the labor cost). Similarly, depending on the DPW's resources, it may be beneficial to collapse some roles and merge certain responsibilities within the project team (see "Building the Project Team", above)

When scheduling facility surveys, consider BP 6 . For survey projects and inspections that are not occupancy-contingent (COBIE as-built surveys, O\&M inventories, etc.), summer months are not ideal; schedule COBIE survey tasks between the months of October through April. On most military installations, particularly Northern Climate Zone bases, summer months are a period of high activity, including troop movements, maintenance tasks, renovations and construction projects, and administrative events (such as ROTC, graduation). These activities may significantly impede COBIE as-built facility surveys, depending on the type of building and occupancy. See Chapter 3, BP 6 for more information.

Logistics is an important aspect of scope planning and scheduling for COBIE survey projects. Based on anecdotal evidence (see Rationale for BP 6.1.1) and the study field trials, access and logistics creates an additional time and cost factor that will impact scheduling, total number of facilities that can be completed, support activities, communication, and role definition. The research team found that the net data collection time for an external, military-escorted survey team was 46\%, shown in Figure 6 . This number corresponds to the actual time spent on data collection, as compared with $54 \%$ of time spent negotiating access, supporting fieldwork, and troubleshooting. It is reasonable to assume that including travel time and communications support, an inhouse DPW Project Team may experience up to $25 \%$, as displayed in Figure 7 . As 
such, this important factor must be accounted for in scope planning and scheduling facility access.

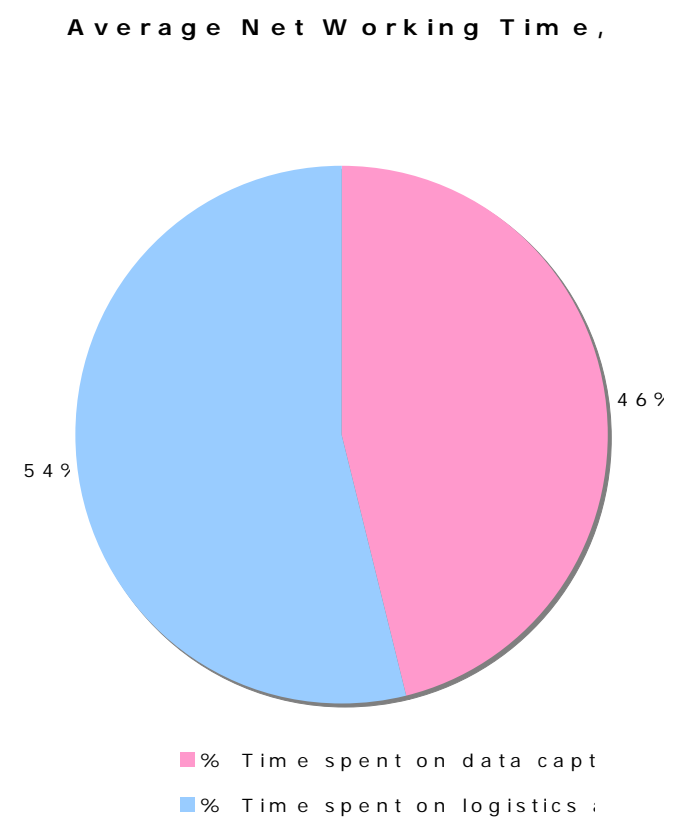

Average $N$ et $w$ orking

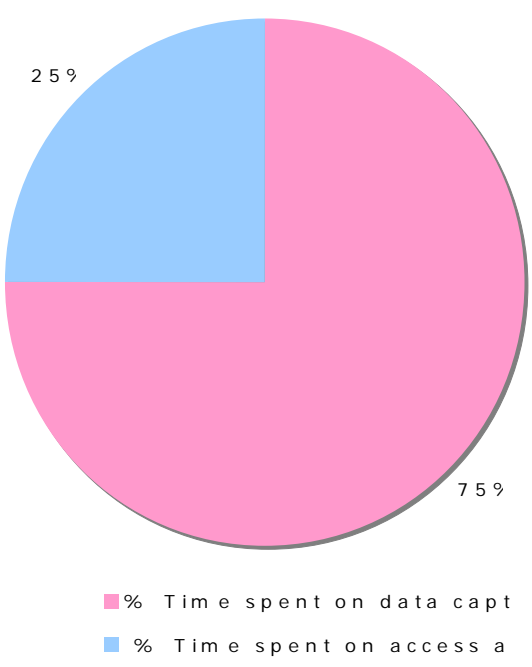

Figure 6: Average Net Working Time, University Study: "Net Working Time" is defined as the difference between total working hours minus time related to logistics, access, and non-datacapture activities.
Figure 7: Average Net Working Time, Ideal Proportions

Establish the Goals for Data

DPW, USACE, and Survey Project Teams can benefit from clearly defining the goals for data integration and usage. These parameters may affect survey methodology, workflow, data conversion, plans for post-field processing and interpretation. Questions that should be asked: 
What is the intended use for the component data?

How will the information gathered be integrated into facilities maintenance?

Who will access this data, and what level of integration is necessary?

Will data be stored and accessed via GIS, Google Earth, or secure web browser?

If the survey data is intended to be merged with BIM data, then a contract should be developed to define the BIM scope and level of component detail. (see BP 1) If the intent is to integrate the data with existing facilities maintenance software and databases, such as Maximo, then what other DPW divisions need to be involved? The project team, clients and developers must establish how the collected data and BIM geometry will be integrated into facilities maintenance. For example, a hyperlinked lowfidelity model with associated space-component data could be stored on a secure server and accessed by a variety of survey and inspection teams (i.e., O\&M, Fair Wear and Tear inspectors, MEP Contractors).

The above questions, in combination with scope planning, will help define the intended use for the survey component data and the type of data integration with BIM geometry. The intended outcomes will have implications for staffing, scheduling, and overall scope of survey tasks. For example, if the client or project team only requires data on a few systems, it is possible that the survey project team may be limited to two members (BIM Developer and Project Manager).

Weaving the Technologies into Survey Procedures and Culture in DPW

A key to the adoption of digital tools is ease of use and rapid assimilation of navigation and interface. It is vital that the professional PDF Survey Application is easy to use, efficient, and well supported. Pre-surveys of the field trial teams indicated that several surveyors anticipated arduous, non-ergonomic tasks, and some reported feeling somewhat anxious about whether or not they would be able to learn to use the software quickly. During debriefing and on post-survey comment forms, surveyors overwhelmingly reported that the task-centered interface was easy-to-use, fast, and quick to assimilate. For more on the professional development of the PDF Survey Application, see Appendix 4. For a discussion of efficiencies and interface familiarity, see Appendix 6.

Stable, fast equipment is essential to adequately run active interfaces. Users should not have to battle system crashes and hard-restarts. It is imperative that the system architecture can handle the task it is being used for. Hardware crashes, slow processing, and compatibility conflicts may greatly undermine efforts to foster acceptance and use of survey technologies. Reliable hardware should be a priority.

Persons conducting COBIE surveys will need support, not only from POCs and supervisors, but from peers as well. It is important to foster a sense of collaborative learning within project teams and across military installations. It is also important to develop a feedback loop between those collecting data and those using the data. Much can be learned through innovations in the everyday use of survey technologies. 
At installations such as Fort Lewis, WA, a tech-savvy culture exists among DPW staff. DPW employees are interested in new tools and the potential for improvements based on the development and adoption of new technologies. It may be extremely effective to create an inter-base training scheme, whereby early-adopters are recruited to fill instructional and support roles for groups that have not yet begun to use the technologies. 


\section{Chapter 6: Technology Issues}

Several methods and approaches were tested when developing best practices for associating COBIE data with the BIM. Software explored included: Autodesk Revit Architecture 2010, Onuma Planning System (OPS), Autodesk Navisworks Manage 2010, Google SketchUp, and Google Earth. Also, a plug-in developed by Autodesk designed to export COBIE data from Revit was explored. In the end, two separate best practice workflows were developed; one workflow to develop a low-fidelity model and second workflow to develop a medium-fidelity model. The workflows are outlined below. See Appendix 6 for detailed instructions for each workflow.

\section{Revit to Google Earth (Low-Fidelity Model)}

The low-fidelity model level of detail is defined as rooms or spaces modeled as solid volume geometric masses (Figure 8).

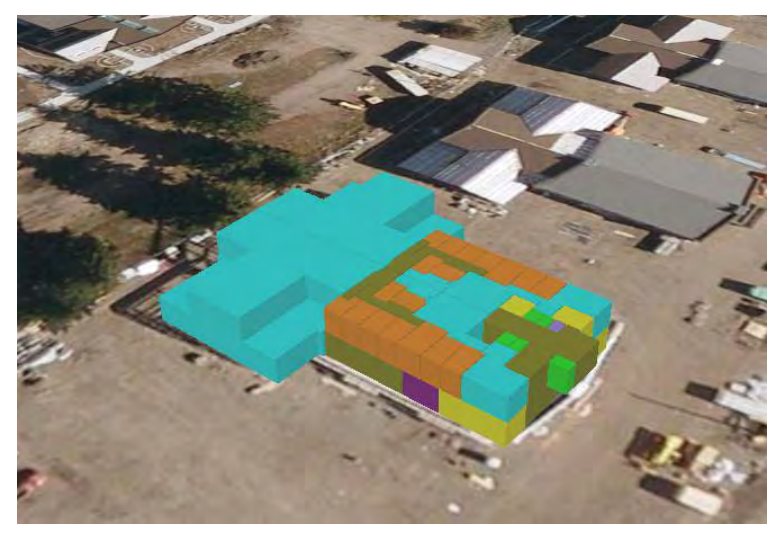

Figure 8: Example of low-fidelity model level of detail.

\section{Workflow}

- Obtain as-built drawings

- Use as-built drawings to model masses of each room or space in Revit

- Export Revit file to Navisworks

- Within Navisworks, link non-spatial data collected from field survey to respective mass

. Export from Navisworks to Google Earth.

\section{Capabilities}

Using Google Earth as the end platform to view the BIM model(s) can be very powerful. The user would be able to populate Google Earth with as many BIM models as necessary. All of the buildings would be centrally located within Google Earth. This would allow quick and easy access to multiple facilities without having to open separate files for each individual building. The buildings are geo-referenced within Google Earth, meaning the user can simply locate the facility with the address or GPS coordinates.

Navigating models within Google Earth is very user friendly. Levels and rooms can be turned off or on by checking/un-checking boxes in the sidebar. When viewing a 
specific building within Google Earth, desired COBIE data is easily accessible. The COBIE data can be viewed by selecting the mass in the model and following the hyperlink (Figure 9) or by selecting the room from the sidebar (Figure 10).

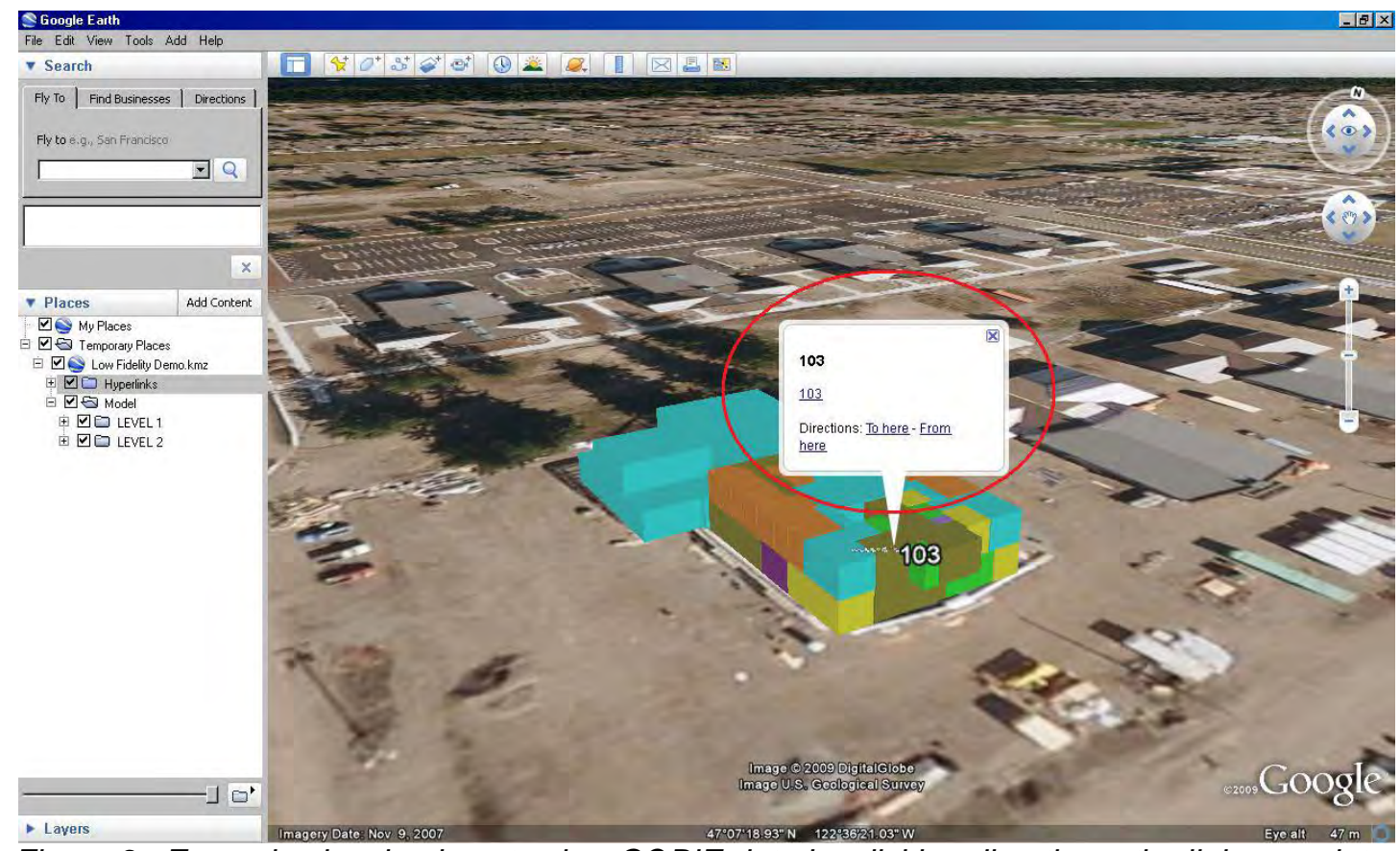

Figure 9: Example showing how to view COBIE data by clicking directly on the link associated with respective mass.

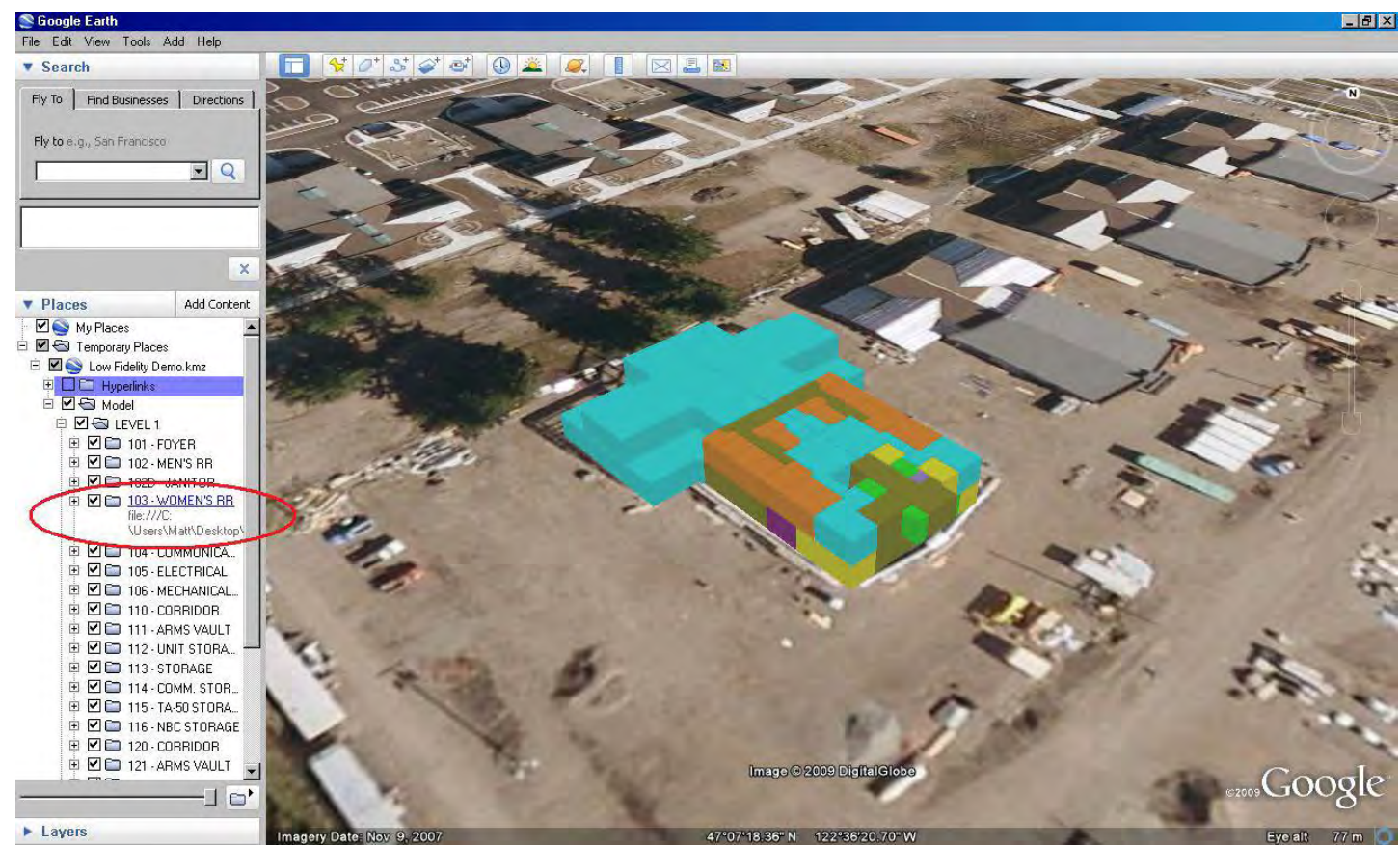

Figure 10: Example showing how to view COBIE data by selecting the space/room from the sidebar.

If updates to the COBIE data links need to be made, such as fixture replacements, they can be made directly to the linked document. The user would 
simply open the link (Word document, Excel spreadsheet, PDF, etc.) and update the document as needed.

\section{Limitations}

When developing a BIM for Google Earth, the level of detail of the BIM should be kept to a low-fidelity model standard. While it is possible to use this method for greater level of detail models, it would be very time consuming to select each component and assign a hyperlink. Also, the BIM would become cluttered and hard to navigate with multiple hyperlink icons in each room.

If rooms or space geometry change, the Revit model would need to be updated to reflect the new changes. The entire workflow process would need to be followed after the Revit model is updated in order to have the new geometry reflected within Google Earth.

\section{Revit to COBIE (Medium-Fidelity Model)}

The medium-fidelity model level of detail is made up of walls, floors, ceilings, and doors. Within each room or space permanent fixtures are represented, such as: sinks, toilets, urinals, lighting fixtures, etc. (Figure 11).

Figure 11: Example of medium-fidelity model level of detail.

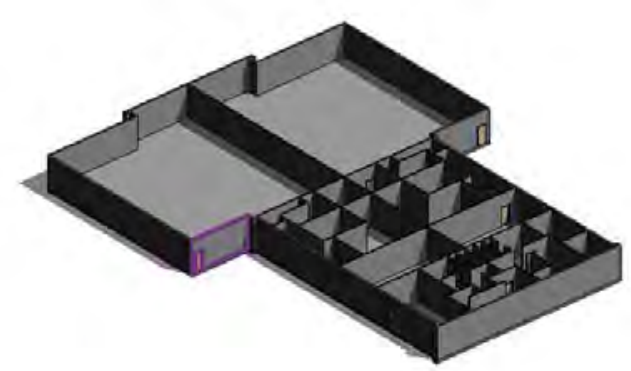

\section{Workflow}

- Obtain as-built drawings

- Use as-built drawings to model specified level of detail

- Export Revit model using Autodesk COBIE Data Aggregator plug-in.

\section{$\underline{\text { Capabilities }}$}

By utilizing the Autodesk COBIE Data Aggregator plug-in, the user is able to export the Revit geometry and generate COBIE data in a spreadsheet format. The data can then be easily modified within the COBIE spreadsheet if it needs to be updated or changed. 


\section{Limitations}

This workflow requires specific versions of software in order to work properly. When using the Autodesk COBIE Data Aggregator plug-in, Autodesk Revit 2010 is required.

\section{Capabilities/Limitations of Other Software Explored}

\section{SketchUp}

\section{$\underline{\text { Capabilities }}$}

SketchUp allowed for very rapid creation of both the low-fidelity and mediumfidelity models. The program supported many different CAD formats, allowing for the import of 2D drawings to use as an underlay when creating 3D geometry. SketchUp also supported a direct export into Google Earth. The ability to geo-reference the building within Google Earth was very easy and straightforward. One would simply open Google Earth, locate the area within Google Earth where the building would be located, and import the site into SketchUp to begin orienting the building correctly.

\section{Limitations}

SketchUp is not as robust as a parametric modeling program and lacks many features a parametric modeling program possesses. SketchUp is essentially a 3D modeler that creates 2D polygons. These 2D polygons that are generated can result in many inaccuracies if using the model to calculate areas. For example, the 2D polygon faces would be double counted if using the model for area take-offs. Google SketchUp also did not support the addition of hyperlinks. There is the possibility to create the ability to add hyperlinks and other features by making a custom add-in using the Ruby scripting language.

\section{Adobe Acrobat Professional 9.0 Extended}

\section{$\underline{\text { Capabilities }}$}

The ability to convert 3D geometry from modeling programs to a PDF format is very promising. This would allow any user that has Adobe Reader, which is a free program, to view and navigate the 3D PDF.

\section{Limitations}

Several issues arose when experimenting with 3D PDF as a potential route. Currently, conversion to a 3D PDF format does not retain much of the property data created in the $3 \mathrm{D}$ modeling program. A test was performed by converting a Revit file over to a 3D PDF, resulting in a failed attempt at a 3D model with linked COBIE data. The hyperlinks that were embedded in the Revit file were not retained. There was also 
nowhere within the PDF file to add a hyperlink, resulting in a 3D model with no linked COBIE data.

The model tree allowed for easy navigation to different rooms and levels, very similar to the exported Google Earth .kmz file from Navisworks. Currently, the only property information viewable in the 3D PDF model tree is superfluous information about the model, such as: number of vertices, number of faces, number of textures, etc.

Currently, 3D PDFs are not compatible with Google Earth. The user would not be able to geo-reference the building or view multiple buildings, as demonstrated in the low-fidelity workflow mentioned earlier.

\section{Future/potential capabilities}

The ability for software vendor's products to support COBIE data is still in its infant stages of development. With the help of annual conferences, such as the COBIE Challenge, the industry is starting to recognize the need for COBIE support in their programs. Autodesk has already started to create and develop plug-ins for Revit Architecture, one that was used during this research. 


\section{Chapter 7: Conclusions and Future Work}

\section{Conclusions}

Based on evaluation of the field surveys, the research team determined that the cost for capturing COBIE data for a building of 25,000 SF and integrating the data into a model of sufficient fidelity to perform operations and maintenance tasks at an installation is estimated to be about $\$ 1,500$, when the process is institutionalized within the DPW. This cost includes the labor necessary to develop the BIM model, customize PDF floor plans for the building, perform the field survey, convert the survey data into COBIE format, and merge the data with a BIM model. This cost estimate includes the amortized cost of survey software and hardware and assumes an average labor cost of $\$ 50$ per hour. Additional costs may be required if CAD files do not already exist for the building to be surveyed.

In organizing survey teams, a one-person survey team should be used for each building if the goal is to minimize the cost of data collection. A two-person survey team should be used for each building if the goal is to minimize the time required to collect the data.

The field surveys data did not demonstrate that teams of two persons were twice as efficient as teams of one.

Low-fidelity and mid-level fidelity BIM models contain sufficient information for most facility operations and maintenance management tasks. Creating low-fidelity models in Revit and using Google Earth as the end platform works well. Navigating models within Google Earth is user friendly, and levels and rooms can be turned off and on readily. Creating mid-level fidelity models in Revit and using the Autodesk COBIE Data Aggregator allows the user to export the Revit geometry and generate the COBIE data in a spreadsheet form. While SketchUp allowed for rapid creation of BIM models, it lacks the parametric modeling capabilities needed to generate the COBIE data.

\section{Future Work}

The research team recommends that the Army:

1. Invest in the development of a professional COBIE 2 data capture application based on the PDF format to run on tablet computers.

2. Pursue getting the COBIE standard synchronized with GFEBS-SAP and SMS (Builder) applications.

3. Contact major BIM vendors to encourage them to include COBIE 2 functionality and support within their applications.

4. Continue exploring the integration of BIM models with navigational interfaces, such as Google Earth. 


\section{Appendix 1: Experimental Design}

Purpose of Study

The goal of this study was to develop tools and methodologies for capturing COBIE data for existing facilities, and to explore the integration of COBIE data with asbuilt BIM geometry. Technologies of interest include PDF-based data collection forms, 3D Building Information Modeling, Geographic Information Systems integration, and Construction Operations Building Information Exchange (COBIE) data hierarchies. Related topics addressed in the study include Google Earth storage and interface, Google SketchUp capabilities and limitations, and the potential of Adobe Acrobat 3D functionality as a means for accessing, viewing, and communicating COBIE and BIM data.

The core of the FY09 study consisted of a series of field trials held during the month of July at Fort Lewis, WA. These field trials were developed and arranged in conjunction with Fort Lewis DPW. Prior to beginning field surveys, the research team designed and commissioned a data collection interface, gathered background material for the survey and BIM development. Figure 12 describes the conceptual overview of the phases of the 2009 study; activities were primarily conducted in three phases: PreField, Field Survey and BIM Development, and Integration and Analysis.

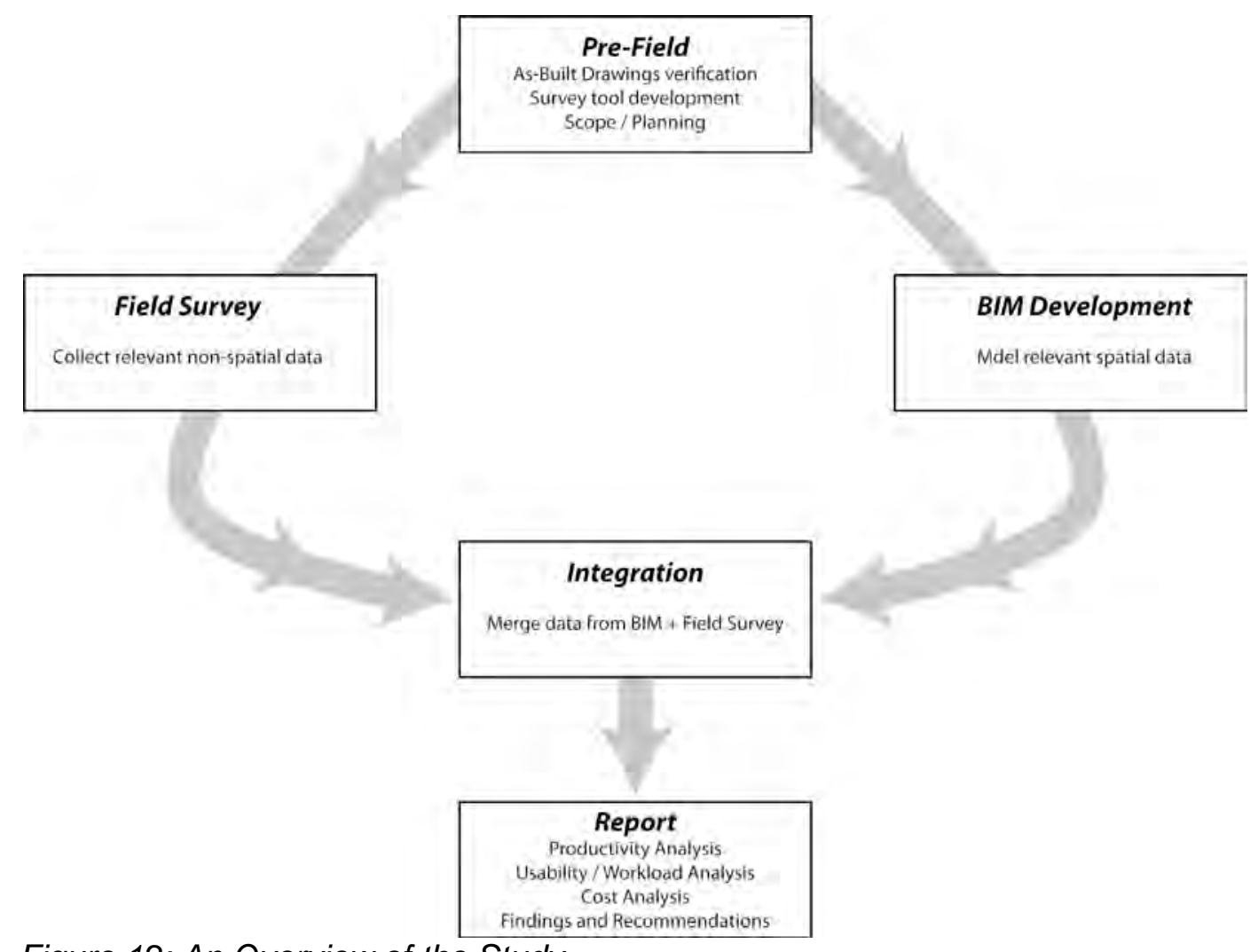

Figure 12: An Overview of the Study. 
In addition, the team developed POCs to facilitate access to the facility being used in the study, and built a survey schedule based on the tasks and methodologies being studied.

The Fort Lewis Summer Field Survey was conducted as a 4-week long field study where two different data collection approaches were used: (1) a space-by-space method, where surveyors collected all data via an "all-systems" method and (2) a "system-by-system" approach, in which surveyors gathered all data from each distinct system category for a given floor, before moving on to the next system category. The "systems" referenced in this study are standard COBIE database System Functions. These system functions are derived from Omniclass Reference Table 23 and are standard definitions within the COBIE system.

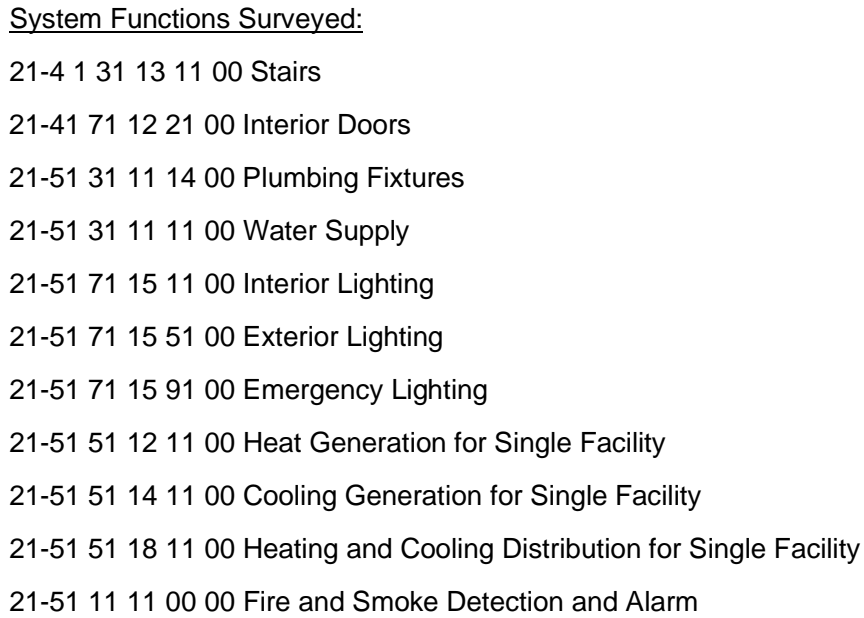

Table 8: System Functions Included in the Study.

The team chose to limit both the number of systems and components, as well as the amount of attribute data to be gathered in the field. The goal was to develop surveys that focus on visually accessible components, to represent realistic scenarios within a range of types and installations. Field surveyors surveyed components from this same system list throughout both workflow approaches.

During the 4-week field study, field survey crew collected data using handheld Tablet PCs running PDF-based survey forms developed by the research team. Lightweight, mobile equipment and efficient, intuitive interface were priorities. The equipment was chosen for its usability, accessibility and durability.

The research team recorded task times to measure the efficiencies of the survey crew on site. In addition, the team collected qualitative data about the crew's experience with the technology. Observational data, both quantitative and qualitative, was used to analyze the productivity and efficacy of survey tools and staff.

\section{Survey Team Composition}

The survey employed one Graduate Research Assistant (GRA) and six Field Research Assistants (FRAs) to conduct the surveys. The FRAs were pre-screened to ensure they could carry out assigned duties on Fort Lewis. To maintain a baseline comparison between teams, each week's field survey team only worked with one data collection methodology and used the same input methodology. Each team worked one week between July 6 and July 31, 2009 (Monday through Friday), see schedule below. 
The on-duty GRA trained, observed, and supervised the survey team throughout the work week. The GRA also coordinated with the DPW to acquire the necessary survey and safety tools, as well as gain access to necessary facilities and areas.

\section{Survey Schedule}

During each week, the same input methodology was used - Motion F5 Tablet PC with stylus running Adobe Acrobat PDF data collection forms. However, the first half and second half of the field survey used different collection strategies. The first two weeks were dedicated to an "All Systems" approach, gathering complete data for each room. The third and fourth weeks were dedicated to a "System-by-system" approach. Each week had a new field survey crew made of up either 1 or 2 FRAs.

\begin{tabular}{|c|c|c|c|c|}
\hline & Week 1 & Week 2 & Week 3 & Week 4 \\
\hline $\begin{array}{c}\text { Pathway / } \\
\text { Method }\end{array}$ & Jul 6 - 10 & Jul 13-17 & Jul 20 - Jul 24 & Jul 27 - Jul 31 \\
\hline Surveyor & AL by Space & Space by Space & System by System & $\begin{array}{c}\text { System by } \\
\text { System }\end{array}$ \\
\hline Surveyor & JB & JS & CLT & TS \\
\hline
\end{tabular}

Table 9: Fort Lewis Summer Field Survey, Weekly Schedule.

Each week, the field survey crew followed the same weekly schedule, though the tasks and methodology were different:

Weeks 1-2, Space-by-Space Method

Days 2, 3, and 4 were dedicated to tasks consisting of different room types within the facility. Friday was used for assessment and debriefing.

Table 10: Fort Lewis Summer Field Survey, Weekly Schedule.

\begin{tabular}{|c|c|c|c|c|c|}
\hline \multicolumn{6}{|c|}{ Space-by-Space } \\
\hline & MONDAY & TUESDAY & WEDNESDAY & THURSDAY & FRIDAY \\
\hline \begin{tabular}{l|} 
A \\
$M$
\end{tabular} & $\begin{array}{l}\text { Introduction, } \\
\text { Pre Survey, } \\
\text { Training }\end{array}$ & $\begin{array}{l}\text { Corridor with } \\
\text { Office } \\
\text { Floor } 2\end{array}$ & $\begin{array}{l}\text { Storage Spaces } \\
\text { Floor } 2\end{array}$ & $\begin{array}{l}\text { Mechanical } \\
\text { Room(s) } \\
\text { Floor } 1\end{array}$ & $\begin{array}{l}\text { Lobby, MultiFx } \\
\text { Additional Time }\end{array}$ \\
\hline $\begin{array}{l}\mathrm{P} \\
\mathrm{M}\end{array}$ & Survey Practice & $\begin{array}{l}\text { Corridor with } \\
\text { Bathrm } \\
\text { Floor } 1 / 2\end{array}$ & $\begin{array}{l}\text { Storage Spaces } \\
\text { Floor } 1\end{array}$ & $\begin{array}{l}\text { Multifunction } \\
\text { Spaces } \\
\text { Floor } 1 / 2\end{array}$ & $\begin{array}{l}\text { Debrief, } \\
\text { Post Survey }\end{array}$ \\
\hline
\end{tabular}

Weeks 3-4, System-by-System Method

Days 2, 3, and 4 were dedicated to collecting data for different system functions. The order of operations was based on a building-wide collection process, and were divided 
by floor or room, depending on the systems surveyed. Again, Friday was used for assessment and debriefing.

Table 11: Fort Lewis Summer Field Survey, Weekly Schedule.

\begin{tabular}{|l|l|l|l|l|l|}
\hline \multicolumn{6}{|c|}{ System-by-System } \\
\hline & \multicolumn{1}{|c|}{ MONDAY } & \multicolumn{1}{|c|}{ TUESDAY } & WEDNESDAY & THURSDAY & \multicolumn{1}{|c|}{ FRIDAY } \\
\hline A & Introduction, \\
M & $\begin{array}{l}\text { Doors and } \\
\text { Pre Survey, }\end{array}$ & Windows & $\begin{array}{l}\text { Plumbing } \\
\text { Fixtures }\end{array}$ & MEP & MEP FL 1,2 \\
\hline $\begin{array}{l}\text { Training } \\
\text { M }\end{array}$ & Survey Practice & Lighting & $\begin{array}{l}\text { Fire, Smoke, } \\
\text { and Emergency }\end{array}$ & MEP & $\begin{array}{l}\text { Debrief, } \\
\text { Post Survey }\end{array}$ \\
\hline
\end{tabular}

Facility Classifications and Description

Survey Building: Company Operations Facility, Building 11751

Training Facility: Department of Public Works, Building 2012

\section{Observation and Assessment}

The GRA measured both the performance of the field crew as well as the crew's reaction to the technologies employed. In the field, the GRA observed and collected performance data as the field survey was conducted each week. The team analyzed the efficiency, effectiveness, relative workload, and implementation costs of the survey methods, as described below.

1. Task Completion: Total completion times were recorded per task type, and per half-building. The team used the areas of each space type to determine the relative rates of completion for each task, for each team. The rates are measured in SF/minute (see Appendix 3).

2. Component History Tool test: The "Office Test". The GRA observed and recorded the effects of the PDF Survey Application's component history functionality during a mid-week assessment of each survey team. Each team was required to survey new two office spaces, approximately $100 \mathrm{sf}$. During the first office data capture, the team was not allowed to utilize the application's built-in component history functions. During the second data capture, the team was able to load components from the history file (see Appendix 6).

3. Interface familiarity assessment: The "Stair Test". At the end of each day in the survey work week, each survey team member was required to capture data for a new stair space within the facility. The user was required to begin from the Login page, and was timed through component data entry and completion of file save functions (see Appendix 6).

4. NASA Task load Index: After each task was completed, the surveyors were asked to fill out a NASA Task load questionnaire. This task-load survey measures the users' reaction to the technologies, demands, and conditions related to the tasks they have recently completed. Surveyors indicate their response on a 
21-point scale, from 1=very low, very bad to $21=$ very high, very good (see Appendix 7).

Inventory of Study Equipment

1. Survey Form Development

Adobe Acrobat 9 Pro Extended

Adobe Photoshop CS4

Microsoft Excel (COBIE formatting)

2. Survey Equipment

PDF Survey Forms

NASA Task Load Survey Forms

Motion Computing F5 "Rugged Tablet PC"

3. BIM Development

Autodesk Revit

Navisworks

Google SketchUp

Google Earth 


\section{Appendix 2: Adobe Survey Application Screenshots}

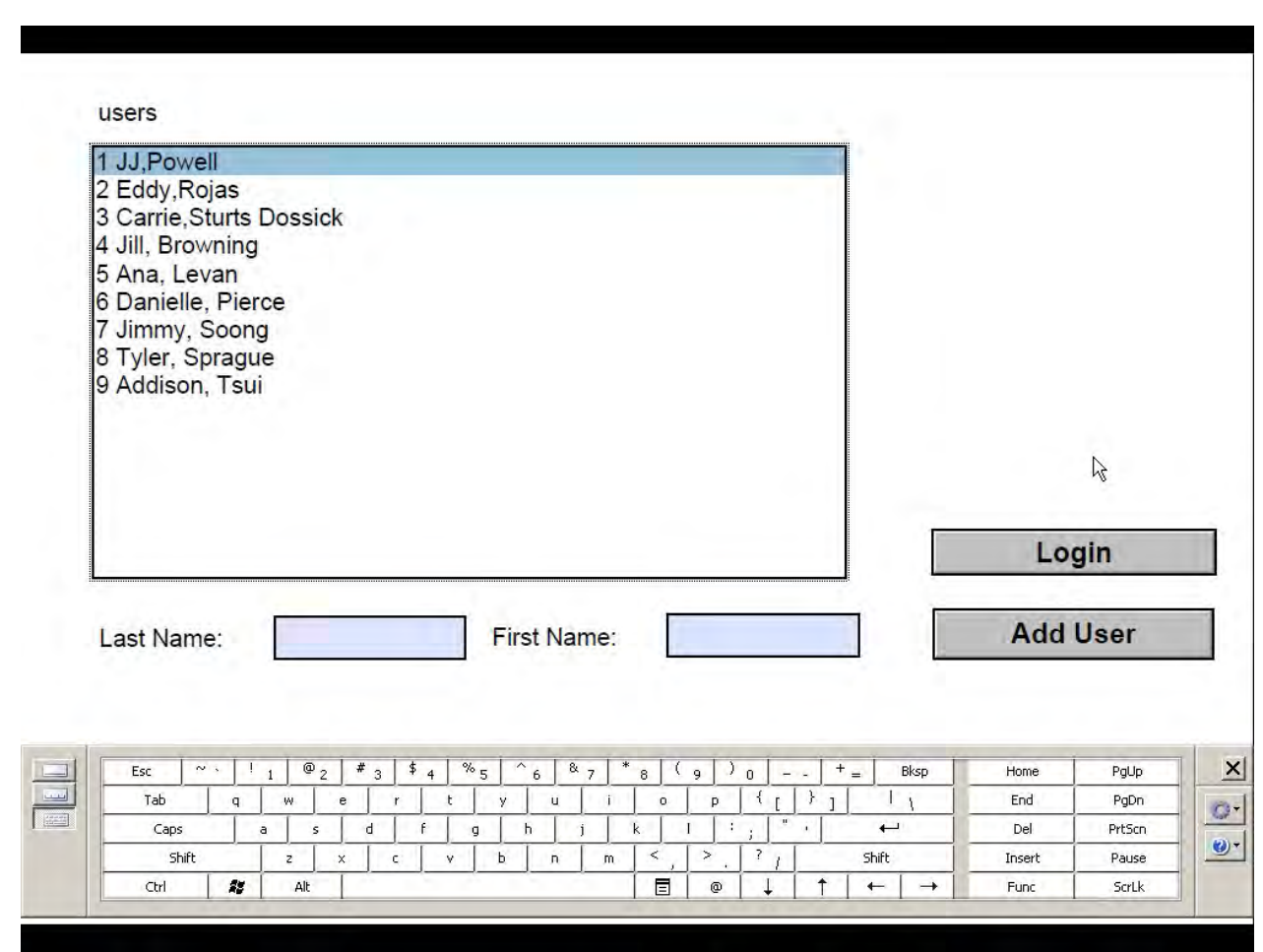

Figure 13: Login Page.

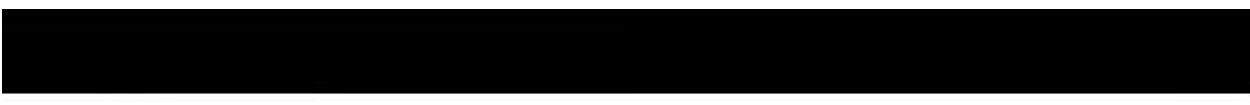

users $1 \mathrm{JJ}$, Powell

\section{System}

System by System
Space by Space
System by System

Select Flow

\section{Log Out}

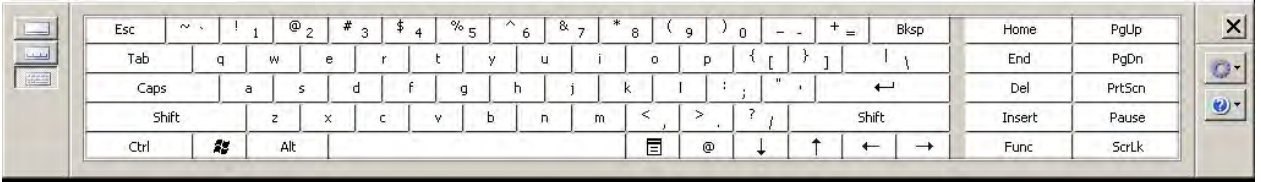

Figure 14: Workflow Selection. 
User: $1 \mathrm{JJ}$, Powell

Workflow: Space by Space

Facility: 11751

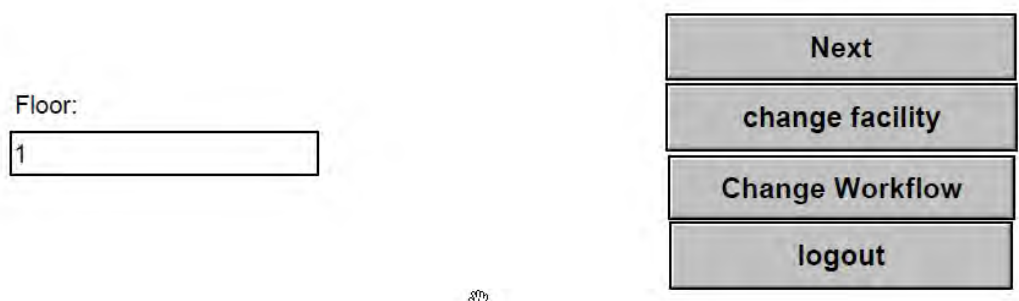

sin

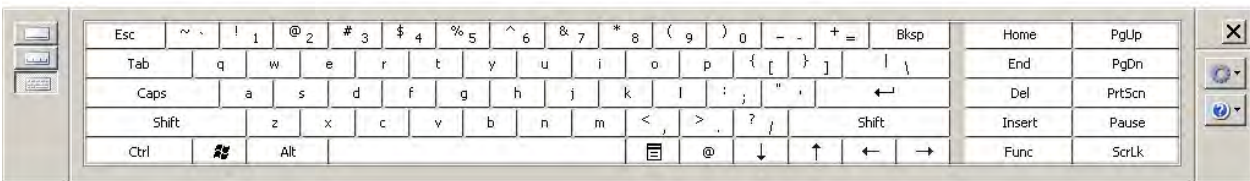

Figure 15: Select Floor.

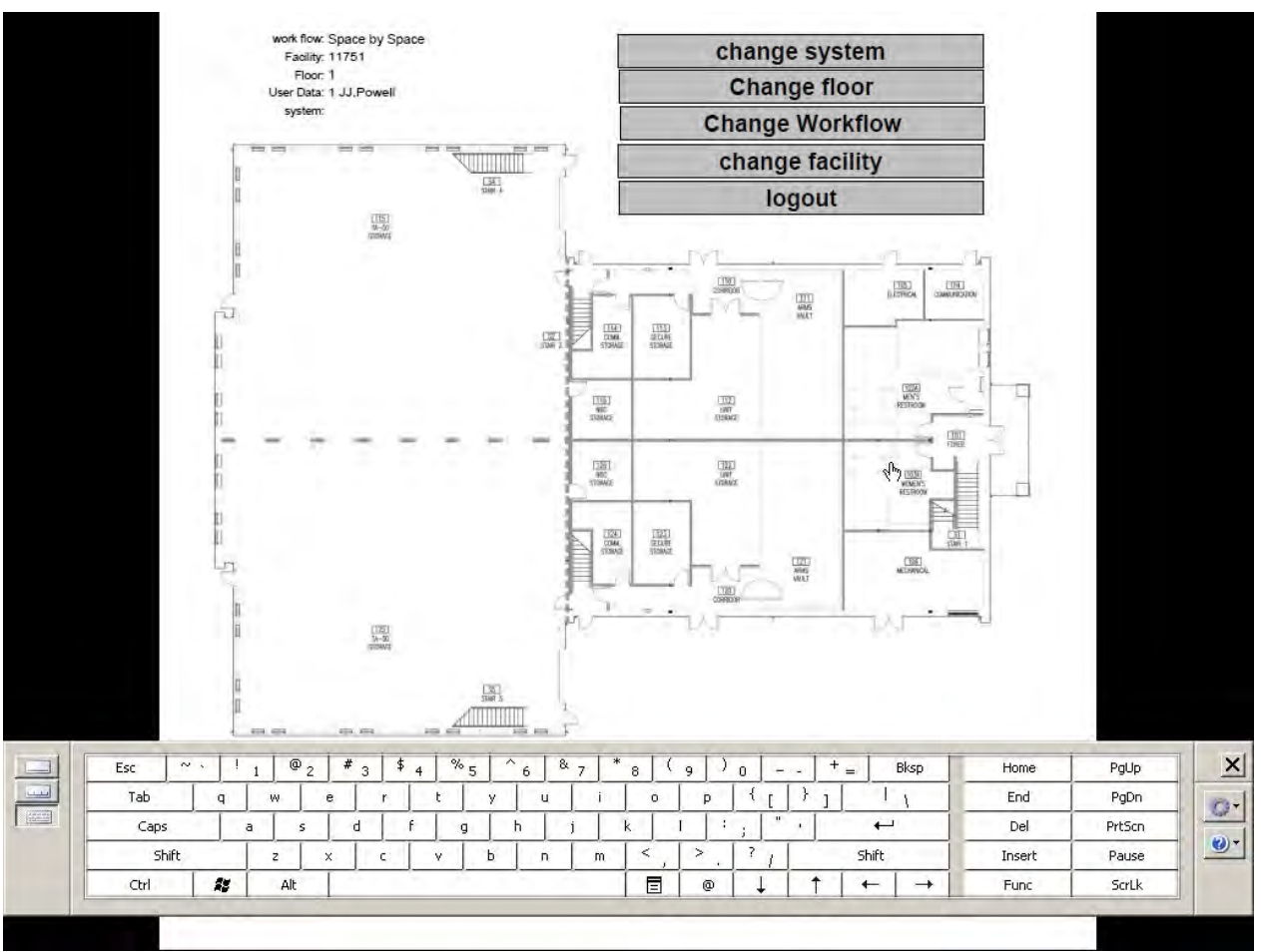

Figure 16: Floor-plan page, select space. 


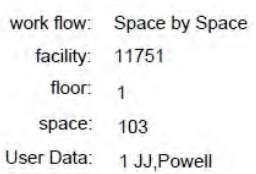

\begin{tabular}{|c|}
\hline Change floor \\
\hline \hline Change Workflow \\
\hline \hline change facility \\
\hline logout \\
\hline change space \\
\hline
\end{tabular}

select system

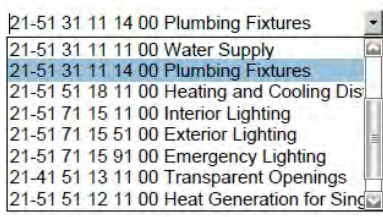

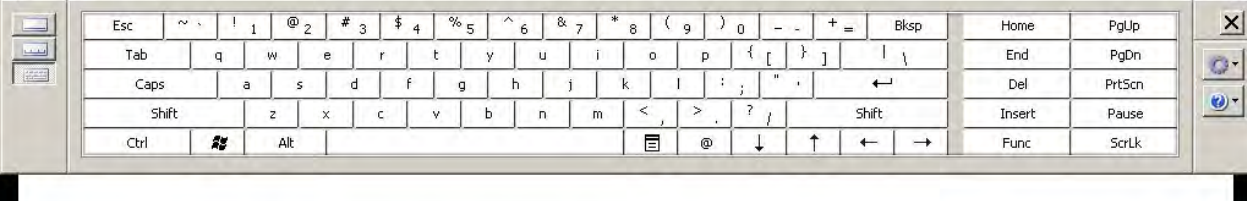

Figure 17: System selection page.

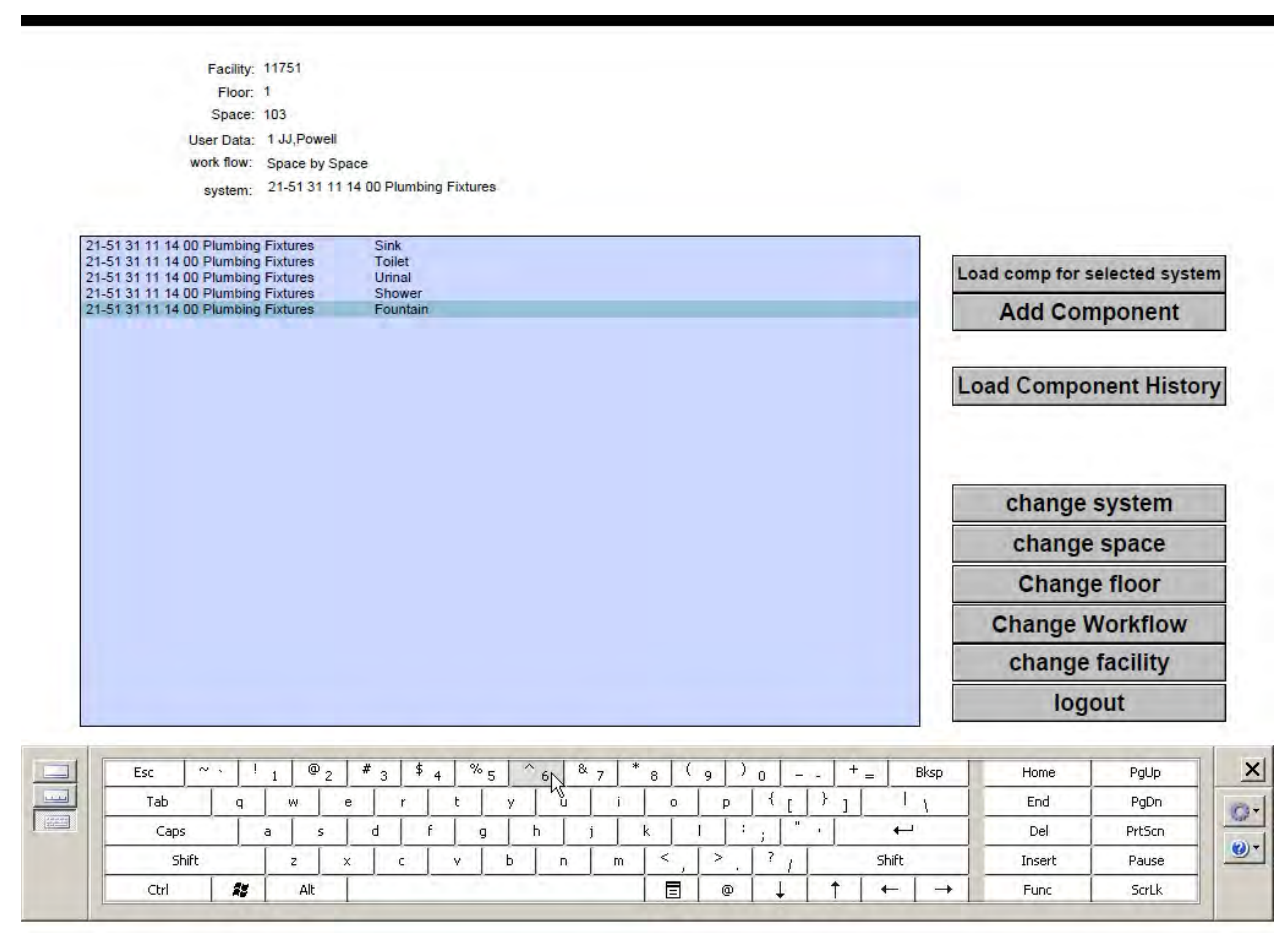

Figure 18: Load Component Page. (Showing "standard components") 


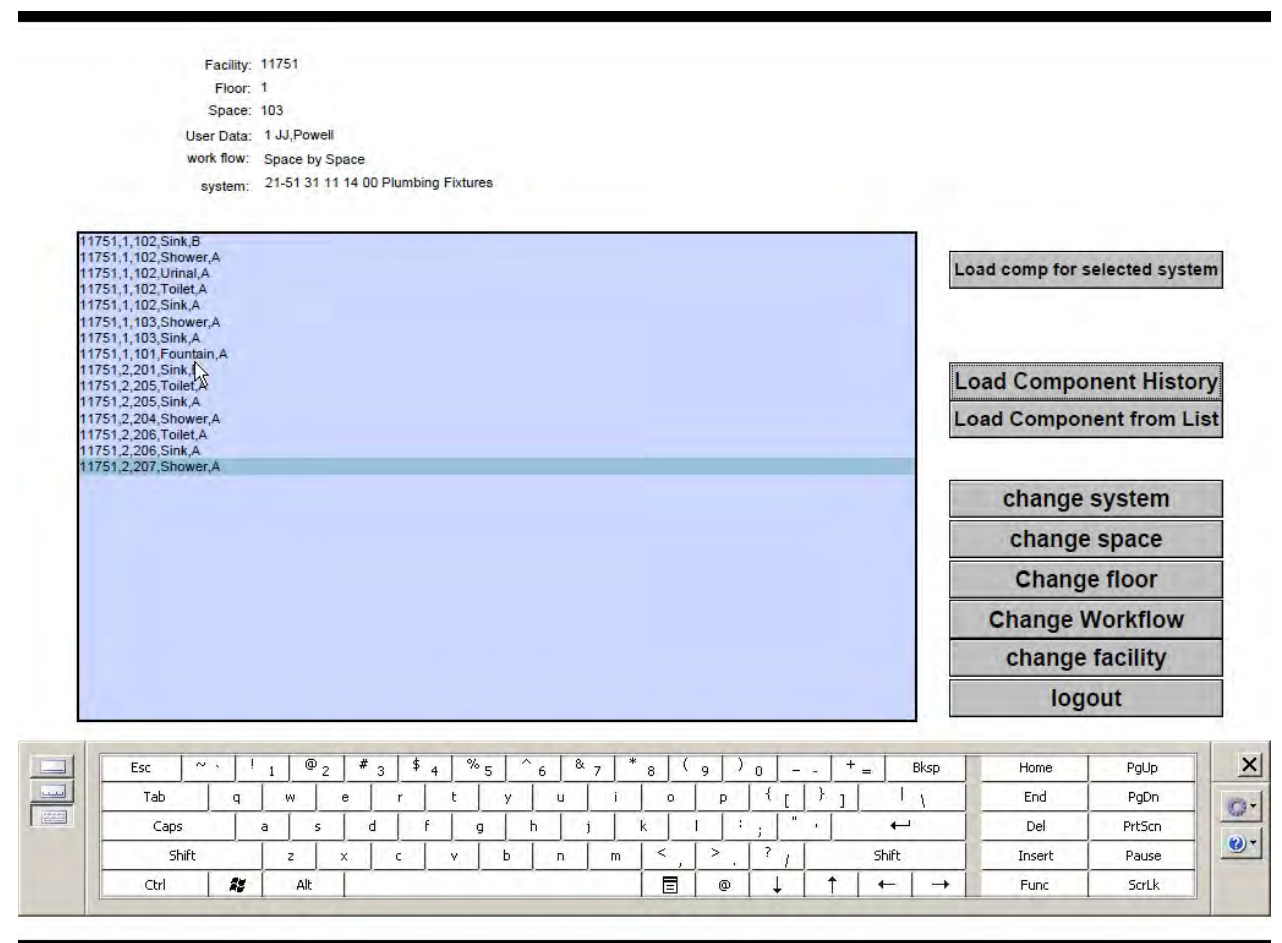

Figure 19: Load Component Page. (Showing component history for selected system)

Fort Lews Summer Field Survey - Phase 2

User: 1 JJ,Powell

Facility: 11751

Floor: 1 Spsce: 103

System 21-51 311114 00 Plumbing Fixtures

Component Name

Sink

Installation Name

11751,1,103, Sink A

SinkType

Unset -

SinkMounting

Manufacturer Name

Unset $\quad$ -

\section{Larer}

Model Name or Number

Quantity to Install

Serial \#

Seriala

\section{Save Component Back}

$\square$

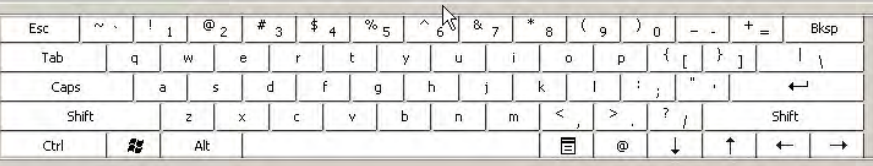

\begin{tabular}{|c|c|}
\hline Home & Pglp \\
\hline End & PgDn \\
\hline Del & PrtScn \\
\hline Insert & Pause \\
\hline Func & Scrk \\
\hline
\end{tabular}

Figure 20: Standard "blank" component page. 


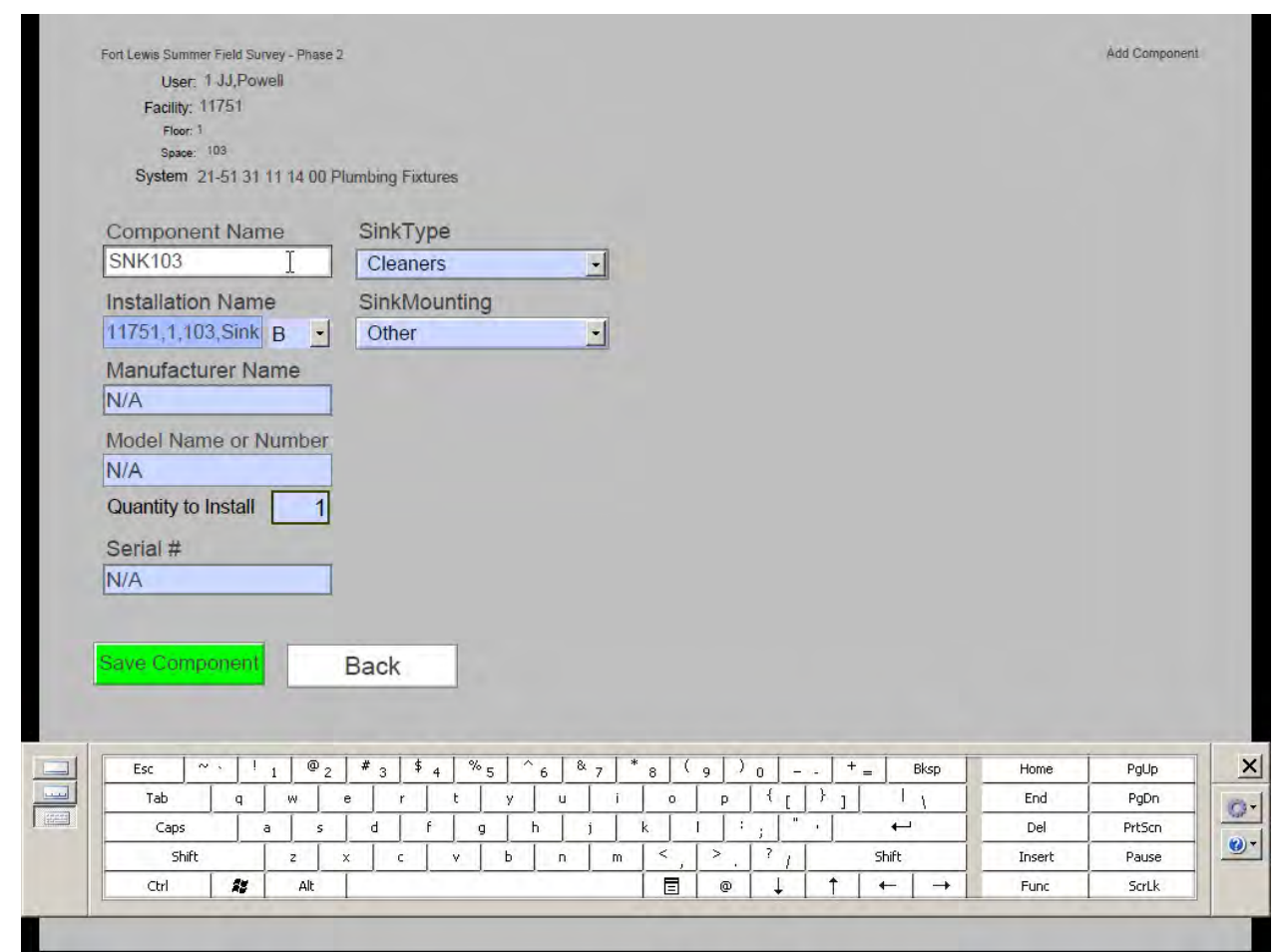

Figure 21: Previously loaded component. The fields retain prior data entries.

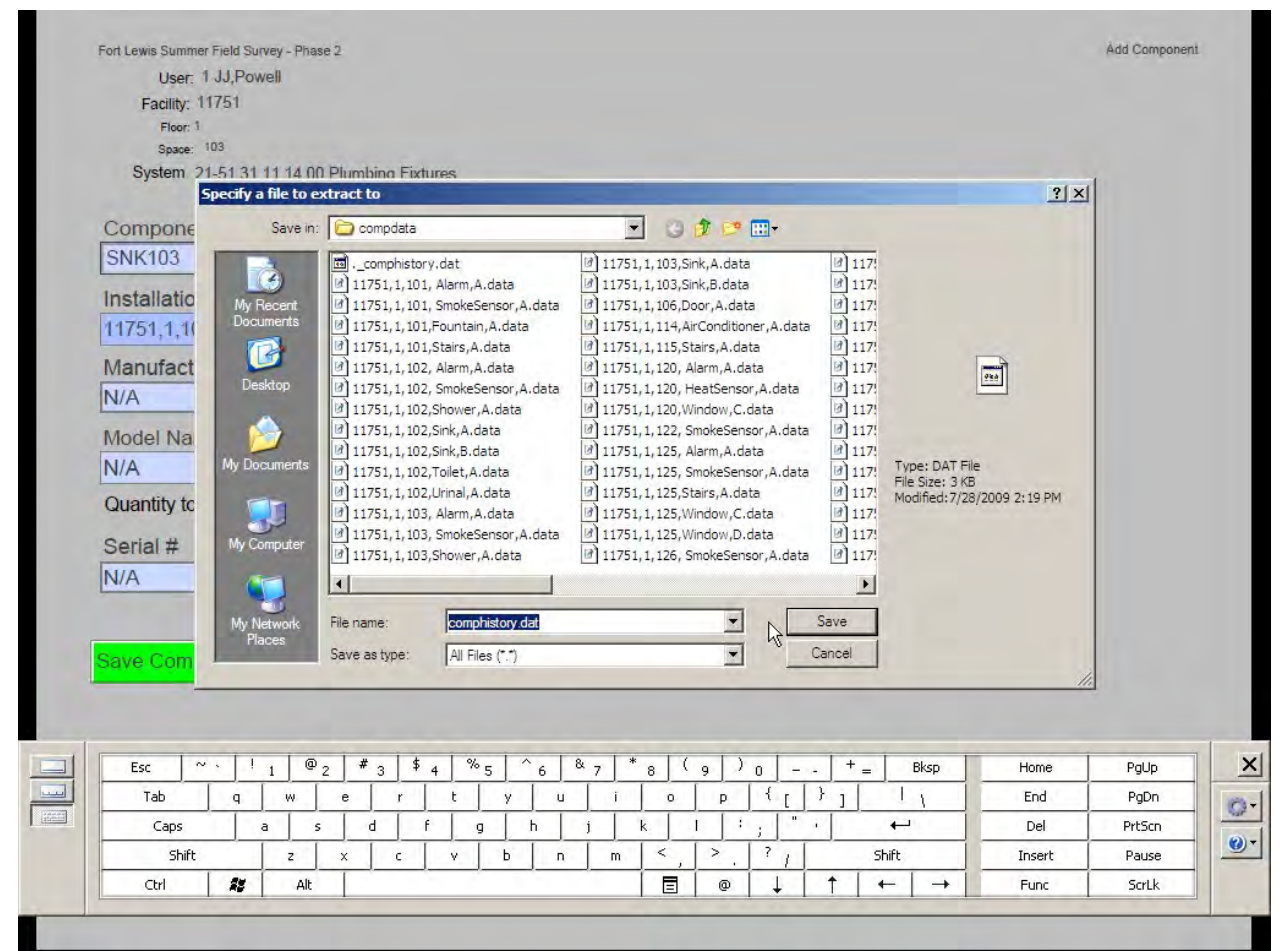

Figure 22: Save component function - saves items to "compdata" folder. The application automatically enters the data filename. 


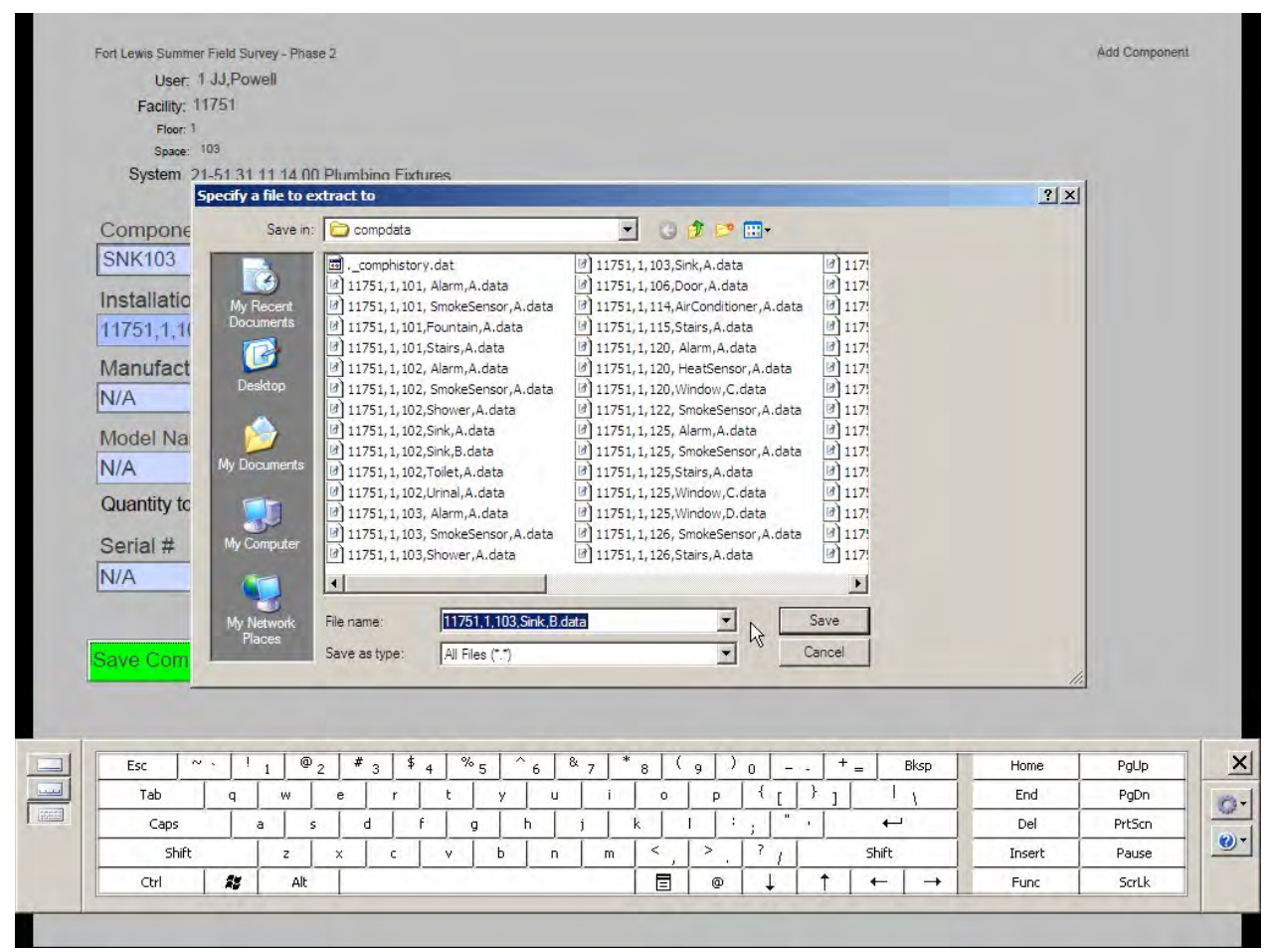

Figure 23: Step 2 in the "save process" - Using the "comphistory" function.

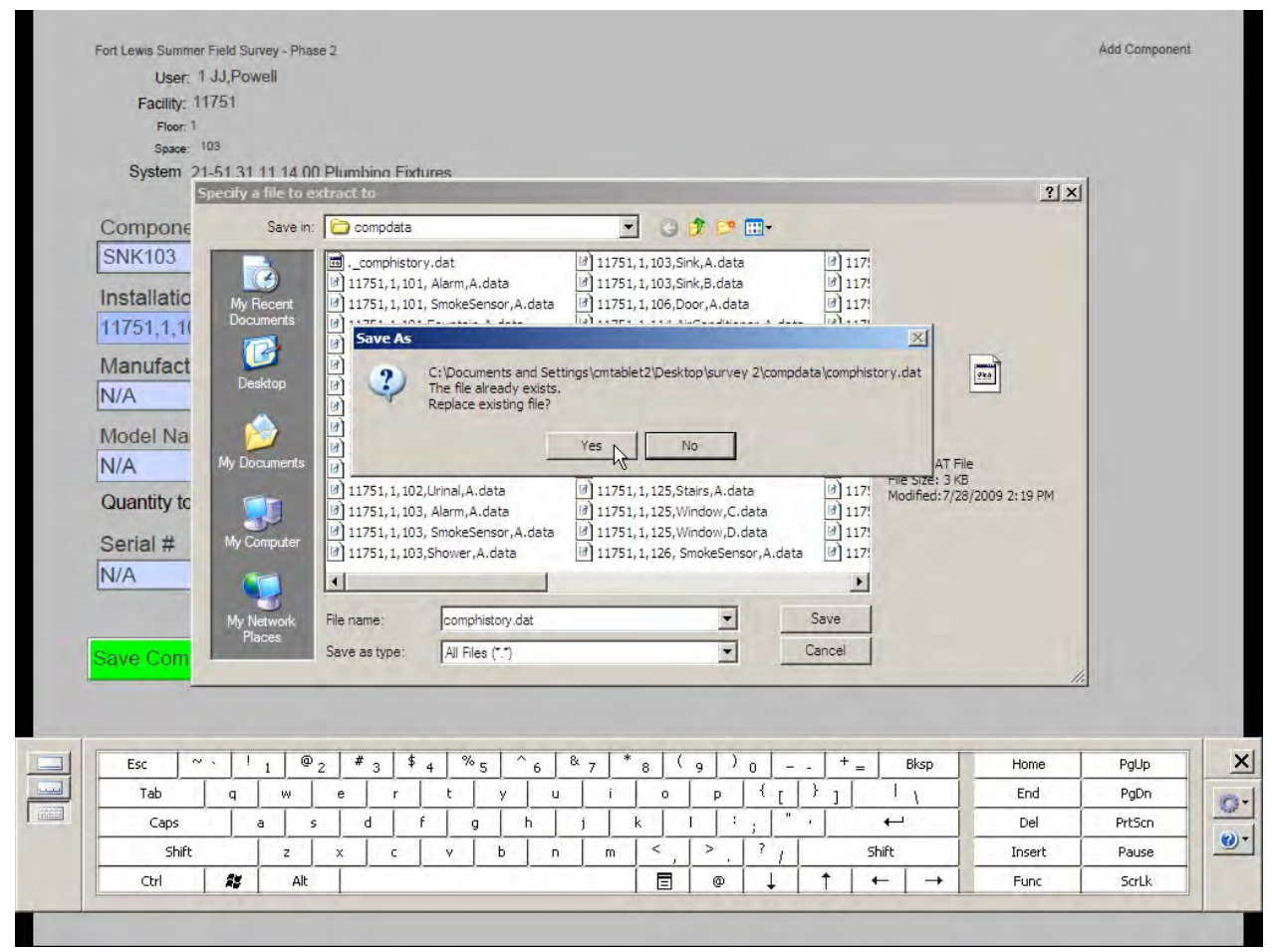

Figure 24: Overwriting the "comphistory" file adds most recently surveyed item to the history list. 


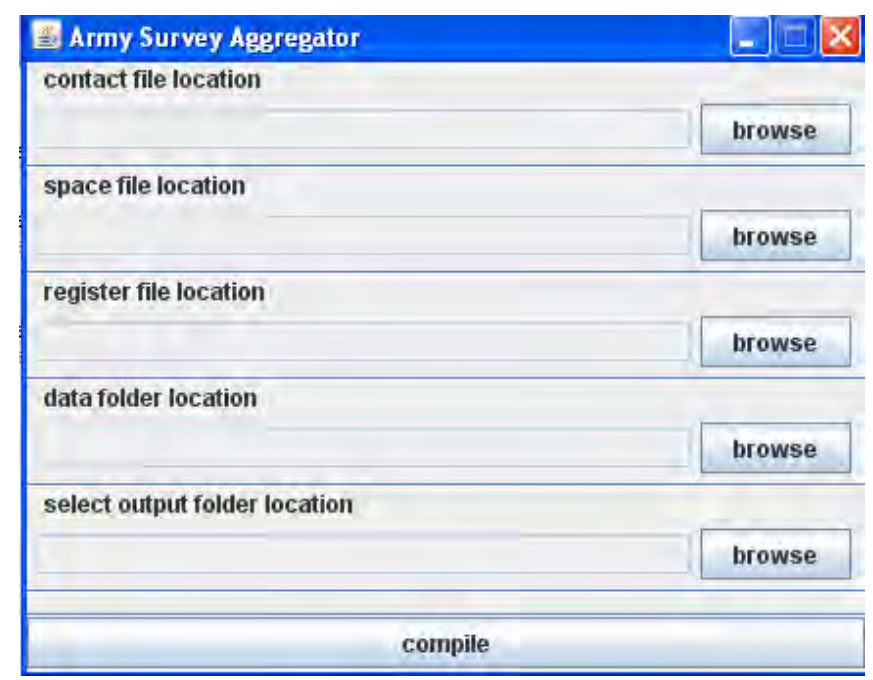

Figure 25: The JAR COBIE Data Converter application interface. Users "browse" to point the converter at the appropriate folders for each of the file locations listed. The first three are the "filter-formatting" files, which dictate the data formatting based on the COBIE Tabs 04,06,07. Once the user selects each of these, and locates the source folder and the output folder, the user clicks "compile". The converter compiles and formats all of the individual files within the "data folder location", and places new "comma-separated-value" files for COBIE Tabs 07Component, 08-Attribute, and 14-Installation into the "output folder location".

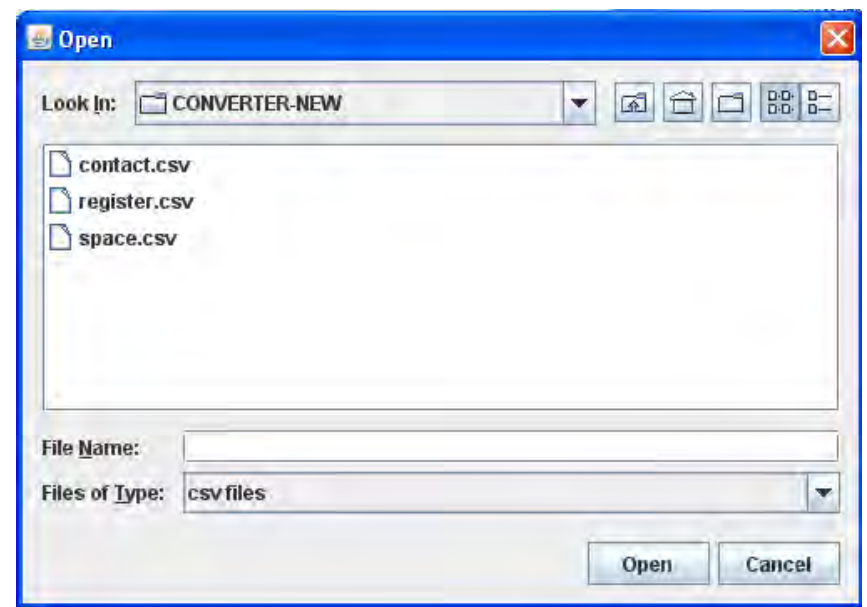

Figure 26: Locating the correct formatting files within the browser window.

Installation instructions for the COBIE Data Converter are located in within the program folder itself. The application is intended to be self-contained in the current iteration, and the folder structure and location of support files should be maintained in order for the program to function properly. 


\section{Appendix 3: Survey Completion Rates and Collected Data}

This section contains the basic data and a comparative discussion of the performance results for each task and team involved in the 4-week Fort Lewis field trials. It is important to reiterate some of the basic information about the fieldwork and how differences in tasks and team composition may have played a role in the outcomes. Weeks 1 and 2 were scheduled to assess a space-by-space method of collecting data within the target facility. Weeks 3 and 4 were focused on a system-by-system approach. During Weeks 1 and 3, teams were comprised of two surveyors, and were equipped with two mobile computing devices (Tablet PCs) running the PDF Survey Application. Teams in Weeks 2 and 4 were limited to one person, appropriately equipped. While there are certainly differences in productivity between weeks where the task order/focus was different, any comparison of the differences is limited to understanding the potential and limitations of each data collection approach. It was difficult to directly compare the two approaches; it is essentially an "apples versus oranges" comparison. However, when examining the differences among weeks of similar task-groupings, comparisons highlight the performance differences between one-person and two-person teams.

Any DPW developing its priorities for staffing, scheduling, and survey outcomes will likely consider the pros and cons of staffing data collection teams with one versus two surveyors. DPW teams may also want to compare the investment and resources required to survey facilities on a systems-only basis, versus capturing data for the entire building. By limiting the survey project scope to one or two systems within each facility, the team will save time and cost. However, DPW may benefit greatly from a priorityphased series of whole-building surveys. The following analysis and rates are intended to be a resource for DPW teams seeking to weigh the costs and benefits between the survey options presented.

Survey tasks and the weekly schedule were based around task types themselves. The goal was to measure the amount of time it would take to complete given tasks, rather than to give surveyors fixed times. In general, surveyors across all weeks completed tasks in significantly less time than was expected. For example, during the FY08 study, the average completion rate for Building 11751's mechanical room was between 2.5 to 3 hours. During this FY09 study, using the PDF Survey Application and Tablet PCs, surveyors spent an average of 45 minutes collecting data in the same room. Survey completion rates from year to year were reduced by as much as two-thirds.

During the summer 2009 field survey, survey teams collected data for the south half of each of the two floors within Building 11751, as described in the Experimental Design. The GRA observed each survey team, and recorded the amount of time it took to complete each task. This time (noted in minutes) was then multiplied by two to arrive at an estimate of the time to complete survey tasks for the entire building. The tables below show the total time to complete the facility survey, and the square feet per minute covered by each team within the field survey. The "completion rate" (SF/Minute) for all weeks was used to develop average completion rates for the respective task types, which was then used to estimated time and cost (see Chapter 4 and Appendix 4). 
Completion Rates: Week 1 Versus Week 2

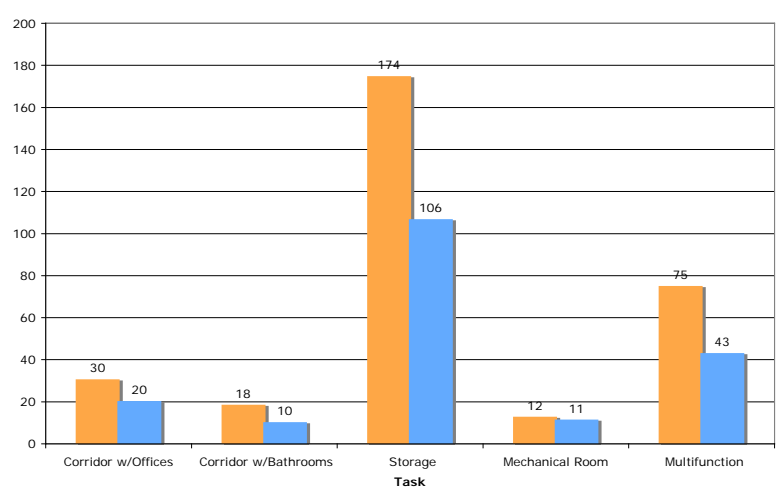

Time to Complete: Week 1 Versus Week 2

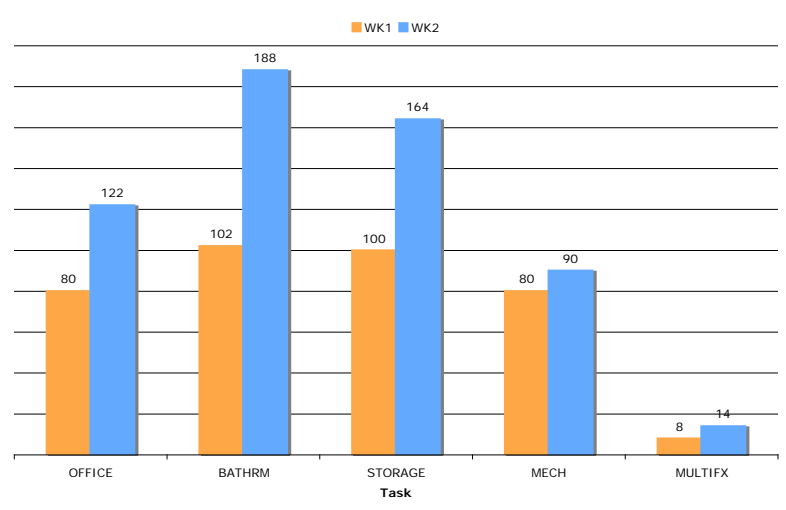

Figure 27: Graphs of Survey Rates by task Weeks 1 and 2.

Figure 28: Graphs of Survey Rates by task, Weeks 1 and 2.

Table 12: Survey Rates for Weeks 1-2, Building 11751, Square Feet/Minute.

\begin{tabular}{|l|l|l|l|l|l|l|}
\hline \multirow{2}{*}{ Team } & \multicolumn{5}{|l|}{ Time to Complete Building 11751 Facility Survey, Minutes } & \\
\cline { 2 - 7 } & OFFICE & BATHROOM & STORAGE & MECH/ELEC & MULTIFX & TOTAL \\
\hline Week 1 & 80 & 102 & 100 & 80 & 8 & 370 \\
\hline Week 2 & 122 & 188 & 164 & 90 & 14 & 578 \\
\hline Team & Completion Rates, Building 11751 Facility Survey, SF I MIN & \\
\cline { 2 - 8 } & OFFICE & BATHROOM & STORAGE & MECH RM & MULTIFX & AVERAGE \\
\hline Week 1 & 30 & 18 & 174 & 12 & 75 & 62 \\
\hline Week 2 & 20 & 10 & 106 & 11 & 43 & 38 \\
\hline
\end{tabular}

Obvious differences are apparent when examining completion rates of the various teams. On the whole, total times for facility completion were much greater for Weeks 3 and 4 (system-by-system), compared to Weeks 1 and 2 (space-by-space). It should be stated that the "systems" approach was not studied for its potential to complete whole-building surveys, rather to test the potential of the PDF Survey Application and Tablet PC methodology to efficiently capture components for buildingwide systems. The best way to compare the performance difference between the two 
approaches is to consider the completion rates in light of DPW's survey goals and budget. DPW may consider the benefits of surveying an entire building, versus MEP systems building-wide. If the department must choose based on budget constraint, then limiting the scope of the survey to a few systems might be beneficial. In such a case, those estimating time and cost, and planning out the survey projects will consult the completion rates for the different system tasks (see Tables 21 and 22). However, if the department has the time and budget to do so, a more complete building survey can be achieved by investing bit more time and cost. For some facilities/projects, this may be a suitable option.

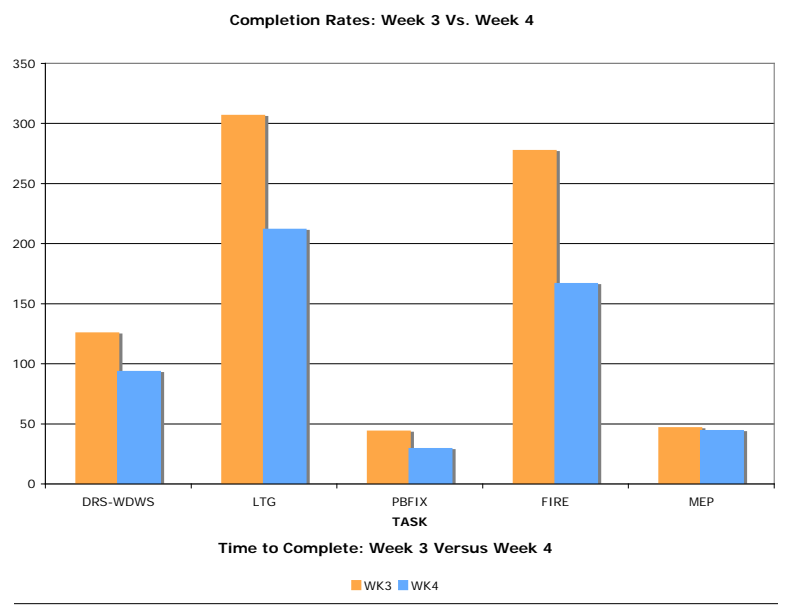

Figure 29: Graph of Survey Rates, by task, Weeks 3 and 4.

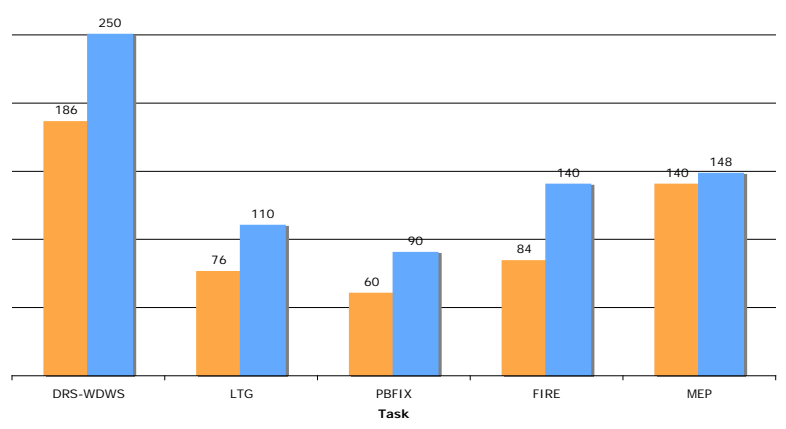

Figure 30: Survey Rates for Weeks 3-4, Building 11751.

Table 13: Survey Rates for Weeks 3-4, Building 11751.

\begin{tabular}{|l|l|l|l|l|l|l|l|}
\hline \multirow{2}{*}{} & \multicolumn{6}{|l|}{ Total Time to Complete Building 11751 Facility Survey, Minutes } \\
\cline { 2 - 7 } & DRS+WDWS & LIGHTING & PLUMB FIXT & FIRE SMOKE & MEP & TOTAL \\
\hline Week 3 & 186 & 76 & 60 & 84 & 140 & 546 \\
\hline Week 4 & 250 & 110 & 90 & 140 & 148 & 738 \\
\hline \multirow{2}{*}{ Completion Rates, Building 11751 Facility Survey, SF I MIN } & AVERAGE \\
\cline { 2 - 7 } & DRS+WDWS & LIGHTING & PLUMB FIXT & FIRE SMOKE & MEP & 160 \\
\hline Week 3 & 125 & 306 & 44 & 277 & 46 & \\
\hline
\end{tabular}




\begin{tabular}{|l|l|l|l|l|l|l|}
\hline Week 4 & 93 & 212 & 29 & 166 & 44 & 109 \\
\hline
\end{tabular}

The GRA noted differences between performance rates among one- and twoperson teams. For teams that included two members, rates were less than those with only one. However, two-person teams did not work twice as fast as one-person teams; a survey project manager and client should consider that two paid labor hours does not equal a doubling in efficiency. In fact, on many tasks, teams performed at an equal rate (see tasks Mechanical/Electrical and Multifunction, Table 20; MEP and Plumbing Fixtures, Table 22). Mechanical rooms, electrical equipment and plumbing fixtures represented lower square-foot-per-minute tasks (slower) than systems such as doors and windows, or space like offices and storage. These lower-rate tasks tend to be more critical from a facilities maintenance standpoint, and tend to be of greater interest to DPW. If the rate for these critical tasks tends to be relatively similar among one- and two- person teams, it may not necessarily be a significant benefit to assign two surveyors to one facility. Consequently, the cost ratio is also impacted, and it turns out that there is no significant savings or efficiency earned by employing two surveyors instead of one (see Appendix 4). 


\section{Appendix 4: Cost Estimate Calculations}

This guide assumes that DPW employees will staff the survey team. Any items outsourced to either an in-house contractor or external contractor will need to be adjusted to account for expected markup of service fees. Logistics for survey tasks and general access and planning are assumed to be approximately $25 \%$ of total time involved in completing the survey for each facility. Amortization is calculated using a three-year replacement cycle for hardware and software, at approximately 500 hours of use per year. Labor for project tasks was calculated at $\$ 50 /$ hour as a baseline.

Although considerable effort went into developing a scripted application interface for this experiment, the team recognizes that there is considerable room for improvement. The assumption is that, if adopted, the client would likely undertake the professional development of a similar application, and that such a process would take many months at an expense close to $\$ 50,000-\$ 60,000$. An additional $\$ 20,000-\$ 30,000$ might be expected for yearly support and continuing development. The application created for the study presents the possible path toward developing a professional, stable, intuitive interface, but its much smaller budget is a fraction of the real cost of a professional application development. Because there are many unknowns in this area, he cost of professional application development and testing was not included as part of the cost estimation guide. This fixed cost could be added, amortized, to the cost of conducting the survey projects.

Other fixed costs excluded from the estimation guide include BIM software training and the cost of licensing for all software other than the custom PDF Survey Application. It is assumed that BIM geometry developers are trained and available. Typical training cycles may involve up to 3 weeks of focused learning, though this is an unknown cost that the team decided to exclude. All software related to the COBIE asbuilt survey process is available on an enterprise-license basis. The actual cost of these licenses is an unknown; the license agreements would likely be assigned through USACE.

It is important to keep in mind that fixed costs include initial investments in project technology including computer equipment used for facility surveys as well as application development and BIM geometry. Some Items have been mentioned, but excluded from cost estimations. Those include: office equipment (such as a desktop computing system, printing, scanning facilities), staff training (Revit Architecture, PDF Survey Application), software licensing. Software licenses are also considered a significant fixed cost related to this survey process.

Operational costs of implementing the COBIE technologies refer primarily to the labor costs of developing, conducting and supporting the survey project. The productivity rates for data collection and data entry (shown in Table 14), refer to data collection alone, and do not include time for logistics, access, and support. The research team recommends adding an additional $25 \%$ of the total estimated data capture time, to account for logistics (see Table 17). Other operational costs are listed in Table 17 and include the estimated preparation time to conduct a survey (PDF Application specification), and estimates of labor-hours related to BIM development and data management. 
Table 14: Survey Rates for Building 11751, Square Feet/Minute.

\begin{tabular}{|c|c|c|c|c|c|c|}
\hline \multirow[t]{2}{*}{ Team } & \multicolumn{5}{|c|}{ Completion Rates, Building 11751 Facility Survey, SF / MIN } & \\
\hline & OFFICE & BATHROOM & STORAGE & MECH RM & MULTIFX & AVERAGE \\
\hline Week 1 & 30 & 18 & 174 & 12 & 75 & 62 \\
\hline \multirow[t]{3}{*}{ Week 2} & 20 & 10 & 106 & 11 & 43 & 38 \\
\hline & \multicolumn{6}{|c|}{ Completion Rates, Building 11751 Facility Survey, SF / MIN } \\
\hline & DRS+WDWS & LIGHTING & PLUMB FIXT & FIRE SMOKE & MEP & AVERAGE \\
\hline Week 3 & 125 & 306 & 44 & 277 & 46 & 160 \\
\hline Week 4 & 93 & 212 & 29 & 166 & 44 & 109 \\
\hline
\end{tabular}

Table 15: Survey Completion Times for Building 11751, Minutes.

\begin{tabular}{|c|c|c|c|c|c|c|}
\hline \multirow[t]{2}{*}{ Team } & \multicolumn{5}{|c|}{ Completion Rates, Building 11751 Facility Survey, SF / MIN } & \multirow[b]{2}{*}{ AVERAGE } \\
\hline & OFFICE & BATHROOM & STORAGE & MECH RM & MULTIFX & \\
\hline Week 1 & 80 & 102 & 100 & 80 & 8 & 80 \\
\hline \multirow[t]{3}{*}{ Week 2} & 122 & 188 & 164 & 90 & 14 & 122 \\
\hline & \multicolumn{6}{|c|}{ Completion Rates, Building 11751 Facility Survey, SF / MIN } \\
\hline & DRS+WDWS & LIGHTING & PLUMB FIXT & FIRE SMOKE & MEP & AVERAGE \\
\hline Week 3 & 186 & 76 & 60 & 84 & 140 & 186 \\
\hline Week 4 & 250 & 110 & 90 & 140 & 148 & 250 \\
\hline
\end{tabular}

Whole-Building Surveys versus Targeted Systems-only Surveys

DPW teams should consider the costs and benefits related to limiting survey project scopes to one or two systems versus conducting whole building surveys. Although budget constraints may favor the staffing and scheduling parameters of a systems only approach, it may still be worthwhile to consider the requirements for and opportunities embedded within full-facility surveys. Table 16, below shows the labor costs associated with completing survey tasks for the target facility included in the FY09 study at Fort Lewis. A comparison should initially be drawn between the labor costs to complete MEP systems versus the cost of completing the whole building (costs shown in blue). 
Table 16: Survey Labor Costs for Building 11751, at $\$ 50$ per hour.

\begin{tabular}{|c|c|c|c|c|c|c|}
\hline \multirow[t]{2}{*}{ Team } & \multicolumn{5}{|c|}{ Cost to Complete Building 11751 Facility Survey at $\$ 20$ / hour } & \multirow[b]{2}{*}{ Total } \\
\hline & OFFICE & BATHROOM & STORAGE & MECH RM & MULTIFX & \\
\hline $\begin{array}{l}\text { Week } 1 \\
\text { ( } 2 \text { people) }\end{array}$ & $\$ 67$ & $\$ 85$ & $\$ 83$ & $\$ 67$ & $\$ 7$ & 308 \\
\hline \multirow[t]{3}{*}{$\begin{array}{l}\text { Week } 2 \\
\text { (1 person) }\end{array}$} & $\$ 102$ & $\$ 157$ & $\$ 137$ & $\$ 75$ & $\$ 12$ & 482 \\
\hline & \multicolumn{6}{|c|}{ Cost to Complete Facility Survey at $\$ 20$ / hour } \\
\hline & DRS+WDWS & LIGHTING & PLUMB FIXT & FIRE SMOKE & MEP & Total \\
\hline $\begin{array}{l}\text { Week } 3 \\
\text { (2 people) }\end{array}$ & $\$ 155$ & $\$ 63$ & $\$ 50$ & $\$ 70$ & $\$ 117$ & $\$ 455$ \\
\hline $\begin{array}{l}\text { Week } 4 \\
\text { (1 person) }\end{array}$ & $\$ 208$ & $\$ 92$ & $\$ 75$ & $\$ 117$ & $\$ 123$ & $\$ 615$ \\
\hline
\end{tabular}

Table 17: Costs Associated with Implementation and Operation.

\begin{tabular}{|c|c|c|c|c|c|}
\hline & Type & Description & Assumptions & $\begin{array}{c}\text { Cost } I \\
\text { HR }\end{array}$ & $\begin{array}{c}\text { Cost I 100 } \\
\text { SF }\end{array}$ \\
\hline \multirow[t]{6}{*}{ Fixed Costs } & \multicolumn{3}{|c|}{ Software and Equipment Costs } & & \\
\hline & $\begin{array}{l}\text { COBIE Survey } \\
\text { Equipment }\end{array}$ & $\begin{array}{l}\text { Motion F5 Tablet PC and } \\
\text { Accessories }\end{array}$ & $\begin{array}{l}\$ 5,000 / \text { unit, 3-year replacement cycle, } \\
500 \text { hrs/year }\end{array}$ & $\$ 3.33$ & $\$ 0.17$ \\
\hline & MS Office 2007 & $\begin{array}{l}\text { Platform for operating } \\
\text { COBIE spreadsheet } \\
\text { output }\end{array}$ & Enterprise license available & & -- \\
\hline & $\begin{array}{l}\text { Adobe Acrobat } \\
9 \text { Pro }\end{array}$ & $\begin{array}{l}\text { Pro version used to build } \\
\text { PDF Survey Application }\end{array}$ & Enterprise license available & & -- \\
\hline & Adobe CS4 & Image editing & Enterprise license available & & -- \\
\hline & $\begin{array}{l}\text { Autodesk Revit } \\
\text { Architecture }\end{array}$ & $\begin{array}{l}\text { BIM development } \\
\text { software }\end{array}$ & Enterprise license available & & -- \\
\hline \multirow{4}{*}{$\begin{array}{l}\text { Operational } \\
\text { Costs }\end{array}$} & \multicolumn{3}{|c|}{ Project-based Costs of Conducting and Supporting COBIE Facility Surveys } & & \\
\hline & Surveyors & DPW Personnel & $\begin{array}{l}13 \text { hours maximum time to complete } \\
\text { Battalion Headquarters Facility }\end{array}$ & $\$ 50$ & 2.60 \\
\hline & \begin{tabular}{|l|} 
BIM \\
Development \\
Labor
\end{tabular} & $\begin{array}{l}\text { Recurring Activities per } \\
\text { Facility }\end{array}$ & 6 hours & $\$ 50$ & 1.20 \\
\hline & \begin{tabular}{|l} 
PDF Survey \\
Form \\
Specification
\end{tabular} & $\begin{array}{l}\text { Detailed COBIE Survey } \\
\text { Information per } \\
\text { Project/Facility }\end{array}$ & 6 hours & $\$ 50$ & 1.20 \\
\hline \multirow{2}{*}{$\begin{array}{l}\text { Logistics } \\
\text { Costs }\end{array}$} & \multicolumn{3}{|c|}{ Mobilization, Access, and Communication During Actual Survey Work } & & \\
\hline & \begin{tabular}{|l} 
Survey \\
Logistics
\end{tabular} & $\begin{array}{l}\text { Access and } \\
\text { Communication }\end{array}$ & $\begin{array}{l}25 \% \text { of survey task time (time spent } \\
\text { collecting data) }\end{array}$ & $\$ 50$ & 0.65 \\
\hline \multicolumn{5}{|c|}{ TOTAL COST PER 100 SF: } & $\$ 5.82$ \\
\hline
\end{tabular}




\section{Appendix 5: Fieldwork Photographs}

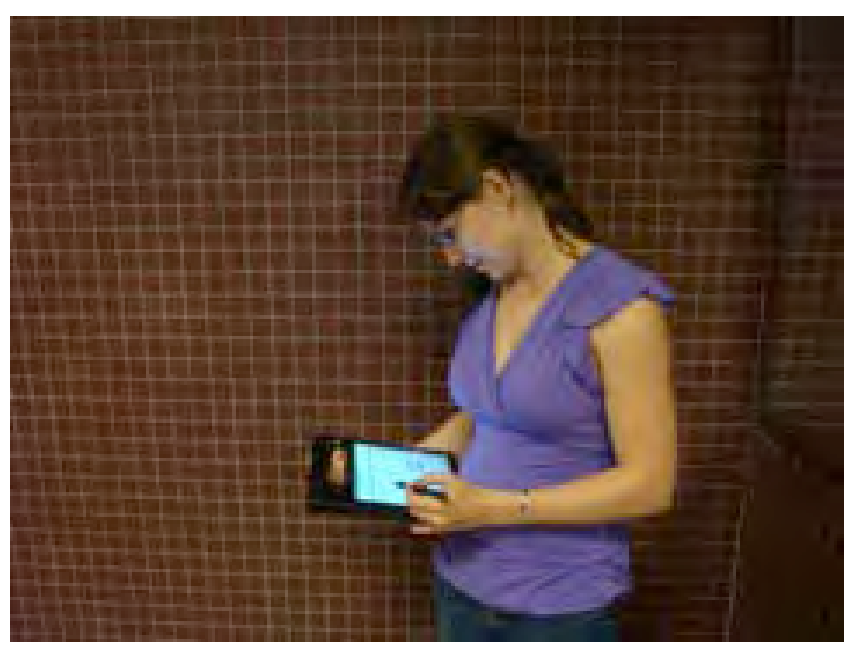

Figure 31: Surveyor entering component data.

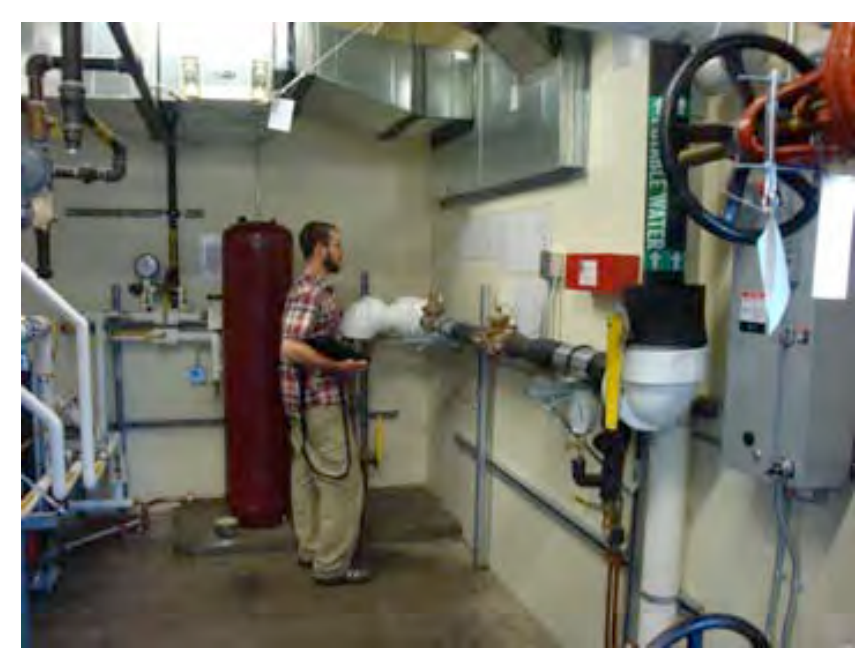

Figure 32: Examining mechanical room documentation.

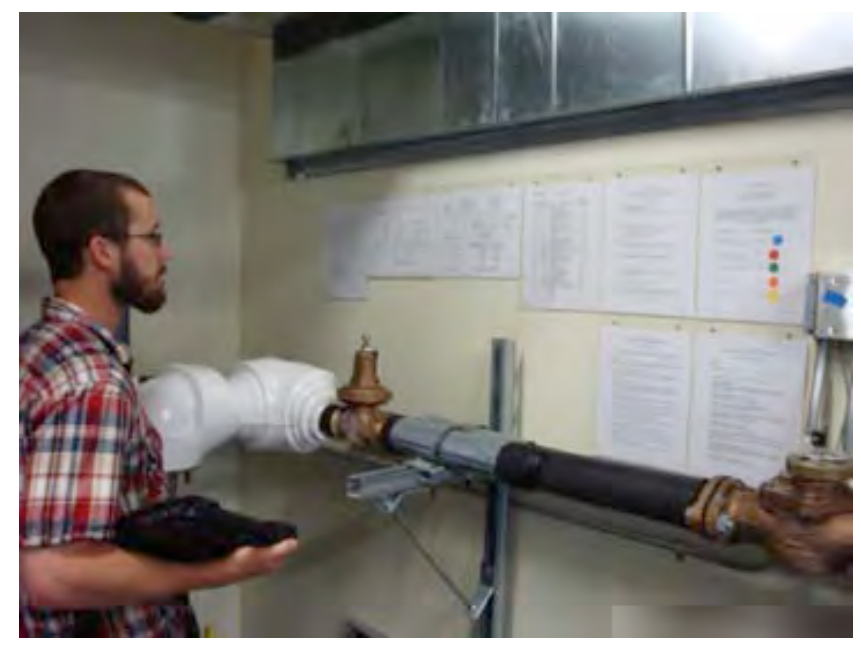

Figure 33: Using all available resources, tags, and component installation information. 


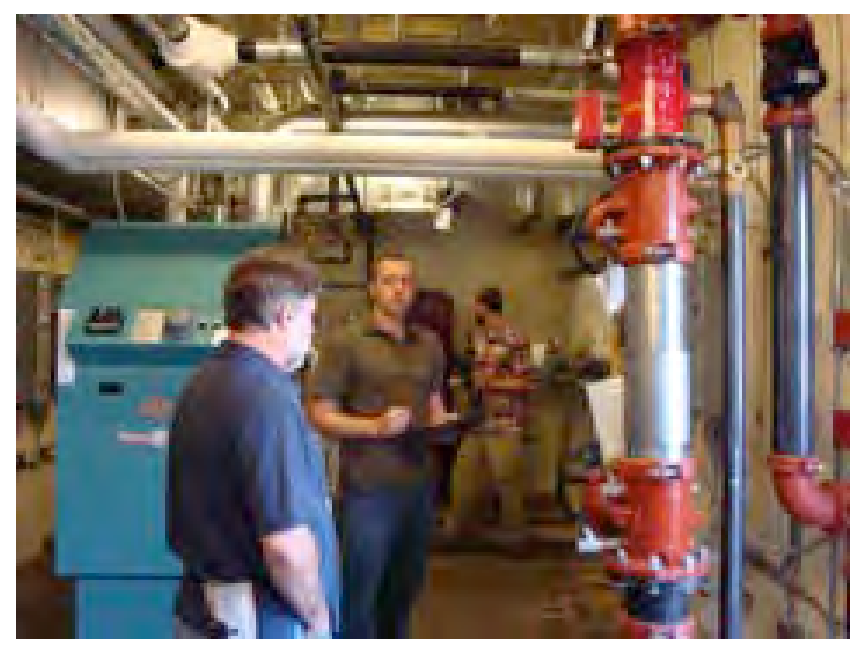

Figure 34: Field survey staff, accompanied by DPW escort, Scott Smith (Qinetiq Contract Employee, within DPW's IT Services).

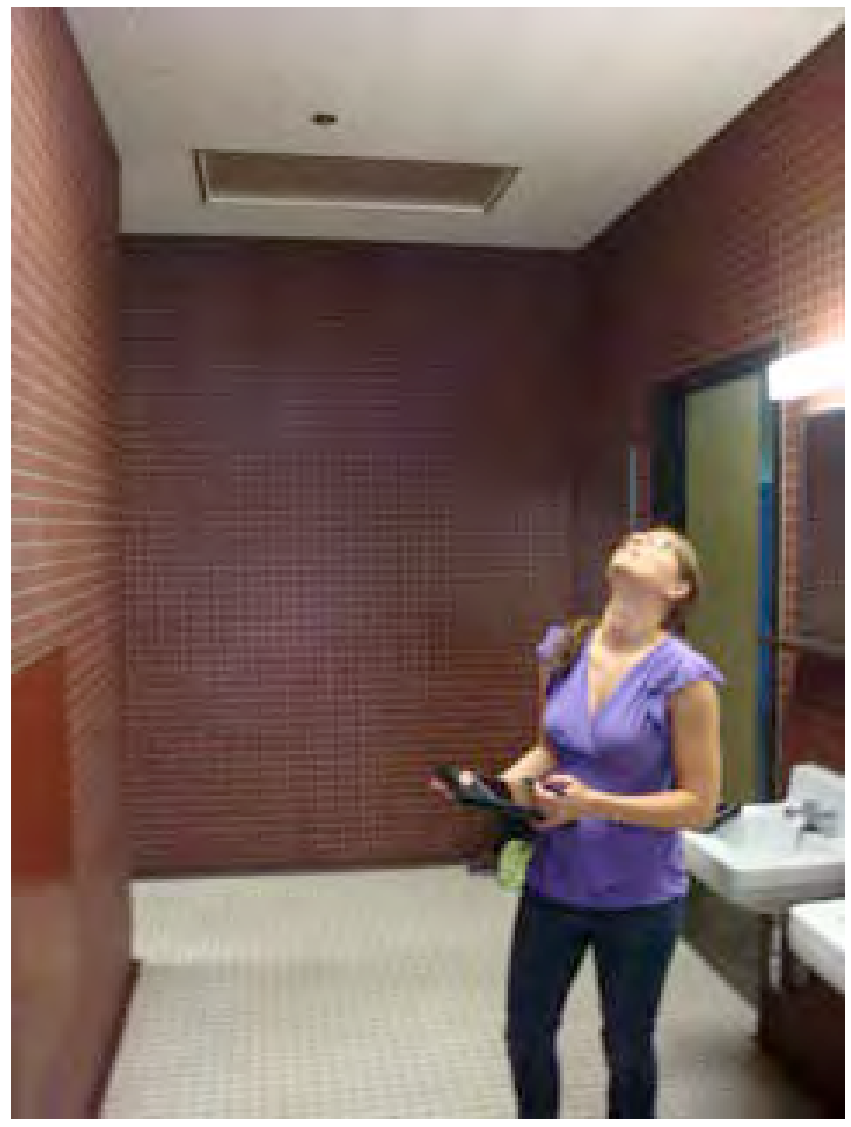

Figure 35: Verifying some component data was challenging, based on physical constraints and the need for additional equipment (e.g., ladder, flashlight). 


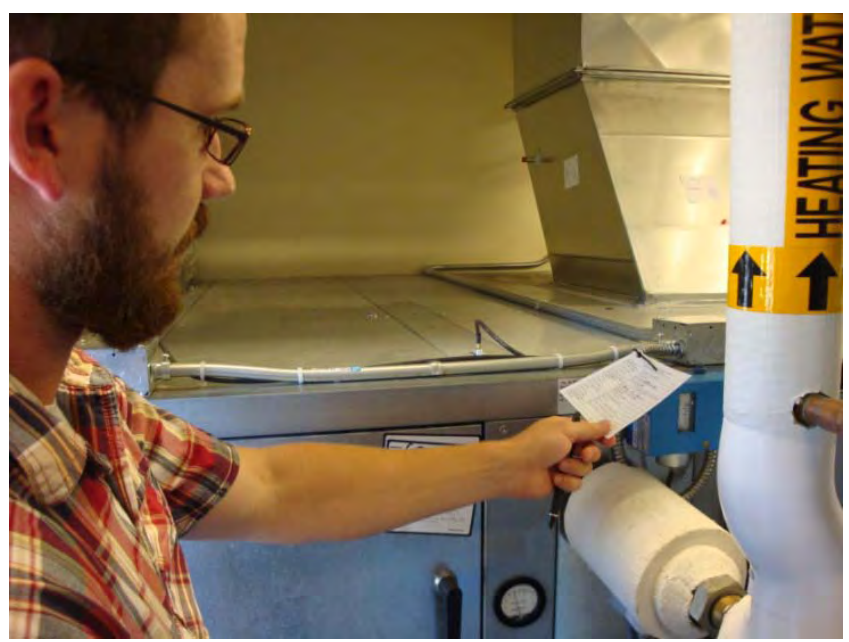

Figure 36: Verifying component data using all available labels, tags, and visually accessible information.

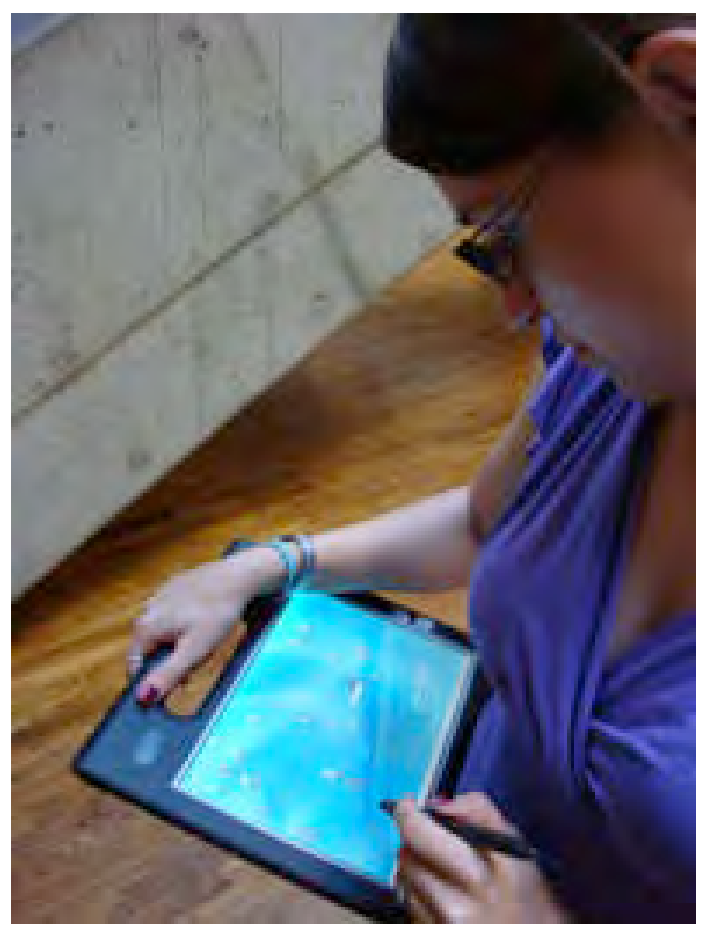

Figure 37: Week 2 Surveyor launching PDF application. Notice that Tablet PC settings can be modified for left-handed use.

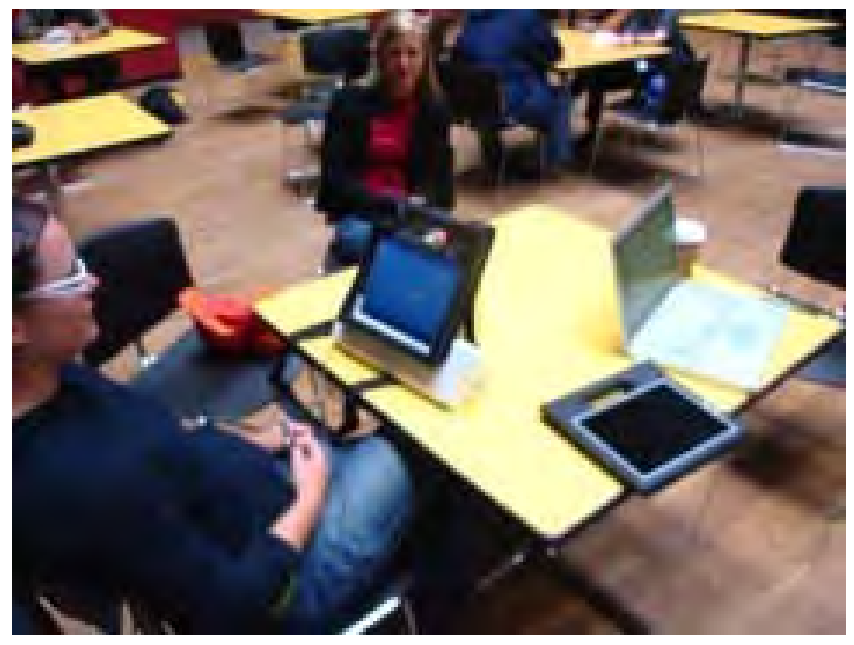

Figure 38: Early Summer software trials, debugging. 


\section{Appendix 6: Timed Tests, Assessing Efficiency and Familiarity}

In addition to collecting task completion times, the GRA conducted a series of timed tests, with the goal of revealing trends related to component history function, tool functions, surveyors' data collection and input over the course of the week.

The first exercise involved observing and recording the time to collect any and all relevant data from two "typical office spaces" within the facility being surveyed. The timed office tests were conducted mid-week, on Day 3 or Day 4, depending on the week. Office tests for weeks 1 and 2 were conducted on Day 3 , while those for weeks 3 and 4 were took place on Day 4 . The following graph shows the results of these timed tests.

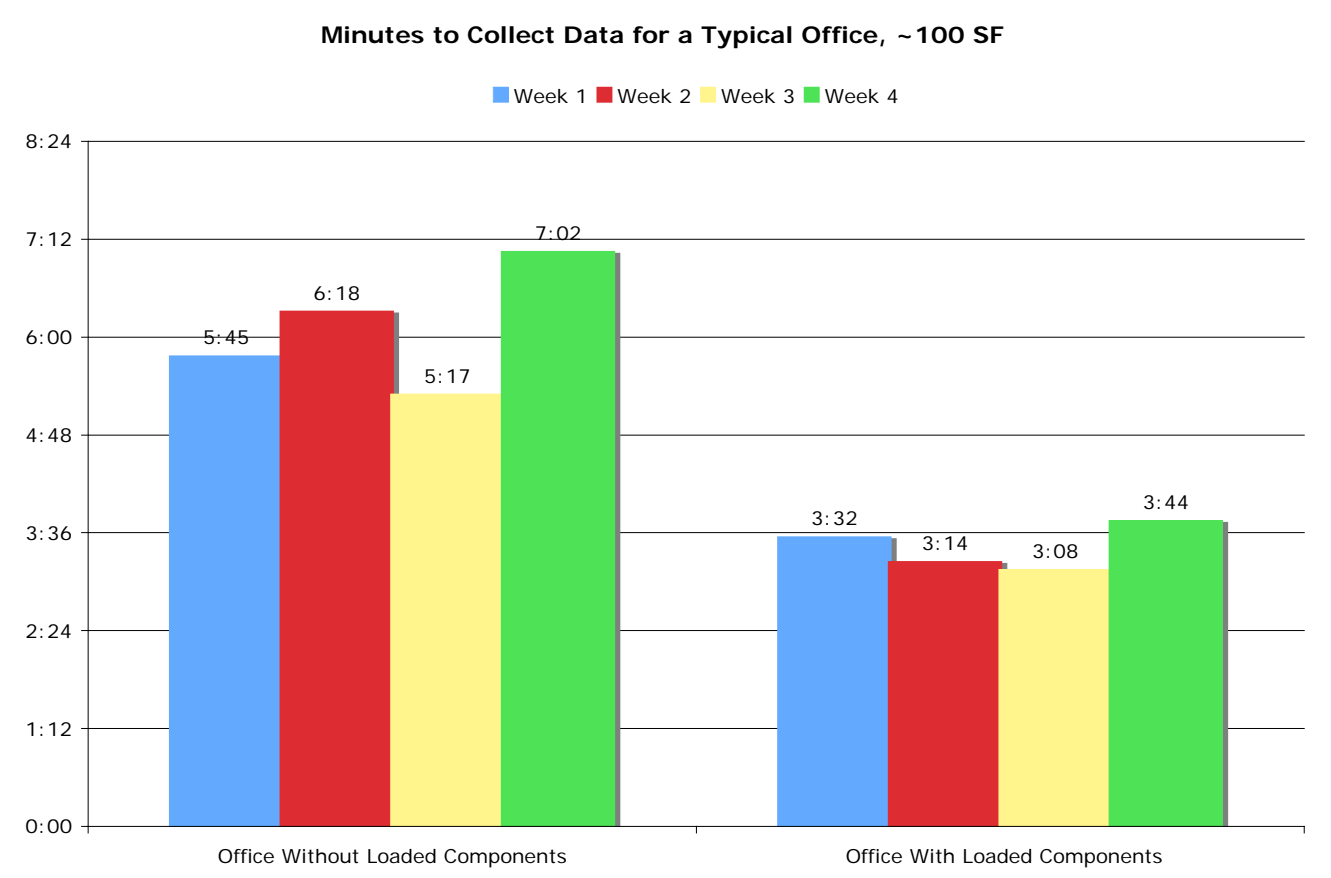

Figure 39: Comparison of Completion Rates for a typical Office, approximately $100 \mathrm{SF}$.

When surveying the first office space, the surveyors did not have the use of the PDF Survey Form "component history tool", which is designed to recall data from previously surveyed components within the same system. When solely working with non-recalled component data, surveyors' times were in the 5-7 minute range. When the history tool was employed, all surveyors were able to complete a similar space in 3-4 minutes. The component history function is particularly helpful when surveyors find new installations of the same component product type (Manufacturer, Model). However, surveyors consistently utilized the history tool to load data from new installations of similar product types, thereby finding a new efficient use for the functionality.

The second exercise was a daily timed test, involving a relatively generic component, and was used to gain a sense of users' efficiency improvements related to navigation and familiarity with the PDF Survey Form interface. Each afternoon, the surveyors were asked to enter data for a new stair within Building 11751. The GRA was able to record 5 times for each surveyor over a 5-day period. The surveyors were timed 
from "login" through completion of the component and history save function. The results of these timed tests appear in the graphs and table below.

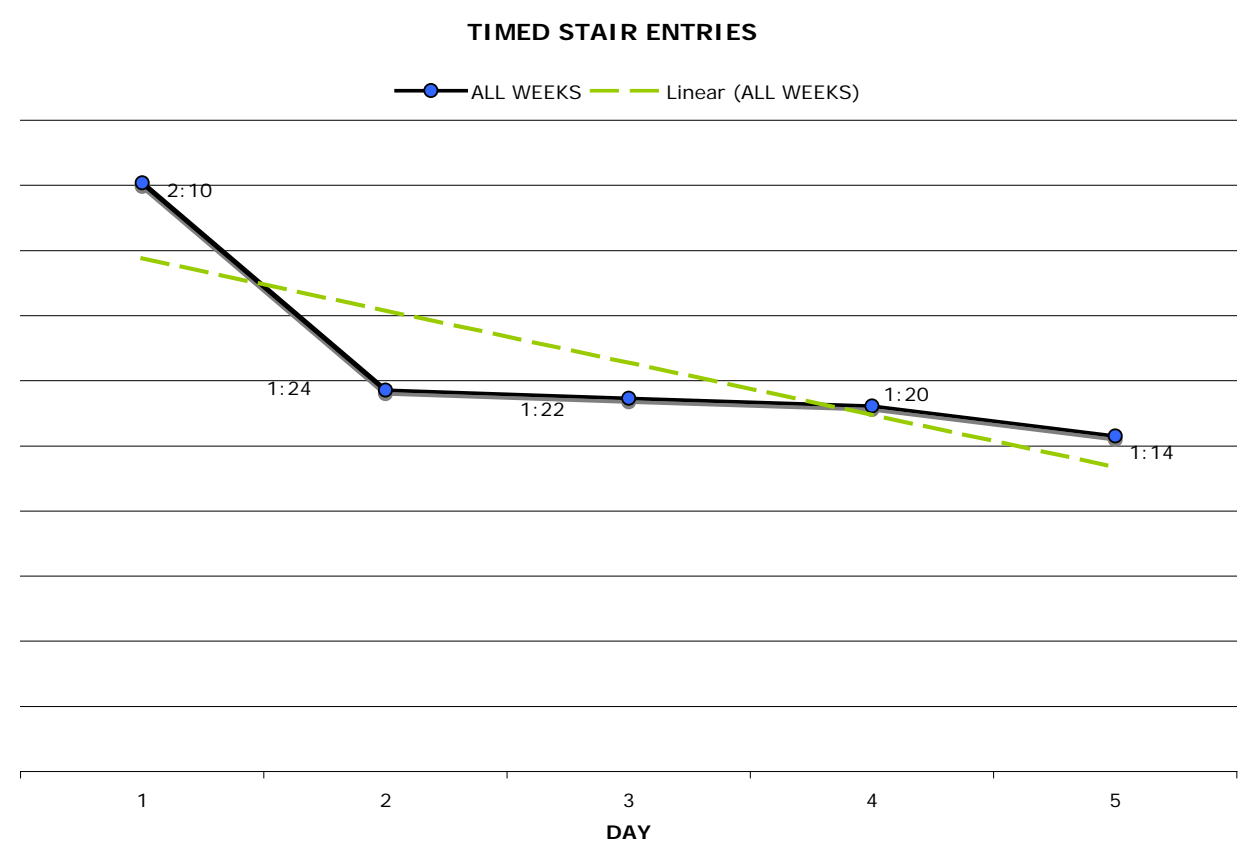

Figure 40: Average Times to enter Data for a Single Stair Component, All Weeks.

Overall, surveyors in all weeks demonstrated a rapid improvement in input times, indicating quick assimilation and familiarity with the application interface. From Day 1 to Day 5, surveyors showed an average of $43 \%$ improvement in the time to enter component data, from login to save. While surveyors started at a range of times on Day 1 , many appear to reach a plateau around Day 3 or 4 , and most end up in the 1 to 1.5 minute range by Day 3 through Day 5 .

Table 18: Average Times to enter Data for a Single Stair Component, All Weeks.

\begin{tabular}{|c|c|c|c|c|c|c|}
\hline Surveyor & D1 & D2 & D3 & D4 & D5 & \% improved \\
\hline JKB & $2: 06$ & $1: 25$ & $1: 23$ & $1: 11$ & $1: 22$ & 35 \\
\hline DLP & $2: 23$ & $2: 02$ & $1: 35$ & $1: 20$ & $1: 14$ & 48 \\
\hline AJL & $2: 33$ & $1: 33$ & $1: 17$ & $1: 17$ & $0: 51$ & 67 \\
\hline JS & $2: 00$ & $1: 26$ & $1: 25$ & $1: 47$ & $1: 30$ & 25 \\
\hline CLT & $1: 55$ & $0: 56$ & $1: 04$ & $1: 15$ & $1: 08$ & 41 \\
\hline TS & $2: 04$ & $1: 04$ & $1: 31$ & $1: 15$ & $1: 20$ & 35 \\
\hline AVERAGE & $\mathbf{2 : 1 0}$ & $\mathbf{1 : 2 4}$ & $\mathbf{1 : 2 2}$ & $\mathbf{1 : 2 0}$ & $\mathbf{1 : 1 4}$ & $\mathbf{4 3}$ \\
\hline
\end{tabular}


Individual timed "stair tests" all reveal a similar pattern (Tables 41, 42, 43, 44, 45, and 46). Every surveyor showed dramatic drops in component entry times within the first two days of using the application. Coupled with the Pre- and Post-Survey comments, the teams concluded that the interface's intuitive design and hierarchy is easy to learn and become familiar with. This user-friendly interface accounts for much of the reductions in data entry time, especially when compared with paper-based or Excelbased inventory input methods.
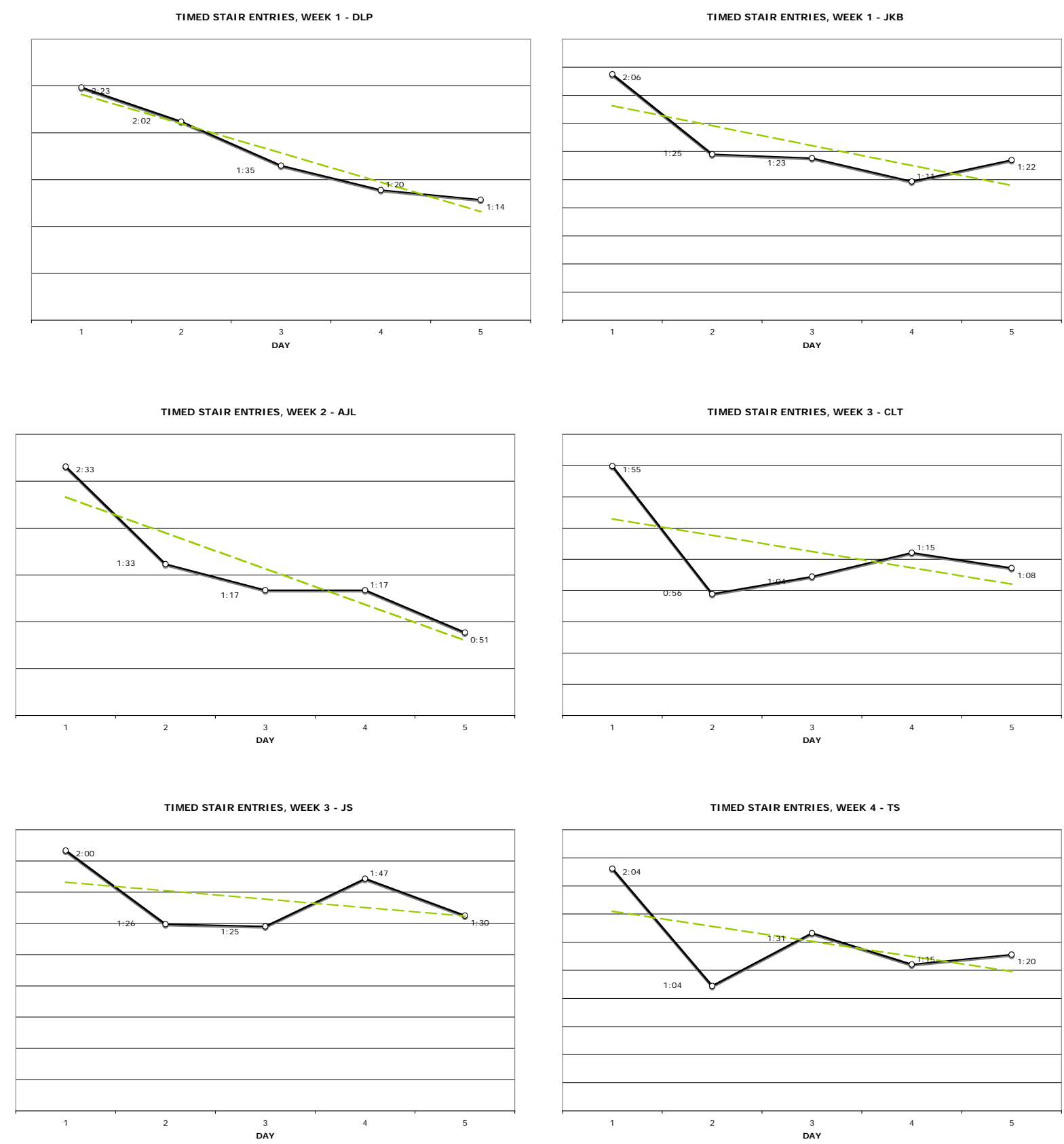

Figures 41-46: Individual Times to enter Data for a Single Stair Component, Weeks 1 - 4. 


\section{Appendix 7: Surveyor Feedback}

Pre- and Post- Surveys

Each week of the field trials, during Day 1 training, surveyors were asked to complete a Pre-survey in order to gain a sense of users' expectations and prior knowledge related to the tasks they would be asked to perform. At the end of each work week, surveyors were given another questionnaire (a Post-survey), to assess users' experience with the technologies and tasks, comments, and observations about the survey work in general.

\section{NASA Task load Index Responses}

To quantify the load on the research students conducting the data capture and data entry, an analytical method known as the Task Load Index (NASA TLX Version 2.0) was used. This method was published by the NASA Ames Research Center in December 2003. The entire report can be found at:

http://humansystems.arc.nasa.gov/groups/TLX

The NASA Task Load index is a multi-dimensional rating procedure that provides an overall workload score based on a weighted average of ratings for the factors shown in Table 19. The goal of using this index was to gather qualitative feedback from the surveyors, and to seek their comments and suggestions regarding the technologies employed. The NASA Task load Index consists of six workload factors:

Table 19: NASA Task load Index, Workload Assessment Categories.

\begin{tabular}{|l|l|}
\hline Title & Description \\
\hline Mental demand & $\begin{array}{l}\text { How much mental and perceptual activity was required (e.g., } \\
\text { thinking, deciding, calculating, remembering, looking, searching, } \\
\text { etc.)? Was the task easy or demanding, simple or complex, } \\
\text { exacting or forgiving? }\end{array}$ \\
\hline Physical demand & $\begin{array}{l}\text { How much physical activity was required (e.g., pushing, pulling, } \\
\text { turning, controlling, activating, etc.)? Was the task easy or } \\
\text { demanding, slow or brisk, slack or strenuous, restful or laborious? }\end{array}$ \\
\hline Temporal demand & $\begin{array}{l}\text { How much time pressure did you feel due to the rate or pace at } \\
\text { which the tasks or task elements occurred? Was the pace slow and } \\
\text { leisurely or rapid and frantic? }\end{array}$ \\
\hline Effort & $\begin{array}{l}\text { How hard did you have to work (mentally and physically) to } \\
\text { accomplish your level of performance? }\end{array}$ \\
\hline Performance & $\begin{array}{l}\text { How successful do you think you were in accomplishing the goals of } \\
\text { the task set by the experimenter (or yourself)? How satisfied } \\
\text { were you with your performance in accomplishing these goals? }\end{array}$ \\
\hline Frustration level & $\begin{array}{l}\text { How insecure, discouraged, irritated, stressed and annoyed versus } \\
\text { secure, gratified, content, relaxed and complacent did you feel } \\
\text { during the task? }\end{array}$ \\
\hline
\end{tabular}


The NASA Task load Index requires respondents to rank each category on a 21point scale, where 1 is "low" and 21 equals "very high". The index was adopted and formatted into a fill-in PDF form for surveyors to access, complete, and save in a local folder on their Tablet PC, shown in Figure 47. The surveyors were able to access this form directly from the Tablet PC desktop, or by utilizing the Motion F5's tablet buttons on the top right of the device.

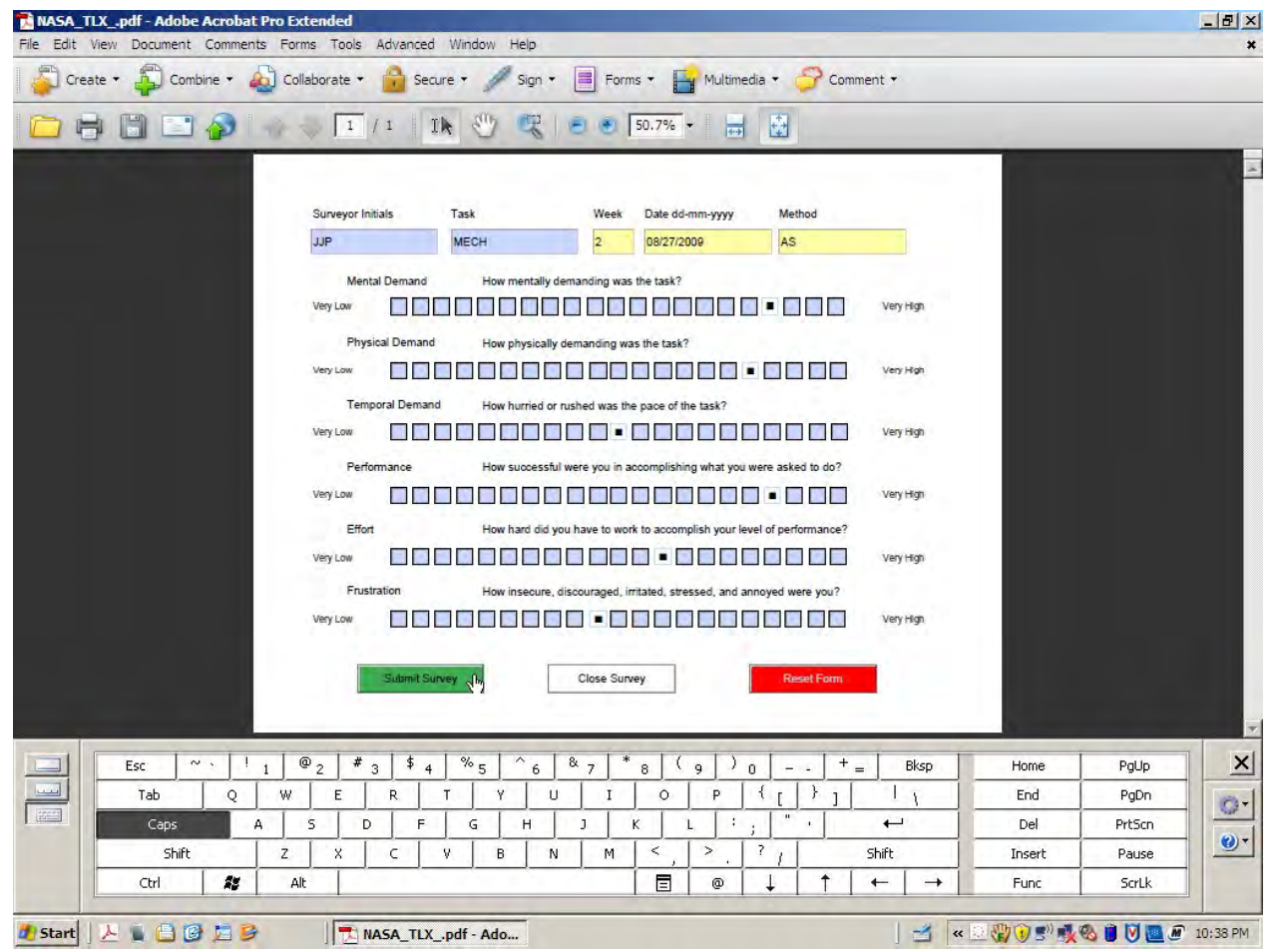

Figure 47: The NASA Task load Index form, adapted as a fill-in PDF document. Users were asked to provide feedback after each task, roughly twice per day in the field.

Following the completion of each task in the survey process, surveyors were required to complete a NASA TLX form to report their assessment of the workload for that task. NASA responses were then merged into a single comma-separated text file, which could then be analyzed in MS Excel. Pre- and post-fieldwork surveys provided relative weights and a context for surveyors' responses. The minimum, maximum, and average responses to each category are presented in Tables 20-25. In general, what is interesting about the surveyors' responses is the similarity and consistency among the weeks, based on team composition. On the whole, one-person teams responded similarly to the demand scales, regardless of task workflow. Consistency of experience appeared to be reported among two person teams as well. Individual surveyors gave a variety of responses to the demand scales, but for the most part, the average values for demands were mid-to-low. On the other hand, individuals throughout the field trial weeks indicated much higher values related to performance (i.e., Table 23, Performance), where average values are between 12 and 19, with a median of 15.5. 
Table 20: NASA Task load Index, Mental and Physical Effort.

\begin{tabular}{|l|c|c|c|c|}
\hline \multicolumn{5}{|c|}{ Effort } \\
\hline Space by Space & Min. & Max. & Average & Std Dev. \\
\hline Weeks 1 + 2 & 1 & 6 & 6 & 4 \\
\hline Week 1 & 1 & 6 & 3 & 2 \\
\hline Week 2 & 1 & 13 & 11 & 4 \\
\hline System by System & & & & 4 \\
\hline Weeks 3 + 4 & 1 & 13 & 7 & 4 \\
\hline Week 3 & 1 & 11 & 5 & 4 \\
\hline Week 4 & 4 & 13 & 8 & \\
\hline
\end{tabular}

For the most part, surveyors reported that the application and the tablet PC were relatively easy to use, and to learn. Most indicated that mental and physical effort was greatest in areas where components where not easily accessed, such as mechanical spaces, storage, and bathrooms.

Table 21: NASA Task load Index, Frustration

\begin{tabular}{|l|c|c|c|c|}
\hline \multicolumn{5}{|c|}{ Frustration } \\
\hline Space by Space & Min. & Max. & Average & Std Dev. \\
\hline Weeks 1 + 2 & 1 & 14 & 7 & 4 \\
\hline Week 1 & 1 & 13 & 8 & 3 \\
\hline Week 2 & 6 & 14 & 10 & 4 \\
\hline System by System & & & & 5 \\
\hline Weeks 3 + 4 & 1 & 14 & 5 & 2 \\
\hline Week 3 & 1 & 14 & 5 & 5 \\
\hline Week 4 & 1 & 6 & 5 & \\
\hline
\end{tabular}

From the post-surveys, several of the surveyors reported problems with hardware crashes throughout the process. In extreme cases, up to 8 crashes per day, and 3 freeze-ups in one task period caused frustration to increase. Restricted access was another frustration-inducing element. As noted, nearly all specialized spaces are equipped with cipher-locked doors, which in most cases required the assistance of the Commanding Officer to open. During the first week, the team entered the facility to find the occupants preparing for deployment. This not only thwarted efforts to complete tasks, but also contributed to an emotionally frustrating experience for occupants as well as surveyors. 
Table 22: NASA Task load Index, Mental Demand.

\begin{tabular}{|l|c|c|c|c|}
\hline \multicolumn{5}{|c|}{ Mental Demand } \\
\hline Space by Space & Min. & Max. & Average & Std Dev. \\
\hline Weeks 1 + 2 & 1 & 14 & 6 & 4 \\
\hline Week 1 & 1 & 6 & 4 & 2 \\
\hline Week 2 & 9 & 14 & 11 & 3 \\
\hline System by System & & & & 4 \\
\hline Weeks 3 + 4 & 1 & 14 & 4 & 1 \\
\hline Week 3 & 1 & 14 & 4 & 5 \\
\hline Week 4 & 3 & 6 & 5 & \\
\hline
\end{tabular}

Most surveyors indicated that mental demand for this type of work was relatively low. Responses on the post-surveys state seems to suggest that a major component of low mental demand is the application interface, which leads surveyors through the necessary steps and utilizes drop-down menus, automatic field population, work history, in combination with a carefully planned task sequence.

Table 23: NASA Task load Index, Performance.

\begin{tabular}{|l|c|c|c|c|}
\hline \multicolumn{5}{|c|}{ Performance } \\
\hline Space by Space & $\begin{array}{c}\text { Mi } \\
\text { n. }\end{array}$ & $\begin{array}{c}\text { Max } \\
.\end{array}$ & Average & Std Dev. \\
\hline Weeks 1 + 2 & 5 & 21 & 16 & 6 \\
\hline Week 1 & 5 & 21 & 19 & 4 \\
\hline Week 2 & 5 & 15 & 12 & 3 \\
\hline System by System & & & & 3 \\
\hline Weeks 3 + 4 & 10 & 21 & 17 & 2 \\
\hline Week 3 & 10 & 21 & 18 & 14 \\
\hline Week 4 & 13 & 16 & 14 & 4 \\
\hline
\end{tabular}

All teams reported a relatively mid-high level of performance. The surveyors seemed to feel that they were able to accomplish a large amount of data collection within a short time. Debriefing comments also indicate that the quick learning curve and relatively fast assimilation of survey tasks and interface functions contributes to high performance assessment. 
Table 24: NASA Task load Index, Physical Demand.

\begin{tabular}{|l|c|c|c|c|}
\hline \multicolumn{5}{|c|}{ Physical Demand } \\
\hline Space by Space & Min. & Max. & Average & Std Dev. \\
\hline Weeks 1 + 2 & 1 & 13 & 5 & 2 \\
\hline Week 1 & 1 & 5 & 2 & 3 \\
\hline Week 2 & 6 & 13 & 10 & 2 \\
\hline System by System & & & & 3 \\
\hline Weeks 3 + 4 & 1 & 9 & 3 & 1 \\
\hline Week 3 & 1 & 9 & 3 & 4 \\
\hline Week 4 & 3 & 5 & 4 & \\
\hline
\end{tabular}

During the field trials, weather at Fort Lewis was hot. During one week, record local temperatures made the survey work uncomfortable at times (high temperatures throughout the weeks ranged from $72-110$ degrees Fahrenheit). Despite this, surveyors did not acknowledge physical demands in the post-surveys. Many reported that the lightweight, compact equipment was a positive aspect of the technology. It could be inferred that a reduction in equipment weight and bulkiness would reduce physical demand.

Table 25: NASA Task load Index, Temporal Demand.

\begin{tabular}{|l|c|c|c|c|}
\hline \multicolumn{5}{|c|}{ Temporal Demand } \\
\hline Space by Space & Min. & Max. & Average & Std Dev. \\
\hline Weeks 1 + 2 & 1 & 13 & 6 & 4 \\
\hline Week 1 & 1 & 8 & 3 & 2 \\
\hline Week 2 & 8 & 13 & 10 & 2 \\
\hline System by System & & & & 2 \\
\hline Weeks 3 + 4 & 1 & 7 & 3 & 2 \\
\hline Week 3 & 1 & 6 & 3 & 5 \\
\hline Week 4 & 3 & 7 & & \\
\hline
\end{tabular}

This was not an area of significant load. Survey tasks had initially been scheduled within 3-hour blocks, based on assumptions and experience from the FY08 fieldwork. However, FY09 surveyors, working with the PDF Survey Application and Tablet PCs, were able to complete tasks in as much as $30 \%$ of the time it took similar teams using other technologies and methodologies. 


\section{Appendix 8: Autodesk Revit to Google Earth (Low-Fidelity BIM)}

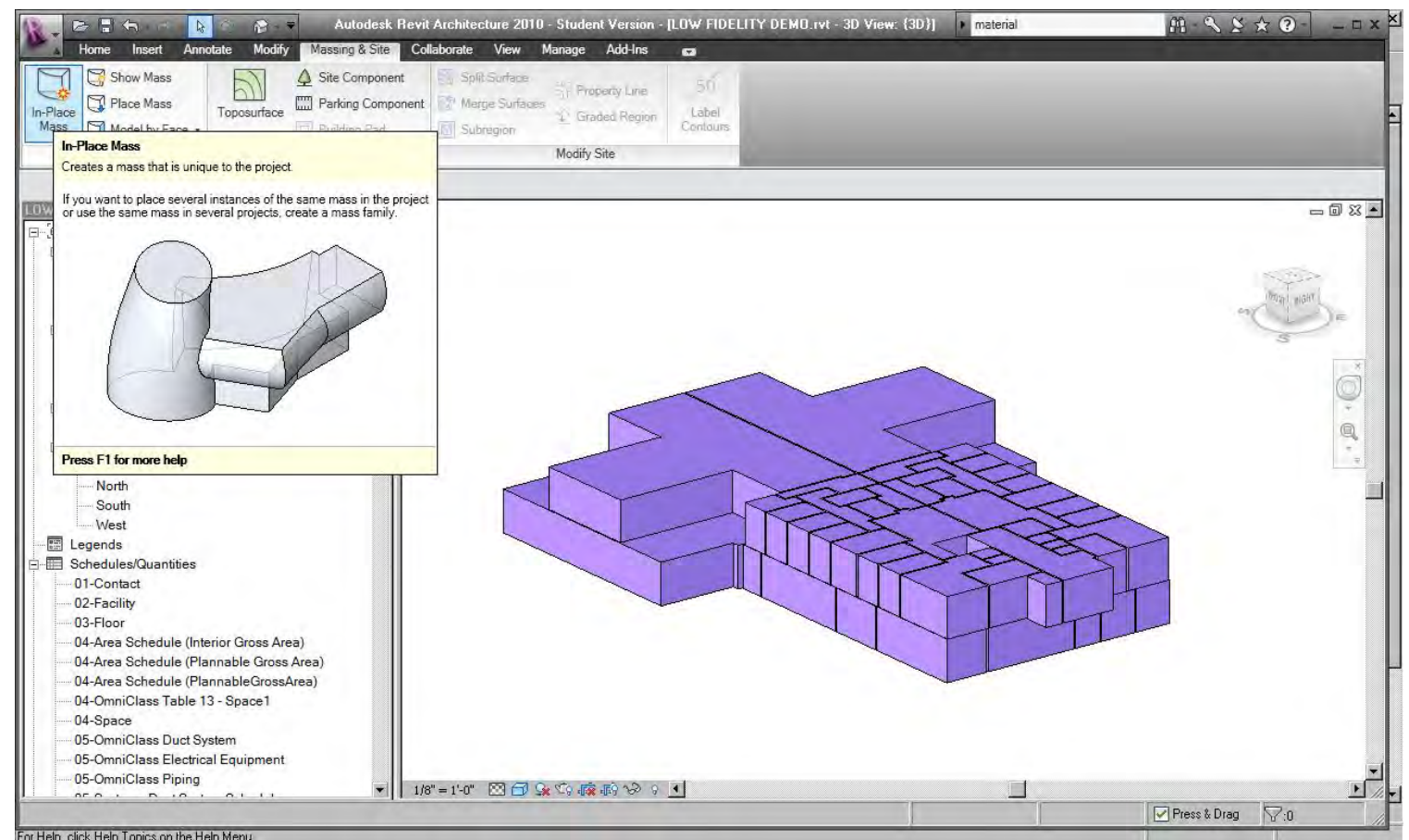

Figure 48. Create rooms/spaces in Revit as individual masses using the In-Place Mass tool.

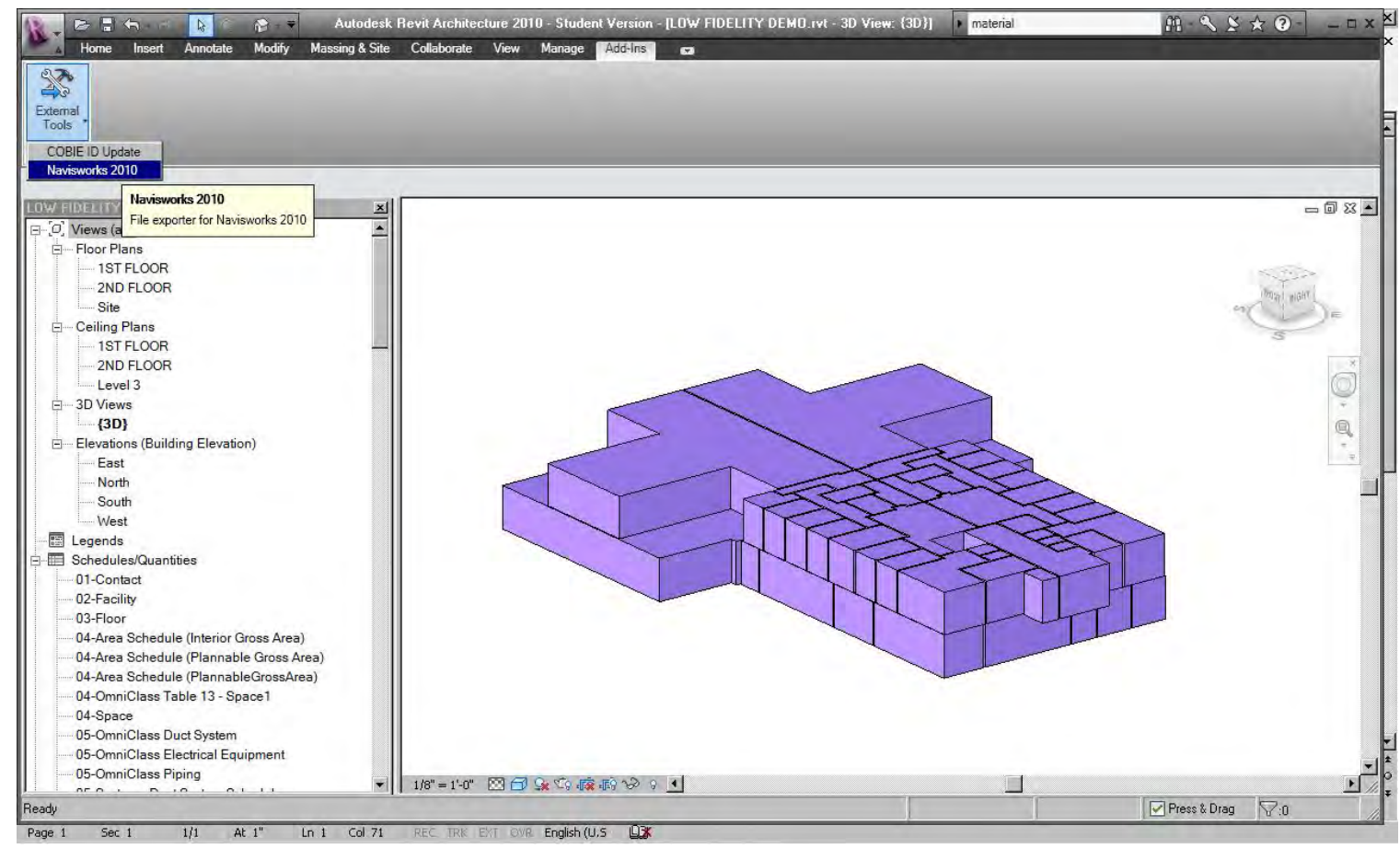

Figure 49.Run the Revit utility - Navisworks 2010. 


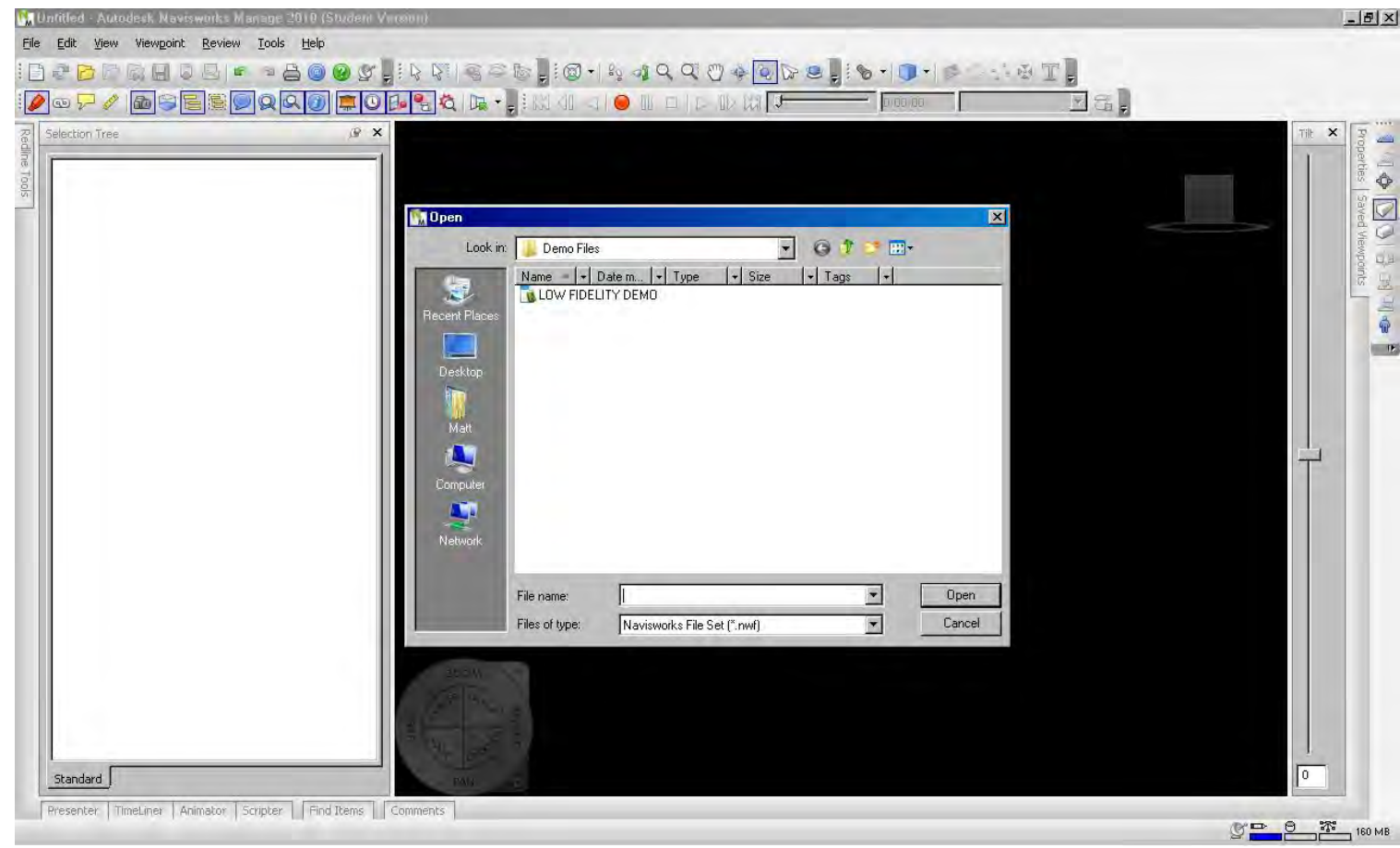

Figure 50. Open file in Navisworks.

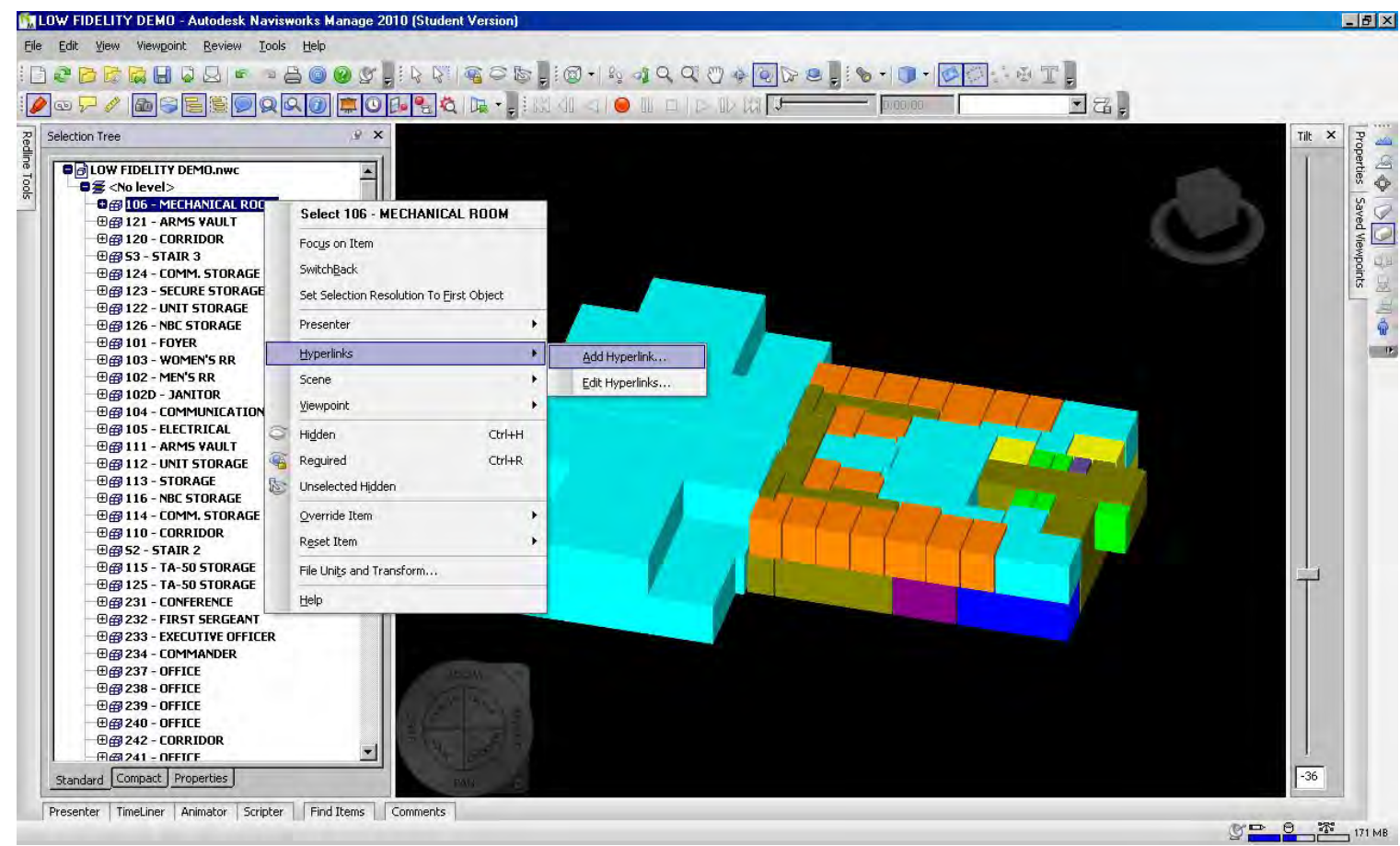

Figure 51. Add hyperlinks by selecting each individual mass using the Selection Tree. Right click on the specific room and go to Hyperlinks à Add Hyperlink. 


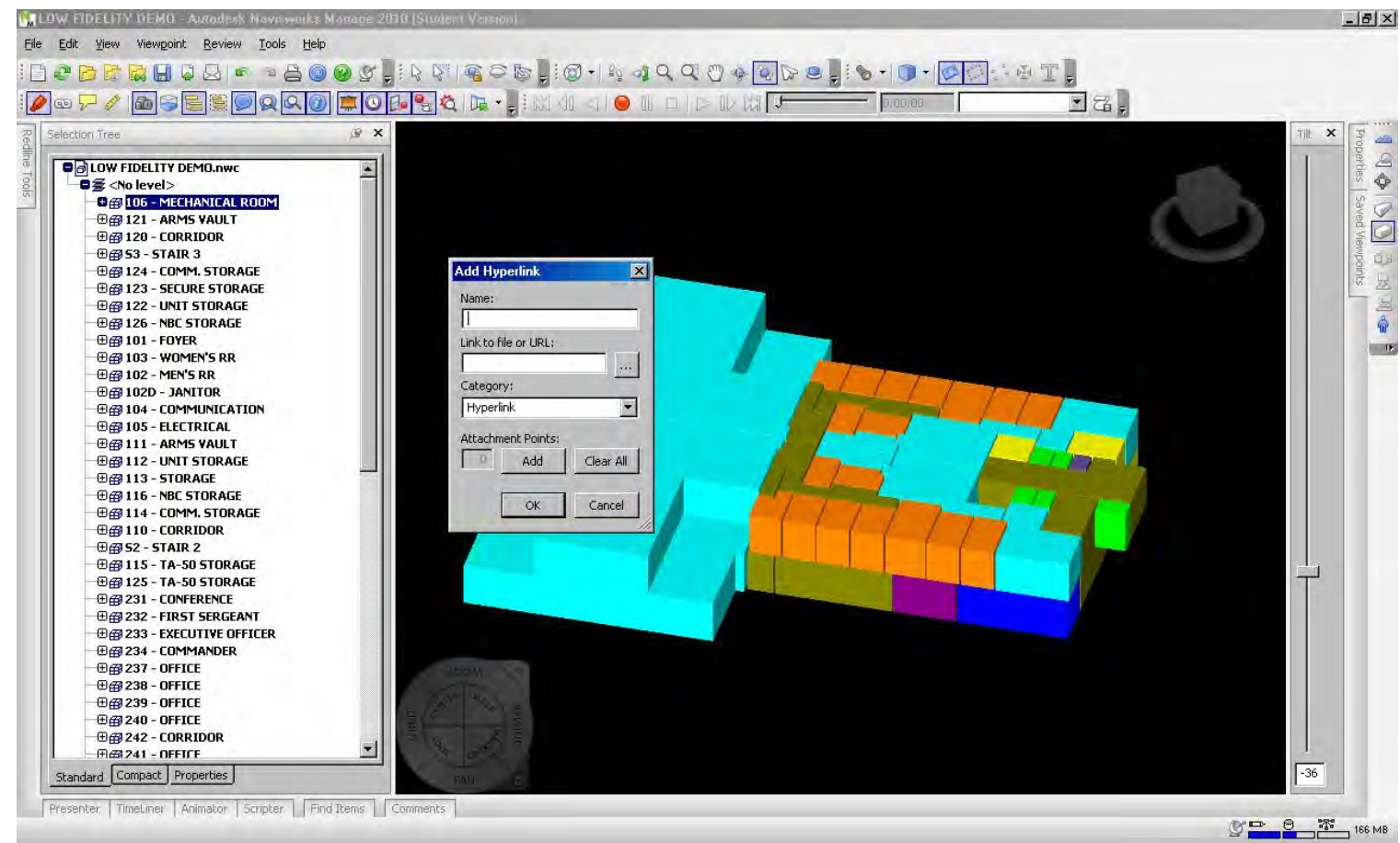

Figure 52. Fill in the link Name you want to appear when hovering over mass, Link to file or URL. Leave Category as "Hyperlink" and select OK.

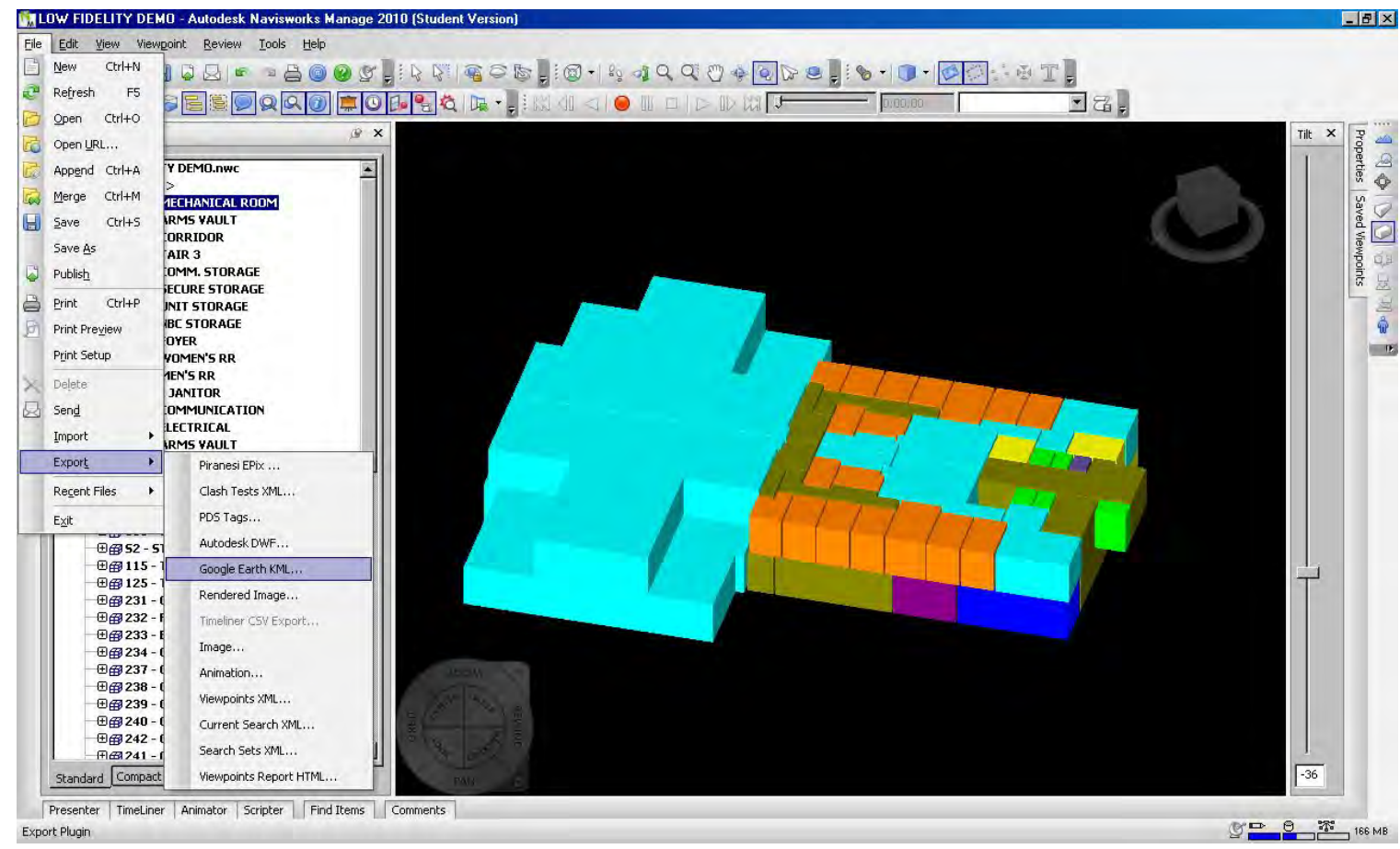

Figure 53. Once all hyperlinks have been associated, go to File à Export à Google Earth KML. 


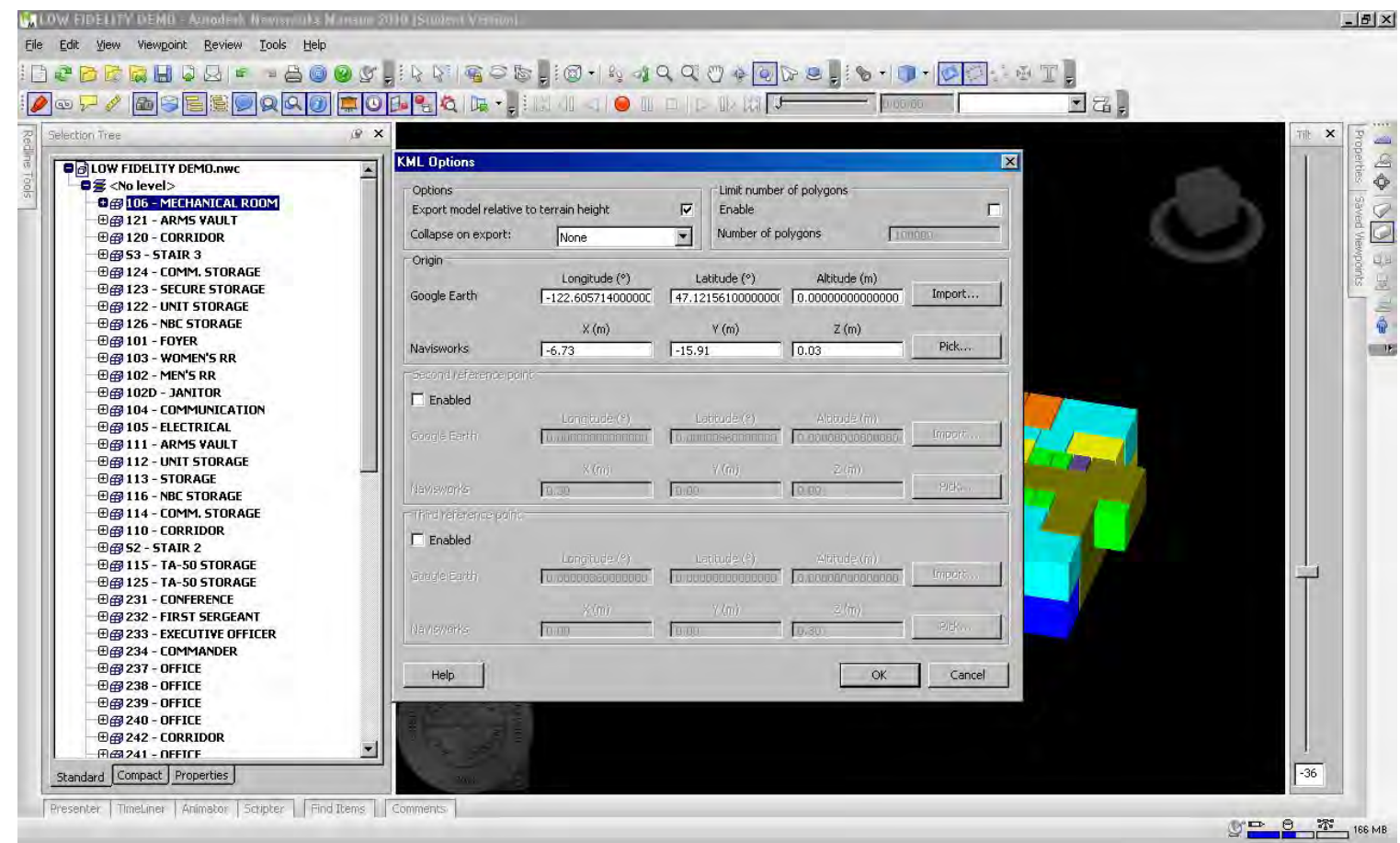

Figure 54. Fill in the desired Google Earth longitude, latitude, and altitude. Select Pick and choose the desired point within the model where the GPS coordinates are. Select OK.

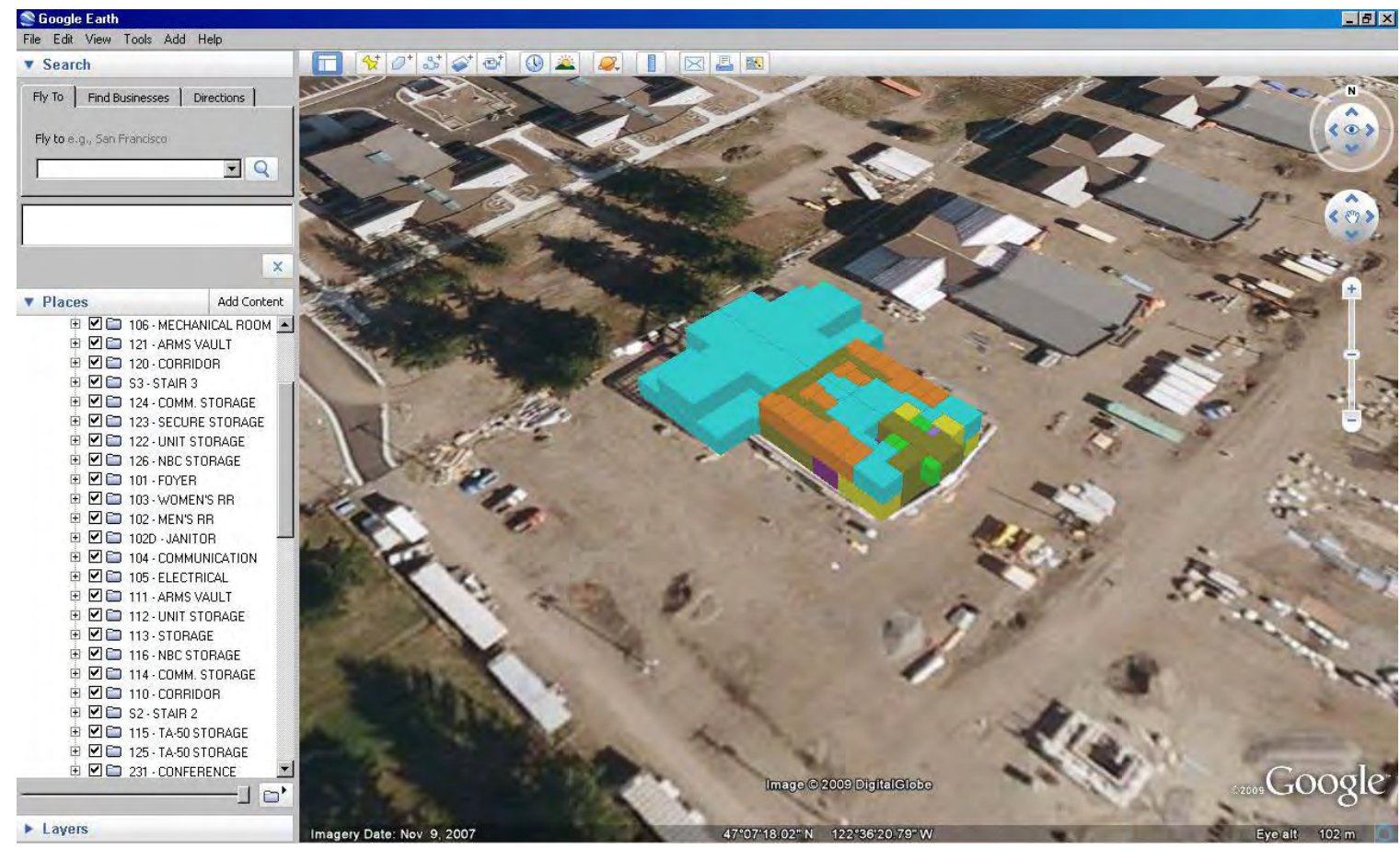

Figure 55. Open the exported .KMZ file to view in Google Earth. 


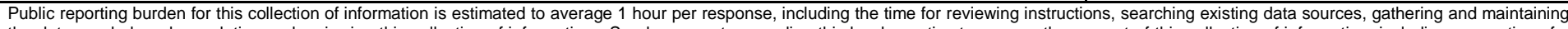

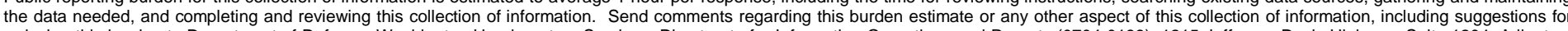

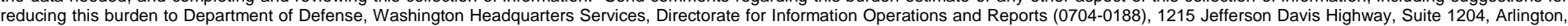

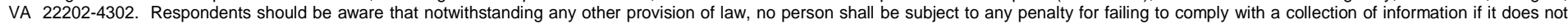
display a currently valid OMB control number. PLEASE DO NOT RETURN YOUR FORM TO THE ABOVE ADDRESS.
1. REPORT DATE (DD-MM-YYYY)
2. REPORT TYPE
3. DATES COVERED (From - To)

August 2010 Final

\section{TITLE AND SUBTITLE}

Developing Best Practices for Capturing As-Built Building Information Models (BIM) for Existing Facilities

5a. CONTRACT NUMBER

W9132T-08-2-0020

5b. GRANT NUMBER

5c. PROGRAM ELEMENT NUMBER

\section{AUTHOR(S)}

Eddy Rojas, Carrie Dossick, and J ohn Schaufelberger

5d. PROJECT NUMBER

5e. TASK NUMBER

5f. WORK UNIT NUMBER

7. PERFORMING ORGANIZATION NAME(S) AND ADDRESS(ES)

University of Washington

8. PERFORMING ORGANIZATION REPORT

Department of Construction Management

Seattle, WA 98195 NUMBER

9. SPONSORING I MONITORING AGENCY NAME(S) AND ADDRESS(ES)

Office of the Assistant Chief of Staff for Installation Management

Facilities Branch (DAIM-ODF)

2511J efferson Davis Highway

Arlington, VA 22202

(see Supplementary Notes)

10. SPONSOR/MONITOR'S ACRONYM(S)

ACSIM

11. SPONSOR/MONITOR'S REPORT

NUMBER(S)

ERDC/ CERL CR-10-2

\section{DISTRIBUTION / AVAILABILITY STATEMENT}

Approved for public release; distribution is unlimited.

\section{SUPPLEMENTARY NOTES}

Monitored by U.S. Army Engineer Research and Development Center, Construction Engineering Research Laboratory, P.O. Box 9005 Champaign, IL 61826-9005

\section{ABSTRACT}

The operation and maintenance of U.S. Army real property could greatly benefit from the availability of advanced forms of digital asbuilt facility data, such as those used in Building Information Modeling (BIM) systems. The Army Corps of Engineers requires the use of BIM on all new construction projects associated with the Army Standardization program. This study extends an earlier analysis performed by the University of Washington for the U.S. Army Engineer Research and Development Center under the Installation Technology Transfer Program, documented in ERDC/ CERL CR-10-1. The objective was to determine the most efficient method for capturing essential as-built information about U.S. Army facilities for application in a BIM-driven support tool for operation and maintenance decision making. The study also evaluated the potential applicability of readily available tools such as the Construction Operations Building information exchange (COBie) data format, Google SketchUp, Google Earth, three-dimensional Portable Document Format (3D PDF), and BIM integration technologies, with a focus on task-centered interface and workflows. The findings constitute a summary of best practices for meeting the research objective and facilitating implementation by Army Departments of Public Works.

\section{SUBJECT TERMS}

Building Information Models (BIM), operations and maintenance (O\&M), Construction Operations Building information exchange (COBie), design- construction, facility management, modeling

\begin{tabular}{|l|l|l|l|l|l|}
\hline \multicolumn{2}{|l|}{ 16. SECURITY CLASSIFICATION OF: } & $\begin{array}{l}\text { 17. LIMITATION } \\
\text { OF ABSTRACT }\end{array}$ & $\begin{array}{l}\text { 18. NUMBER } \\
\text { OF PAGES }\end{array}$ & $\begin{array}{l}\text { 19a. NAME OF RESPONSIBLE } \\
\text { PERSON }\end{array}$ \\
\cline { 1 - 2 } $\begin{array}{c}\text { a. REPORT } \\
\text { Unclassified }\end{array}$ & $\begin{array}{c}\text { b. ABSTRACT } \\
\text { Unclassified }\end{array}$ & $\begin{array}{c}\text { c. THIS PAGE } \\
\text { Unclassified }\end{array}$ & & $\begin{array}{l}\text { 19b. TELEPHONE NUMBER (include } \\
\text { area code) }\end{array}$ \\
\end{tabular}

